\title{
A História da Alimentação: balizas historiográficas
}

\author{
Ulpiano T.Bezerra de Meneses \\ Departamento de História - FFLCH/USP
}

Henrique Carneiro.

Doutor em História Social / USP

Introdução

Este texto não pretende realizar um levantamento panorâmico da História da alimentação, muito menos fornecer um repertório bibliográfico. A indefinição e plasticidade e a ubiqüidade do tema, sua extensão universal, a multiplicidade de abordagens, a amplitude (na quantidade e nos graus de qualidadel dos trabalhos publicados tornam inviável uma bibliografia que se pretenda abrangente, ainda que não exaustiva. $E$, mesmo, talvez, de utilidade problemática.

Assim, o objetivo é antes caracterizar um campo de estudos que, nesta segunda metade do século, vem assumindo certa personalidade própria, não só nos domínios da História (nosso foco principal de interesse), mas também nas demais ciências sociais. Longe de nós pretender, com isso, dar status epistemológico à História da Alimentação. Não se trata de aumentar o elenco das múltiplas 'histórias' em que a disciplina se vem fragmentando, perdendo de vista o princípio de que, se a História não tiver como objelo essencial de atenção a sociedade como tal - a sociedade como um todo -, forçosamente comprometerá sua capacidade de produzir conhecimento lao invés de simples informaçãol e entendimento dos fenômenos e seus atributos.

No entanto, é forçoso reconhecer que a prática da História organiza suas necessidades e conveniências em torno de certos referenciais, plataformas, problemas, recursos, articulações com outras disciplinas, hábitos 
- e até modas -, que constituem efetivamente algo próximo da noção de campo proposta por Bourdieu.

E a formação desse campo e sua consolidação, assim como traços hoje predominantes, que se procurará traçar. Por certo será conveniente, antes disso, inserir a História propriamente dita num quadro mais amplo e diversificado de disciplinas que se interessaram pelo problema da alimentação. (Ainda mais que, dentre as disciplinas congêneres, a História está longe de se distinguir pela atenção dada ao tema). E, depois, caracterizar a bibliografia histórica, salientando, de um lado, alguns marcos e, de outro, selecionando o que se acreditou referência exemplificativa de tendências, padrões, tipologia de fenômenos e assim por diante.

Em conseqüência, a estrutura que nos pareceu mais eficaz é a seguinte: De início, um panorama dos estudos da alimentação, salientando, além dos principais enfoques, a contribuição específica das ciências sociais. A seguir, vem uma tentativa de acompanhar a formação do que hoje se pode chamar propriamente de História da Alimentação e sua instifucionalização. Segue-se o quadro de caracterização geral da bibliografia histórica. Algumas questōes relevantes mereceram tratamento mais específico: assim, foram-thes reservadas, na seqüência, espaço proprio: a fome, o universo religioso, a mundialização da alimentação e o gosto e a gastronomia. Finalmente, tentou-se também delinear um rápido perfil da problemática da alimentação na historiografia brasileira.

Uma última ressalva introdutória deve ser apresentada. A bibliografia aqui considerada é essencialmente européia e norte-americana. São esporádicas as menções à literatura sul-americana (salvo Brasil), africana e asiática. E mesmo a literafura européia se concentra basicamente na França, Itália, Inglaterra, Alemanha e alguma coisa de seus vizinhos. Tais lacunas se devem, seja à origem predominante dos estudos e ao interesse maior que despertou a pesquisa nessas áreas, seja a seu viés europocêntrico, seja, enfim, às grandes dificuldades, com que nos defrontamos, de acesso à bibliografia.

\section{Estudos da Alimentação}

Desde a Antigüidade pode-se dizer que a alimentação vem sendo objeto de atenção e conhecimento. De um lado, a necessidade inescapável de ingerir alimentos para manter a vida e, de outro, a enorme variedade de escolha neste processo, permitiram sem dúvida perceber um conjunto de fenômenos prenhes de implicações. Mas convém desde já introduzir uma questão determinante: ao se falar de alimentação, de que se está falando, qual, precisamente, o objeto desse interesse, desses registros, crônicas e estudos? A julgar pela situação hodierna, há vários focos que se cruzam ou superpõem e, às vezes, seguem em paralelo. Falar-se em alimentação é privilegiar o alimento Isua produção, aquisição, circulação, consumo, carência, o mercado, representações, funções sociais e culturais e assim por diante)? Ou a nutrição? Não existe, hoje, uma Aniropologia nutricional, assim como uma Sociologia do alimento? Ou o objeto seriam a dieta e os modelos e sistemas alimentares? Ou os hábitos à mesa, as práticas alimentares e a 
culinária (a 'cozinha'), os espaços e equipamentos, contextos e agentes, em particular os próprios comedores e bebedores? E a história do gosto e da gastronomia, seriam subcategorias da alimentação? E a educação alimentar, a segurança alimentar e as políticas alimentares?

Há, pode-se ver, grande oscilação de sentido e de centros de gravitação. Estas fronteiras estão longe de poderem ser claramente demarcadas - e não é evidente que devam sê-lo. No entanto, maior esclarecimento pode derivar de um exame dos enfoques predominantes na análise desses variados objetos. São eles, basicamente, cinco: o enfoque biológico, o econômico, o social, o cultural e o filosófico. Segundo tais enfoques, muda a própria natureza do objeto de atenção: o alimento pode ser enfocado enquanto plantas econômicas ou animais domésticos lou, hoje, matérias-primas de diversa proveniência ou sintetizadas), como mercadorias ou nutrientes, como vetores de ação social e política, como elementos simbólicos ou ideológicos e suportes de práticas culturais.

enfoque biológico

O enfoque biológico de todos é o que conseguiu monfar o quadro mais equilibrado de problemas e métodos, assim como um apreciável acervo de informação e conhecimento, associados basicamente à nutrição.

Na Antigüidade, há uma farta literatura médica, principalmente entre gregos e romanos: Hipócrates, Galeno, Oríbase, Antímio, Dioscórides, Apuleio, Celso etc. procuram desvendar os mistérios do metabolismo humano e, particularmente, o fenômeno da digestão. Um tratado famoso do século XVIII, o Traité des aliments de Louis Léméry (1702), ainda se enquadra neste filão. Toda a História da Medicina, aliás, é uma fonte de informações para a história da alimentação. As teoriais nutricionais, a idéia da digestão como cozimento, as prescrições dietéticas, são pródigos reveladores dos hábitos e concepções de uma sociedade (cf. Mazzini 1996). Aliás, a Etnomedicina, hoje em dia, prolonga tal tradição, buscando coletar e explicar informação laté mesmo historicamente) sobre crenças associadas a alimentos ou formas pelas quais os grupos e sociedades os classificam, no tocante aos aspectos da nutrição e saúde (Wilson 1979).

Além disso, estatísticas, censos e outros registros oficiais no campo alimentar, nos séculos XVIII e XIX, na Europa, ficavam normalmente a cargo de médicos. Caso exemplar é o do Reino de Nápoles: a pesquisa estatística ordenada em 1811 tinha, entre suas cinco seções, a lll, relativa à "sussistenza e conservazione della popolazione", cujos dados, muito ricos e precisos, foram coletados e processados exclusivamente por médicos (De Benedettis 1995).

A Botânica e a Zoologia trouxeram aporte fundamental para a constituição de um acervo de conhecimentos básicos referentes a alimentos. No Renascimento, os pioneiros estudos gregos e latinos sobre plantas, como a Matéria médica de Dioscórides, a História Natural de Plínio, o Velho, ou a História das plantas de Teofrasto, que tratavam da flora de um ponto de vista utilitário, econômico, tecnológico e medicinal, foram traduzidos e pela primeira vez publicados no Ocidente. Os herboristas (que, na origem, eram médicos), 
tiveram um papel desbravador no fornecimento de dados históricos das plantas alimentícias. Não nos esqueçamos que muitos herbários do século XVI se chamavam justamente 'História das plantas' (De Historia Stirpium, de Leonhardt Fuchs, 1542) ou "História dos frutos" (Frugum Historia, de Rembert Dodoens, 15521, por exemplo.

As ciências modernas relacionadas à nutrição desenvolveram-se a partir do século XIX, com um caráter interdisciplinar, reunindo os avanços obtidos em diferentes ramos das ciências naturais juntamente com os da Medicina AAgronomia, tecnologia alimentar, análise química de alimentos, Fisiologia, Bioquímica, Toxicologia, Microbiologia, Patologia, Epidemiologia e Genética, entre outras). Por volta de 1850 é que começa a desenvolver-se tal gênero de estudos, principalmente na França, na Alemanha e na Holanda, acompanhado de sistemas de coleta de dados, em âmbito nacional.

Os objetivos da pesquisa biológica, com ênfase na nutrição, foram assim definidos por Teuteberg (1992: 2):

"Nutritional research is supposed to examine the processes of digestion within the human body and to gather data for an optimal diet which can be modified according to age, gender and the amount of work humans do. Of special importance is the search for a sound basis for a dietary treatment for diseases of the metabolic, digestive, and excretive processes, and progess towards optimal food conditions, determined by clinical research".

Cumpre notar que, por muito tempo, nesta área, os pesquisadores raramente se interessaram por questões fora do âmbito biológico, constituindo um domínio de alta competência, mas excessivamente circunscrito, como na caracterização de Teuteberg a esta dimensão bioquímica da alimentação, vista apenas como um processo orgânico e metabólico.

Mas já no século XIX, estudos de Medicina procuravam determinar implicações históricas. É o caso, por exemplo de Watt, Freeman e Bynum (1881) que, ao estudarem a fome crônica dos marinheiros, trataram de estabelecer a influência da nutrição na história marítima e naval.

Doutra parte, a necessidade que outras disciplinas sentiram de um apoio biológico há algum tempo começou a estabelecer pontes, ainda que assimétricas. Em 1983, por exemplo, Scrimshaw publicava um artigo destinado a realçar a importância do conhecimento nutricional para os historiadores. Mais tarde apareceram até mesmo instrumentos de difusão, como a obra de Harold McGee (1988), que procura transmitir aos não especialistas referências básicas de Botânica, Zoologia, Fisiologia, Bioquímica, apontando as propriedades de matérias-primas e suas combinações (leite, carnes, ovos, álcool, grãos, legumes, etc.), os efeitos de métodos e equipamentos de cozinha e assim por diante.

Desse contacto com as ciências sociais criaram-se áreas de investigação e ałuação interdisciplinar, como, nos Estados Unidos e na Europa, a já mencionada Antropologia Nutricional (Freedman 1977. Wilson 1979, Fieldhouse 1986). Fala-se também de uma Psicofisiologia e de uma Biopsiquiatria da alimentação, assim como de Nutrição Social e, ainda, de Educação Nutricional (Cf. Messer 1984). 
Hoje não se contesta que os grandes problemas de base biológica não podem ser encaminhados apenas no âmbito restrito da nutrição. Basta apontar alguns temas críticos - fome e patologias alimentares, segurança alimentar, jejuns e dietas, demografia, adoção/rejeição de alimentos, gosto - para não falar de temáticas mais amplas como a evolução biológica ou os processos nutricionais adaptativos: são todos temas imbricados em outras dimensões.

A fome, como se verá mais adiante, assim como a desnutrição ou a subnutrição, não podem mais ser entendidas apenas em seu nivel orgânico, fisiológico. Uma obra importante como a de Amartya Sen 11988), por exemplo, propôs um modelo explicitamente sócio-cultural para definir a fome e nele é que incorpora o biológico.

A compreensão de patologias como a bulimia e a anorexia nervosa exigem que elas sejam tratadas como 'welfare diseases', típicas de uma sociedade de consumo - para o que as condições favoráveis começaram a se condensar já no século passado. As dimensões não biológicas são aqui determinantes. Caplan (1994: 181, por exemplo, preocupada com as relações de poder, não hesita em caracterizar a anorexia "as an extreme form of selfcontrol, but also involves the exercise of control over others'.

Problema associado é o do jejum, que convém examinar, como tem sido freqüente (cf. Bynum 1987), conjuntamente com a festa. $\bigcirc$ jejum tanto pode ser um ato de subordinação, quando de resistência: em ambos os casos le não só nas greves de fomel, sua matriz é política.

Já as dietas (restrições alimentares ou, ao contrário, reforço alimentar) têm sempre implicações sociais, políticas, culturais. Apenas para ficar num exemplo evidente, lembre-se como o ideal corporal feminino depende do processo de socialização da mulher Kaplan 1994: 14-5; Orbach 1978 , Charles \& Kerr 1986). Movimentos populares, como os inúmeros health movements dos americanos e também de europeus, integram conhecimentos médico-biológicos, além de premissas filosóficas e, às vezes, religiosas, modelos culturais, sem contar um sem-número de pressões sócio-econômicas (como se patenteia no caso exemplar do vegetarianismol. Nessas circunstâncias, uma autonomia da dimensão biológica seria em extremo deformante. Felizmente, a bibliografia de base procurou ultrapassar tais limitações (ct. Schwartz 1986, Baver 1989, Spencer 1995). Merece menção à parte a obra de Fiddes (1991) sobre a rejeição e consumo da carne - tratada como um 'símbolo natural'.

Estudos recentes de evolução biológica insistem diretamente na dimensão social, ao tratarem da alimentação, como por exemplo no tocante à nutrição dos coletores-caçadores. Um caso que merece referência são os esforços para explicar a partilha da carne de animais de grande porte e que têm mobilizado argumentos variados, mas sempre de conotação social: seleção pelo parentesco, tolerância ao furto, reciprocidade, redução dos riscos da imprevisibilidade dos recursos, etc. '

Por sua vez, lembre-se como, entre nós, um conceito de conteúdo biológico vinculado à produção de alimento - o conceito de domesticação não dispensa a inclusão de seu significado social. Assim é que Pierre Ducos transfere o foco de definição para o papel dos animais como 'propriedade viva': a domesticação pressupõe uma forma específica de integração dos animais vivos
1. "...Kent has recently suggested that meat is shared primarily for social reasons, not economic ones, and Peterson has argued that foragers share for social reasons. There is probably not one explanation. (...) I propose that men share meat because it enables them to feed their other children - those not born to their wives and this directly increases their reproductive succces" (Thiel 1994: 440). 
à organização socioeconômica do grupo, que implica a possibilidade de posse, herança, troca, comércio, etc. (Ducos apud Clutton-Brock 1989; ver também Vialles 1994). Na mesma linha, estudos de domesticação de plantas não apenas enformam o conceito de 'sociedade agrícola', como, ainda, e melhor, o de 'sistemas específicos de exploração agrícola', entendidos como sistemas sóciotécnicos (Leaf 1996: 32).

Em nossos dias se trata correntemente a adoção ou rejeição de alimentos como tendo mais a ver com sua consideração social do que com suas propriedades nutritivas. Burguière (1986: 10) lembra as dificuldades com que certos alimentos foram introduzidos na Europa, embora posteriormente desempenhassem papel relevante, por seu valor nutritivo, principalmente em tempo de fome. Assim, o milho, cuja origem indígena suscitou "une réaction de repugnance", ou a batata, cujo "anoblissement social" se deveu à ação promocional de Parmentier. De igual modo, a castanha, alimento de bom teor nutirtivo e muito imporłante na Europa do sudoeste até o séc.XIX, além de pouco custosa na produção e na demanda de mão-de-obra, entra em declínio pela imagem de pobreza e de atraso com a qual passa a ser associada.

De mesmo teor, o gosto não pode ser tratado como exclusivo problema biológico - apesar da importância fundamental que o paladar exerce, principalmente como sentinela do organismo; o sabor amargo, por exemplo, é indício de alcalóides, substância tóxica que cumpre evitar; já o sabor doce indica a presença de glucídios, sinal de alimento bom (Nicolaides 1993-6: 39, Moskowitz 19711. Por isso mesmo, os especialistas sentiram necessidade de estabelecer distinções, como foi o caso de Rozin e Fallon lapud Garine 1994: 232), que propõem separar distate ("corresponding to sensory rejection") de disgust ("corresponding to refusal on cognitive grounds").

Deve-se ainda mencionar um campo importante, intimamente vinculado a uma base biológica, mas que tem tido, no tema da alimentação, presença menor do que a desejável: trata-se da demografia. Por certo, existem muitas obras relevantes que poderiam ser lembradas, como The rise of modern population, de Thomas McKeown (1976), que relaciona crescimentos populacionais com melhorias nutricionais, ou Popolazione e alimentazione, de M.Livi-Bacci (1987), que percorre a história demográfica européia; ou então, trabalhos que procuram acentuar a importância da Demografia Histórica nos estudos de alimentação, como Biraben (1976). Também, como se verá mais adiante, nas décadas de 60 e 70 - momento de institucionalização da História da Alimentação -, principalmente os historiadores franceses referiram-se com freqüência a questões de conteúdo demográfico. Mas ainda há muito o que fazer, neste domínio.

Por fim, para inferir a estreiteza da perspectiva biológica, se desenvolvida autonomamente, atente-se para o fato de que os enfoques nutricionais não são suficientes para explicar a alimentação na sociedade industrial. Na verdade, trata-se de casos amplíssimos de inadaptação nutricional, como já notaram os especialistas, pois os padrões alimentares contemporâneos são, antes, os de uma sociedade tipicamente agrícola, orientada para intensa atividade corporal, muito diversa da sedentariedade que caracteriza nosso modo 
de vida - além de favorecerem inúmeras tendências psico-patológicas (Teuteberg 1992:6, Garine 1994: 238).

\section{enfoque econômico}

Ao contrário do enfoque examinado até agora, é no campo da História que se concentam os estudos de alimentos em que predomina 0 interesse econômico.

Com efeito, até mais que na Antropologia, foi na História lou com prespectiva histórical e, secundariamente, na Geografia, que se produziram abundantes trabalhos sobre a obtenção e utilização de um dado alimento, numa época ou contexto dados, explorando-se, ainda, seu processamento, consumo e ingestão, aramazenamento, transporte, comercialização e distribuição. Na verdade, a produção, preparo e utilização dos alimentos, como observa Valeri 11977: 347) é "il più antico e fondamentale processo economico".

Nos últimos vinte, trinta anos, como já se disse em particular quanto à França (Barlösius 1992), foi a descóberta, pelos historiadores, da cultura material que fomentou os estudos de alimentação. Claro está que a noção de 'civilisation matérielle' utilizada pela historiografia dos Annales e, a seguir, pela Nouvelle Histoire, não coincide com as propostas que hoje caracterizam este campo /comparar, por exemplo, uma visão tão estreita e tacanha como a de Pesez 1988, com o quadro amplo, embora por vezes incompleto, traçado por Poulot 1997). Assim, cumpre reconhecer o débito implícito com a categroia marxista de infraestrutura, o que em grande parte justifica a forte marca econômica de uma História que vai preocupar-se com a produção, sobretudo a produção agrícola, a ponto de se ter podido falar de uma Agrohistória, acoplada a uma história do abastecimento. Abastecimento, safras, preços, mercados e suas flutuações diversas são alguns itens que mreceram destaque. Em conseqüência, afirma-se a necessidade de consultar orçmentos e dados censitários e investigar as técnicas de aquisição, consumo, circulação, tansporte, as carestias e fomes. Contextos, em especial os da urbanização e industrialização, também mereceram atenção particular. (Burnett 1989, Cépède \& Lagelle 1954, Teuteberg \& Wiegemann 19721.

Por certo que à distância é mais facil identificar as limitações dessa abordagem, que eventualmente ocorreram, quando se ignoraram ou minimizaram cautelas hoje consideradas fundamentais: a necessidade de trabalhar com sistemas e complexos inteiros, ou de considerar variáveis como o cotidiano e as festas, a alimentação humana e a animal, a produção doméstica e suas formas de distribuição (via parentela, vizinhança, etc.). Se as fontes para estes fenômenos "que fogem da contabilidade formal", como se tem apontado, são mais escassas para a História, não há como negar o desinteresse das pesquisas sociológicas, antropológicas e geográficas, que dispunham de situação mais favorável, a esse respeito.

Releva notar que na Antropologia, talvez mais que na História, foi possivel conceituar com bastante rigor alguns fenômenos básicos de caráter econômico, inserindo-os no contexto sócio-cultural adequado. É o caso dos 
sistemas agrícolas, em que o estudo da terminologia revelou graves distorções principalmente nas taxonomias de base geralmente etnocêntrica:

\begin{abstract}
"While 'gardening' and 'farming', 'horticulture' and agriculture' are appropriate to discussing the development of these activities in Southwest Asia and Europe, even in that 'home territory' these terms can imply a greater complexity in food production systems that may have existed. The agricultural threshold may lie within the Neolithic rather than mark its commencement. For the rest of the world, we should justify the applicability of western terms like 'agriculture' and 'horticulture' before employing them to describe recent or ethnographic practices, and consider adopting new or neutral terms when discussing origins" (Helen Leach 1997: 146)
\end{abstract}

Um exemplo de inadequação é dado pela própria autora quando, citando Harris e os estudos de Malinowski sobre horticultores da Oceania, aponta como ënganosa a expressão produtores', que deveria ser substituída pela de 'parceiros', em vitude do tipo de relação de 'amitié respectueuse' mantida entre o homem e o meio ambiente.

Nesse quadro poder-se-ia supor que a atenção dada à cultura material teria produzido bons estudos sobre espaços, utensílios ou equipamentos envolvidos na alimentação. Isto, porém, não ocorreu, nem de forma sistemática, nem abrangente. Há, sim, exploraçōes tecnológicas, como as de Braudel (1970), ou inventários monográficos, muitas vezes puramente descritivos e classificatórios, como, por exemplo, os raros estudos sobre talheres /Giblin 1987, Strung 1976) ou sobre equipamentos de aparato de determinados período (Rainwater 1983), etc. Mas é só recentemente que a Antropologia e a Sociologia, além da História, introduziram nos estudos de alimentação dimensões do artefato além da econômica. Convém assinalar, todavia, o número cada vez maior de estudos vinculados às tecnologias de produção, dada a importância assumida entre nós pelos alimentos sintéticos, pela bio-tecnologia, etc. (referências em Mennell et alii 1992: 71-2).

O enfoque social

enfoque social, como se pode ter apreendido acima, é reconhecido hoje como inerente a qualquer estudo de qualquer aspecto da alimentação. Com efeito, a rede de interrelações que o alimento obrigatoriamente evoca transforma-o, na expressão de Johan Pottier /1996: 2381, num "most powerful instrument for expressing and shaping interactions... a repository of condensed social meanings".

Embora esse entendimento possa ter raízes já na própra constituição da Sociologia e da Geografia Humana, é sem dúvida na segunda metade do século que se consolida este enfoque, o qual, a partir da década de 70 , vai ceder a primazia ao cultural.

Duas obras podem ser apontadas para amostrar as grandes linhas. A primeira é o estudo clássico sobre a batata, de R.Salaman (la.ed. 1949), que representa os trabalhos centrados no alimento/alimentação mas procuram desvendar seus conteúdos sociais. Como vem no título, o que o autor pretende é trabalhar "a história e a influência social da batata". Seu eixo de atenção, portanto, é um alimento, sua origem, seu transplante para a Europa, as condições 
e dificuldades de sua aceitação e difusão, os aspectos de suprimento e as flutuações na resposta a fomes e carências, nas quais desempenhou papel fundamental, como no famoso caso da Irlanda no século passado..

Uma segunda obra são os dois trabalhos de Sidney Mintz sobre o açúcar $(1986,1996)$. Na verdade, o que ele está efetivamente estudando é a sociedade capitalista, num espaço de quase dois séculos, utilizando-se da história do açucar como plataforma de observação. O vasto panorama que ele montou se compõe das conclusões a que pode chegar examinando as condições de produção do açúcar nas colônias, as repercussões de sua dependência do trabalho escravo (um dos 'pecados da escravidão') e a exploração moral decorrente, as funções nutricionais, medicinais e luxuárias do açúcar, seu papel no imaginário e nas classificações sociais e na emergente sociedade de consumo e a construção de uma nova subjetividade, a organização do mercado, não só como mercadoria, mas também como primeira necessidade exótica, produzida em massa, para uma classe operária. Em suma, como já se disse, o açúcar funcionou como uma metáfora para articular os diversos agentes sociais e dar inteligibilidade à interação entre eles.

Num contexto sócio-político poderíamos incluir os trabalhos relativamente raros que consideram o tema sob o ângulo do poder, como no estudo que John Super (1988) fez do papel da alimentação no processo de conquista e colonização da América espanhola, no século XVII, ou, então, aqueles que giram em torno das políticas alimentares (McMillan, ed. 1991).

$\bigcirc$ enfoque cultural

Este enfoque não ignora a necessidade física da alimentação, mas desloca decisivamente a atenção dos alimentos para as formas de preparáto e, sobretudo, consumilos como espaços de articulação de sentidos, valores, mentalidades, etc. (CF. Lupton 1994). São as implicações semiológicas do beber e do comer que sobressaem, para atender às decorrências do 'arbítrio cultural', como expresso no dito famoso de Trémolière: "I'Homme est consommateur de symboles autant que d'aliments" lapud Garine 1990: 14531. Ou, na versão de Leslie White (1949: 24): "man is the only animal able to distinguish between distilled water and holy water". Embora não se tenha constituido uma verdadeira Semiologia da alimentação, houve um avanço considerável neste rumo, desde pelo menos as tentativas dos antropólogos estruturalistas ou de semióticos como Barthes (1961), que procurou definir uma 'gramática' para o sistema alimentar.

Hoje a idéia de código é muito mais flexivel, e é em todos os desvãos da vida social e nas suas múltiplas formas que se procuram identificar e explicar as significações associadas à alimentação. Sirva de exemplo um trabalho como o de Lifschitz (1993) que, ao estudar a produção contemporânea de alimentos, demonstra como a indústria e o consumo criaram alimentos-signo, cuja ingestão corresponde a introduzirmos em nosso corpo biológico um fragmento do imaginário social; em decorrência, "se o alimento constitui nosso ser biológico de dentro para fora, desde o invisível do orgânico ao visível da pele, o alimentosigno nos constitui de fora para dentro, do visível do signo ao invisível da consciência, ou seja, conforma nossa identidade social" (ib.: 147). 
Para sumarizar, em suas variantes, o essencial da perspectiva cultural, compensa reproduzir o que propõe Stephen Mennel, quando se refere ao que chama de cultura culinária, desenvolvendo pistas abertas por Norbert Elias:

"Culinary culture, by extension, includes everything that we mean by the 'cuisine' of society or social group, but a lot more besides. It refers not just to what foods are eaten and how they are cooked - whether simply or by increasingly elaborate methods but also to the attitudes that are brought to cooking and eating. Those attitudes include the place of cooking and eating in people's patterns of sociability leating out, in company, or in privatel; people's enthusiasm or lack of it towards food; their feelings, conversely of repugnance towards certain foods or methods of preparation; the place of food, cooking and eating in a group of society's sense of collective identity, and so on. Because culture is 'learned, shared and transmitted', in my view we can only understand 'the cultural controls of perception' by studying how they develop and are transmitted over time. An anthropology or sociology of food must also be a history of food" (Mennell 1992: 279; v.também 1987).

Oenfoque filosófico.

Resta falar de um enfoque de desenvolvimento recente e, ainda, sem muita densidade. Duas linhas podem ser mencionadaś

A primeira, mais geral, é exemplificada pelo livro de Elizabeth Telfer (1996) que se intitula, precisamente, Food for thought. Philosophy and food. Tais título e subtítulo prometem mais do que oferecem. (No entanto muitas das questões aqui tratadas também ocorrem em trabalhos dos mais diversos campos). A autora acentua os aspectos de prazer, não-necesssidade, na alimentação, assim como os preconceitos contra a dimensão corporal do homem e, a partir daí comenta posições de filósofos, de Platão e Aristóteles a Kant e Stuart Mill. Discorre sobre - valor do prazer de comer, as obrigações implícitas, as virtudes morais da hospitalidade e da temperança. Coletâneas como a organizada por Curtin e Heldke (1992) também se alocam aqui.

A outra linha é repesentada pela coletânea de Ben Mephan led., 1996) sobre a ética da alimentação. Questōes abordadas: a fome enquanto problema ético, a segurança alimentar, o respeito à vida animal e às condições ambientais, a moralidade das modernas biotecnologias, os aspectos culturais da ética da alimentação, etc.

\section{A Contribuição das Ciências Sociais}

Também aqui o que se pretende não poderia ser um quadro definido, nem um balanço crítico sistemático, muito menos uma listagem bibliográfica substancial. Pretende-se, tão somente, assinalar traços que registrem a contribuição que as disciplinas sociais trouxeram para o conhecimento de um tema multifacetado como a alimentação.

Desde já convém esclarecer que as compartimentações entre Antropologia, Sociologia, Geografia, etc., são artificiais e destinam-se apenas a acentuar comodamente algumas características específicas dominantes e não recortes epistemológicos e metodológicos rigorosos e consistentes. Nessa mesma 
ótica, deve-se salientar a perspectiva histórica que caracteriza muito desta literatura - o que faz que o esboço a seguir também abranja, implicitamente, a História.

Convém ainda esclarecer que não se abriu espaço próprio para a Psicologia, pois muitas de suas contribuições fundamentais encontram-se aticuladas a outros temas ou contextos disciplinares, aqui citados (seleção de alimentos, dietas, patologias, etc.).

Antropologia

A Antropologia, sem dúvida, pode ser considerada a disciplina que mais se preocupou com nosso tema, que recolheu o maior acervo de informação e que exerceu, sobre as demais disciplinas, inclusive a História, a influência mais considerável. Para se ter uma idéia da amplitude, diversidade e consistência da produção antropológica, basta compulsar, por exemplo, a revisão bibliográfica, já não tão recente, feita por Ellen Messer (1984) e que se organiza segundo temas tão diversificados como os estudos ecológicos e de abordagem materialista (energia, coletores-caçadores, problemas bioculturais), princípios de seleção de alimentos, classificação e construção dietária latributos sensiveis do alimento; dimensões cultuais, simbólicas e cognitivas), estudos semióticos, identidade, etnia, enculturação, estrutura dietária, fatores econômicos. Ou então, para se ter uma visão de conjunto, segundo outros parâmetros, pode-se examinar uma coletânea, como aquela organizada por Carole Counihan e Penny van Esterik (1997), que reproduz textos 'clássicos' como os de Margaret Mead, Claude LéviStrauss, Roland Barthes, Mary Douglas, Jean Soler, Anna Meigs, Anna Freud, Jack Goody, Marshal Sahlins e muitos outros mais. Doutra parte, um livro como o de Stephen Mennell, Anne Murcott e Anneke van Otterloo leds. 19921, além de constituir um bom exemplo do trânsito de dupla mão de direção entre a Antropologia e a Sociologia (sem excluir a História), cobre uma gama extensa de temas, sobre os quais oferece uma síntese bibliográfica de interesse: as conexões entre alimento, nutrição e saúde; desordens alimentares; desigualdades de consumo por classe, gênero, idade, nação; relação do alimento com as esferas pública e privada, perspectiva antropológica e histórica sobre as culturas culinárias; o impacto do colonialismo e das migrações sobre a alimentação; a transformação das tecnologias de produção e suas conseqüências sociais, etc.

Os antropólogos, desde o século XIX, se empenharam em desenvolver uma etnografia sistemática dos hábitos alimentares e em buscar interpretá-los culturalmente. A primeira fase da Antropologia caracterizou-se por um comparativismo das diferentes tradições culturais. A análise dos tabus, onde se destacam os alimentares, foi desde os primórdios da Antropologia Cultural um terreno fértil para especulações sobre o significado simbólico da alimentação. No interior da extensa obra The golden bough, de James Frazer, publicado pela primeira vez em 1890, desenvolveu-se a interpretação destes temas, particularmente no livro Taboo and the perils of the soul. O resultado de interesses semethantes ao de Frazer foi estimular o mapeamento dos diversos hábitos alimentares, cuja especialização, de caráter local, regional e, mesmo, continental, foi devidamente fixada. A alimentação serviu, ainda, para proposição de 'áreas culturais': exemplos de qualidade são comuns na 
Alemanha, como, entre tantos outros, os levantamentos de Moriz Heyne (1901) ou os de Eckstein et alii (1938).

Em tempos mais recentes, os estudos antropológicos de alimentação podem ser considerados segundo matrizes diferentes, ecoando transformações globais que ocorreram no seio da disciplina.

Até os anos 60, imperava uma perspectiva funcionalista acentuada. É aliás de uma discípula de Malinowski, Audrey Richards (1932), um estudo pioneiro de alimentação que toma os Bemba, uma tribo Bantu da África Central, como referência. A autora não apenas retrata a produção, preparo e consumo do alimento, mas os insere num contexto sócio-psicológico, levando em conta diferenciais como ciclos de vida, grupos e estuturas sociais, modalidades diversas de interação, etc. Infelizmente, esse rico modelo não parece ter tido a difusão que merecia.

Somente nas décadas de 60 e 70 , na voga do estruturalismo, é que os estudos antopológicos sobre alimentação deslancham e se define um padrão de análise cultural. Claude Fischler (1990: 17) o caraceriza com felicidade, em poucas palavras: "While' the functionalists looked at food, the structuralists examined cuisine". O alimento passa a ser investigado como sistema cltural e abordado linguisticamente.

Algumas obras publicadas por Claude Lévi-Strauss (Le cru et le cuit, de 1964; Du miel aux cendres, de 1967, L'origine des manières de table, de 1968 e Le triangle culinaire, também de 1968, começam a ter considerável repercussão entre os estudiosos da alimentação. Elas não tratavam apenas do tema, especificamente, mas de estruturas mitológicas. Todavia, reconhecendo que é em torno da alimentação que as diferentes culturas estruturam sua vida prática, assim como parte considerável de suas representações, Lévi-Strauss não deixou de mobilizar a problemática alimentar. A diferença enre o cru e o cozido torna-se para ele um dos marcos que fundam a própria cultura. Seu triângulo culinário (cru, cozido, assado) teve ampla divulgação e suscitou endosso apaixonado, tanto quanto recusa exacerbada.

A voga, nos anos 80 , é de estudos de base materialista, como os de Marvin Harris (1989, ed.or. 1986) e enfatizando aspectos históricos. Além disso, vai ser inensa e explícita a discussão de problemas teóricos e metodológicos relativos ao tema.

Se quisermos assinalar quais os temas que, nesta última década, têm provocado o maior investimento da Antropologia, no campo da alimentação, independentemente de orientações teóricas, salientaríamos as práticas culturais, os processos de aculturação, a identidade cultural,

Se as práticas já eram importantes desde os levandamentos dos 'modos de vida', agora ganham mais relevo quando o que se procura é pesquisar, nos hábitos, nas etiquetas, nas maneiras à mesa, problemas como aqueles propostos por Norbert Elias (1990, ed.or. 1939) ao tratar do 'processo civilizator. Assim, Mennell (1987) procura explorar os usos sociais de aspectos concretos desta domesticação da natureza pela cultura, examinando os mecanismos que 'civilizam o apetite'. O controle do corpo, o controle das emoções em público, a 'ordem à mesa', as hierarquias e os padrões de relação, o avanço do individualismo e o espaço privado, etc., etc., são explorados, 
principalmente entre o séc. XVI até a contemporaneidade, como produtos e vetores de mecanismos sociais (v.Roche 1997: 255-7). Vários estudos desta natureza têm recortes nacionais, como o de Cooper (1986) sobre as maneiras chinesas, ou de Arnaboldi (1986) sobre as francesas.

As questões de identidade também tem sido foco de pesquisa. Quanto à identidade pessoal, há vinculações com as diversas vertentes de estudo do corpo e da corporalidade (Fischler 1990; Lupton 1996). Mais espaço tem merecido a identidade étnica, a caracterização e funções da 'comida étnica' (principalmente entre migrantes e minorias): foco do imaginário, delimitação de fronteiras, base de conflitos, fonte de estereótipos e estigmas /'alemão-batata', ou 'chucrute'; ' 'sírio-libanês-quibe'; 'nos Estados Unidos, 'spaghetti' para os italianos e, na Inglaterra, 'frogs' para os franceses, etc.). Entre os inúmeros títulos, podem ser citados: Kraut (1979), Jerome (1980), Calvo (1982.

A identidade nacional, por sua vez, tem sido vista como de estatuto ambíguo. Mennel (1985) já reconhecera que o aparecimento das 'cozinhas nacionais', dos 'estilos nacionais de comer' - e, mais que isso, seu reconhecimento público, tomado possível pela difusão de 'histórias' e livros de cozinha - coincidem com a formação, desde o fim do séc. XV, nạ Europa, dos estados-nação, culminada no séc.XIX, século privilegiado da gastronomia. Entretanto, nem mesmo para o século passado é possivel falar de cozinhas essencialmente nacionais, seja pelo substrato comum histórico ou trazido pelos comércio e processos de aculturação já em curso, seja pela regionalização ainda muito marcada dos padrões (Murcott 1997). Poucos estudos existem como os de Catherine Palmer (1998), que procurou examinar, no cotidiano, o funcionamento dos mecanismos da identidade nacional, incluindo a alimentação.

No próprio espaço das identidades e em relação às práticas alimentares se tem associado a problemática da enculturação (Fischler 1985 e 1988; Widdowson 1981) e, portanto, o papel da alimentação na reprodução da sociedade e, principalmente, da família. Sidney Mintz, após referir-se aos hábitos alimentares como veículos de emoção profunda, resume seu papel enculturativo:

"The learning of personal fastidiousness, manual dexterity, cooperation and sharing, restraint and reciprocity are commonly linked to the consumption of food by children. Indeed, getting to eat with the adults as an adult, rather than as a child, may be one of the major hurdles of growing up in some cultures" Mintz, 196: $70 \mid$

Para finalizar, cumpre assinalar a criação, no interior do campo antropológico, de várias instituições agrupando os profissionais interessados no estudo da alimentação, algumas de âmbito internacional, outras, de vinculação nacional mas repercussão muito ampla e responsáveis por pesquisas, publicações, encontros de especialistas e outras formas de atuação acadêmica e política: US National Academy of Sciences Committee on Food Habits (1945), International Committee for Anthropological Food and Food Habits (1968), International Commission for the Anthropology of Food and Food Problems/International Union of Anthropological and Ethnological Sciences, Ethnological Food Research Group (1970), Foundation of Chinese Dietary Culture (1991), Ajinomoto Foundation for Dietary Culture (1989). 
Arqueologia

Na Arqueologia, o tema da alimentação tem ocupado espaço central. Antes de mais nada, pela relevância do problema diante das perspectivas holísticas da Arqueologia. Em seguida, pela disponibilidade de evidências e testemunhos freqüentes de documentos alimentares entre os restos arqueológicos e da viabilidade de inferências. Assim, não é de estranhar que a Arqueologia tenha fornecido contribuição de monta a estudos de evolução cultural. Helen Leach (1997: 135) chega a afirmar que foi no tocante à substituição de um sistema de caça e coleta pelo da produção de alimentos que, nos útimos cinqüenta anos se travou o debate mais importante no domínio arqueológico. Infelizmente, não há ainda nenhum tratamento consistente e abrangente do tema. A bibliografia é esparsa e muito volumosa e de qualidade variável, sobretudo nas tentativas de sintese (como Perlès 1996), mas já se começa a ter um quadro mais definido de problemas (Arnott, ed. 1997; Harris \& Ross, eds., 1987, Ellen 1994 ou Garine 1994). Uma coletânea que justifica lembrança, pela diversidade de contexto, é a que engloba os trabalhos monográficos de Sigfried J. De Laet, Jack R.Harlan, Sandor Bököny, José L.Lorenzo, Mario Sanoja Obediente, Luís G.Lumbreras Salcedo e outros que colaboram com a Parte II (From the beginnings of food production to the first states), incluida no primeiro volume da History of Mankind, da Unesco, dirigida por S.J.De Laet (1994: 366-39), estendendo-se desde o Neolítico até ca. 5.000 anos atrás, com os inícios do processo de domesticação de plantas e animais em vários domínios geográficos, como o Velho e o Novo Mundo e o Oriente.

Mais que tudo, a perspectiva holística da Arqueologia, como se disse acima, e sua vocação para explorar todas as possibilidades inerentes à cultura material obrigou-a a defrontar-se permanentemente com o problema da alimentação, da subsistência, das tecnologias de obtenção, processamento, conservação e distibuição dos alimentos, dietas e carências, etc.etc., a partir de restos materiais e sua inserção espacial. Seria ocioso mencionar títulos, pois são excepcionais os estudos não monográficos que excluam a alimentação de seu arco de interesse.

Disso resultou a necessidade de formular e calibrar métodos e técnicas de identificação, recuperação e análise de evidências - o que não se encontra, em nivel comparável, em nenhuma outra disciplina que se tenha ocupado da alimentação, salvo, em parte, nas ciências da nutrição (v. Brothwell \& Brothwell 1998). Bastaria, por exemplo, examinar um manual corrente de introdução à Arqueologia, como o de Colin Renfrew e Paul Bahn (1991), para se ter uma idéia da panóplia de recursos desenvolvidos pela Arqueologia, com auxílio interdisciplinar. (E que a História, por exemplo, desconhece, mesmo naquelas circunstâncias em que tais recuros the poderiam ser de grande valia.) $O$ capítulo 7, sobre subsistência e dieta, desfila as posibilidades crescentes que se têm aberto. Análises macro e microbotânicas, técnicas de flotação para recuperação de vestígios, estudos palinológicos ou de impressões de vegetais permitem recuperar quadros páleo-botânicos e definir, às vezes em niveis impressionantes de pormenores, a interação humana. O exame de restos faunísticos e humanos, principalmente de material osteológico, é capaz de produzir dados de vasto 
alcance. A análise isotópica de colágeno do osso humano, por exemplo, vem sendo utilizada para esclarecer a origem da agricultura no Novo Mundo, pois registra informação sobre consumo alimentar em padrões de longa duração. $O$ estudo do desgaste dentário, por sua vez, revela não só dados preciosos sobre dietas, patologias e carências alimentares, como também sobre técnicas de manducação. O conteúdo estomacal, coprólitos, resíduos culinários, tipos de utensílios e traços dos padrões de uso nos artefatos asseguraram o conhecimento individuado de refeiçōes, de técnicas de processamento, de variações sazonais, de combinações alimentares com implicações nutricionais, de constantes na distribuição per capita etc. O conteúdo de concheiros é convertido em índices nutricionais, que podem, por sua vez, fornecer pistas para variáveis demográficas. E assim por diante. Sumarizam os autores:

\begin{abstract}
"All the methods described in this chapte are providing archaeology with new tools, not to say with 'food for thought'. The evidence available varies from botanical and animal remains, both large and microscopic, to tools and vessels, plant and animal residues, and art and texts. We can discover what was eaten, in which seasons, and sometimes how it was prepared. We need to access whether the evidence arrived in the archaeological record naturally or through human agency and whether the:resources were wild or under human conrol. Occasionally we encounter the remains of individual meals left as funerary offerings or as the contents of stomachs or feces. Finally, the human body itself contains a record of diet in toothwear and in the chemical signatures left in bones by different foods" (Renfrew \& Bahn 1994: 270).
\end{abstract}

Sociologia

Embora os grandes nomes da Sociologia, de Marx a Spencer, de Durkheim a Weber, de Simmel a Sorokin, tenham incluído em suas obras reflexões sobre alimentação, não desenvolveram um campo sistemático de problemas. É somente a partir da difusão da Sociologia da Cultura que vão surgir os trabalhos de maior continuidade e os verdadeiros especialistas do ramo (para uma visão panorâmica do campo, ver Mennell et alii 1992, Murcott, ed. 1983).

Como aliás é desejável, a Sociologia partilhou com a Antropologia um campo comum de interesses - de que também participaram a Geografia e a História. Não obstante, há cerłas áres de problemas que ela privilegiou.

A primeira refere-se a questões de diferenciação social pelo alimento, de status, e, em suma, de poder. Apesar de se tratar de uma perspectiva corriqueira, não deixa de apresentar resultados interessantes, ao identificar as especificidades que, no caso, assume o alimento (v. Wiessner \& Schiefenhövel 1996).

Entre as diferenciações sociais, as de gênero são as que mais têm ampliado seu campo na pesquisa. $O$ eixo tem sido a divisão social do trabalho doméstico, com o homem como provedor externo do alimento e a mulher como processadora e responsável pela reprodução da família (para exemplificar: Charles \& Kerr 1988, Murcott 1983 e 1993, Wall 19911. As questões de gênero também têm sido vistas de ângulos mais reduzidos, como a associação da carne à virilidade - o que terá implicações muito amplas em movimentos como o vegetarianismo (Twigg 1983, Caplan 1994: 17 ). 
Em escala superior, é a associação da alimentação ao campo do poder que tem sido uma constante. Arjun Appadurai (1981) forjou, mesmo, o neologismo 'gastropolítica' para caracterizar num estudo sobre hindus, o uso do alimento como meio de proteger ou contestar posições sociais. Ele também observou o conteúdo político dos eventos alimentares festivos: "the marriage feast is a quintessentially gastro-political arena" (1981: 502). Young (1971) já caracterizara a festa como oportunidade impar de disputa de poder: "fighting with food". E Mary Douglas repetidamente assinalou o banquete como recurso para mobilizar forças (p.ex. 1972). Na ordem internacional, como demonstram Carole Counihan e Penny van Esterik (eds., 1997: 3), a hierarquia de 'primeiro mundo' e 'terceiro mundo' se assenta no acesso diferencial ao alimento, especialmente a carne.

A segunda área de questões é a comensalidade. Comer e beber juntos sempre foi reconhecido como matriz de sociabilidade (Mennell et alii 1992: 115-9, Levenstein 1993, Aurell et alii 1992, Douglas 1984). Daí a preocupação em estudar a alimentação e as práticas alimentares como ritos de passagem e incorporação, de solidariedade e hospitalidade ou exclusão, de identidade e socialização, oportunidade de transgressões, de reforço compromissos e de hierarquias, etc. A importância visceral da comensabilidade em certas sociedades antigas - basta atentar para o symposion dos gregos motivou obras de elevado interesse sociológico (Pantel 1992, Lombardo 1989, Nielsen 1998).

Doutro ângulo, os estudos de comensalidade se orientaram para a refeição como instituição social, sua natureza e funcionamento, seus ícones como a mesa (Douglas 1972, 1974, Wood 1995, Herpin 1988, Visser 1987. Lucas 1994 etc.).

Neste contexto, os avanços da tecnologia alimentar (com os alimentos industrializados), a ampliação do hábito de comer fora, o aparecimento da fast food vão comprometer a cozinha doméstica e seus significados sociais (Fischler 1979. Mintz 1985, Leidner 1993, Carney 1995). Fischler até cunhou um termo - 'gastro-anomia' - (1980: 28) para expressar a dessocialização que a liberdade irrestrita de escolha individual está provocando, ao criar a oportunidade de 'comer sem refeições'.

Problema correlato, o do 'jantar fora' tem sido, por isso mesmo, examinado como performance social (Finkelstein 1989) ou 'teatro das relaçōes sociais' (Shelton 1990), estendendo-se tais enfoques ao estudo do resaurante como espaço simbólico e de seus agentes, os cozinheiros, chefs, garçons (ver refers. em Fine 1996, Pillsbury 1990).

Dentro dos padrões de sociabilidade, não se pode esquecer a alimentação institucional: escolas, prisões, hospitais, navios, quartéis etc. (Lambert 1968, Valentine \& Longs 1998).

A bebida e seus desvios têm recebido espaço da Sociologia làs vezes acoplada à Antropologia e com perspectiva histórical. Mary Douglas se interessou pelo que chama de Constructive drinking (1991) para identificar a embriaguez como expressão de uma cultura; Véronique Nahoum-Grappe, em La culture de l'ivresse (1991), procura, com auxilio da fenomenologia histórica, estudar a "conscience collective de ce que peut être un tel état (l'ivressel"; Didier 
Nourrisson, que já havia produzido uma tese sobre o alcoolismo e o antialcoolismo na França sob a llla. República (1988), toma a figura do 'buveur', no séc.XIX, como eixo de sua investigação (1990); Harrison (1971) ocupou-se com a bebida entre os vitorianos (e organizou em 1967 uma bibliografia crítica sobre bebida e sobriedade na Inglaterra, ente 1815-1872) e Brennan (1991) com a bebida como padrão público de sociabilidade e com a cultura popular do séc.XVIII. lossifiedes \& Gefou-Madianou (eds. 1992) associam o álcool a questões de gênro. G.E.Vaillant (1983) traçou uma história natual do alcoolismo'. Um número especial da revista Terrains (Boire 1989) apresenta vários estudos sociológicos sobre bebidas (álcool, café, chá, chocolatel, suas instituições e contextos sociais.

Finalmente, aponte-se o grande tema, que está mobilizando a Sociologia da alimentação: o consumo. O papel central da alimentação nesta faixa foi salientado por Fine, Heasman e-Wright leds. 1995). Em articulação ao consumo, alguns temas têm sido introduzidos: a publicidade alimentar, seu caráter alienador e valorizador do que Barry Smart (1994) cunhou de 'gastro-porn' lalimentos sedutores, mas impossiveis de obter e artificial e estereotipicamente perfeitos): o papel da alimentação na constituição da cultura popular contemporânea (Bell \& Valentine 1997) e na constituição de estilos de vida (Tomlinson 1990); paralelamente, na contracultura (Belasco 1993).

Finalmente, o consumo permitiu fornecer um contexto de entendimento para alterações de monta que a alimentação vem sofrendo no tocante ao tempo. O tempo das refeições, tempo regrado, dos ritmos regulares do cotidiano que integravam o tempo dos consumidores e dos produtores, tempos naturais, vai-se desintegrando (Aymard et alii 1993, Palmer 1952). As tecnologias alimentares suprimem o tempo natural, pois mascaram as estações, momentos do calendário, marcos sociais repetitivos (Gofton 1990).

Geografia

A Geografia, como não poderia deixar de ser, há muito tempo vem contribuindo para iluminar os componentes espaciais da problemática da alimentação. Um artigo como o de M. Sorro (1952) dá idéia das principais preocupações em meados deste século, em que ainda tinham peso específico a produção, transporte e comercialização dos alimentos (v. Também Géographie de l'alimentation 1980).

Para que se perceba a relevância do espaço neste campo de estudos, basta lembrar que a maioria dos staple foods (que alguns especialistas, como lgor de Garine 1994: 239 preferem chamar de cultural superfoods) das sociedades modernas têm origem em expaços externos àqueles em que vieram a dominar: a cassava e o milho, na África Equatorial (origem americana), a batata, para grupos himalaios, a cassava e as batatas doces na Indonésia e Melanésia e Nova Guiné; o arroz, cuja dispersão esteve vinculada ao sistema colonial; o trigo, as especiarias, o tomate, a pimenta chilli etc.etc.etc. ISantieri \& Zazzu 1992, Foster \& Cordell, eds. 19921. Num outro rumo, aponte-se, ainda, a importância do tema da fome no seu enquadramento espacial (Young 1998). 
Mais recentemente, a disciplina ampliou a escala de ocorrência dos fenômenos que investiga: o corpo, a casa, a comunidade, a cidade, a região, a nação e, finalmente, o globo, com suas forças polares de homogeneização e diferenciação (glocalisation), que redundam seja na universalização de uma rede de lanchonetes como a McDonald's, seja na valorização particularística do 'autêntico exótico' (Bell \& Valentine 1997: 19). Dentro desse quadro, a 'globalização local' da cultura culinária e o fetichismo da mercadoria obrigam a considerar os alimentos como materiais e práticas 'destocadas', como fazem Cook \& Crang (1996). E assim que os autores arrolados por James Watson (ed. 1998) procuram, também tomando McDonald's como referência, observar o papel da fast food diante das cozinhas locais, em Hong Kong, Beijing, Taipei, Tóquio e outras metrópoles asiáticas.

Nesse percurso, a Geografia está cada vez mais procurando aprofundar duas questões, que se associam intimamente: o consumo e as identidades regionais e nacionais. Não é puro jogo de palavras que o livro de David Bell e Gill Valentine (1997) intitulado Consuming geographies, tenha por subtítulo We are where we eat.

No entanto, é preciso observar que, na:maioria, os estudos de geógrafos sobre alimentação têm convergido para preocupações comuns com as dos sociólogos, antropólogos e, mesmo, historiadores. Os próprios Bell e Valentine, já citados, também exploram, ao lado do espaço, a problemática do tempo na alimentação ou, mais precisamente, o consumo alimentar como forma de organização do tempo, numa direção semelhante à que foi acima apontada para a Sociologia: os ritos de passagem no consumo la primeira gota de álcool, a primeira vez que se cozinhou um prato etc.l, a pontuação e periodização da vida, a estruturação do ritmo temporal, a criação do tempo pelo consumo la naturalização das sasonalidades do consumol e, finalmente, a supressão do tempo pelas tecnologias alimentares.

\section{A Instituição de um Campo Especializado}

As páginas precedentes já permitiram perceber alguns traços marcantes da História nos estudos sobre os problemas da alimentação. Também se percebeu que a História está longe de ser a disciplina dominante. Impõe-se, porém, examinar mais de perto a natureza, formação e transformaçōes do que se poderia hoje chamar de História da Alimentação.

É difícil situar o processo constitutivo e acompanhar o desenvolvimento de um "campo" de estudo histórico tão vasto, heterogêneo e difuso. Nosso esforço, por isso, será o de fornecer apenas uma certa carlografia histórica desse território, apresentando indicações sobre sua condensaçāo e institucionalização.

Os pontos de partida

Os historiógrafos franceses (p.ex. Burguière 1986) costumam apontar como marco referencial para um novo rumo, na História da Alimenłação, a obra 
do polonês Adam Maurizius. Maurizio, como veio a ser conhecido, era um botânico, professor na Escola Técnica Superior de Lvov. Além do crédito pessoal que the reconhecem alguns historiadores, como Fernand Braudel, tal imagem talvez se deva em grande parte à própria avaliaçãoque Maurizio fazia de seu livro, originalmente publicado em 1926 e logo traduzido para o alemão e para - francês (1932). Partindo do pressuposto de que a história da civilização e a história da utilização do mundo vegetal se confundem, e mesmo conscientemente excluindo a alimentação de origem animal, Maurizio empreendeu uma vasta tentativa de traçar a história dos alimentos vegetais, desde a pré-história alé seus tempos. Seu objetivo era preencher uma lacuna, pois o preocupava a inexistência, até então, de 'qualquer história da alimentação', que ele entendia, portanto, equivalente a uma história da agricultura:

"je veux dire une histoire des plantes importantes au point de vue de l'agriculture et des instruments agricoles. II ne s'agit point de l'histoire de l' exploitation et de l'administration des terres, car rien ne nous manque à ce point de vue là. Mais les quelques ouvrages qui s'intitulent histoire des aliments et de l'alimentation (Bourdeau, Lichterfelt) valent surtout par l'intention. Bien plus utiles sont des ouvrages (souvent utilisés ici) qui traitent des plantes alimentaires au point de vue purement botanique. Le travail très detaillé de D. Bois: Les plantes alimentaires chez tous les peuples et à travers les âges, tome I de I'Encyclopédie biologique (c'est en réalité la 4º́ édition de l'ouvrage de A. Pallieux et D. Bois: Le Potager d'un curieux), n'a malheureusement paru qu'à une époque ne m'ayant pas permis de l'utiliser, mais seulement de l'apprécier extrêmement" (Maurizio 1932:141.

Por certo, o rumo de Maurizio, disciplinado e rigoroso, é diverso das histórias que anteriormente apontamos, de variado teor, desde a Antigüidade e o Renascimento, ou os registros imaginosos como o Catalogue des inventeurs des choses qui se mangent et se boivent (1548) de Ortensio Lando, ou mesmo aquele que é considerado um dos pontos de partida para o reconhecimento do papel da alimentação nas 'histórias dos costumes' e da vida privada - a obra de JeanPierre Legrand d'Aussy (1782), cuja linhagem será numerosa, como alesta a importância das crônicas históricas dos costumes, incluindo os hábitos alimentares (ct. Briffault 1846). No entanto, não se pode ignorar o acervo de informação segura e confiável disponível, no tempo de Maurizio, e acumulada desde o século passado, seja nos repertórios de plantas comestíveis, seja nos levantamentos etnográficos (alguns de caráter regional e, mesmo, geral) a que já nos referimos, seja, enfim, nos dados constantes de uma vasta série de monografias nacionais ou desenvolvendo-se em torno de certos alimentos específicos. A história da agricultura é um dos pontos de partida do estudo sistemático das plantas de uso alimentício e, entre os autores que escreveram ensaios de sistematização histórico sobre as plantas cultivadas, podemos citar Haudricourt \& Hédin (1943), Franklin (1948), Anderson (1952) e Chrispeels \& Sadava (1977).

A Inglaterra foi constante nesse interesse pelas questões alimentares. Já em 1856, George Dodd se preocupava com a alimentação em Londres. Além disso, na própria França, no começo do século Marc Bloch (1914) levantara, na Encyclopédie française, questões que teriam um peso quase programático, como o das transformações dos regimes dietéticos (fatores associados à 
2. As outras três eram sobre os meios de transporte e locomoção, a evolução da forja de aldeia nos últimos cinquenta anos (ou seja, descle 1870 ) e as colheitas e os fogos de São João e de Quaresma expansão colonial, efeitos no equilibrio orgânico e psico-social) a segregação alimentar e seu caráter principalmente social etc. Na década de 30 já se anunciavam outras posições que lambém viriam a deixar importante marca metodológica. Cedo, por exemplo Lucien Febvre se interessou por diversos aspectos inexplorados da alimentação, tendo consagrado uma intervenção no Primeiro Congresso Nacional de Folclore, em 1938, à proposição de um mapa para as gorduras de cozinha utilizadas na França, tema retomado no início dos anos 60 na revista Annales E.S.C. por J.J.Hémardinquer (1961). Como diretor da Encyclopédie française, Lucien Febvre fundou uma comissão de investigações coletivas para buscar uma convergência entre a Etnografia e a História. A Comissão em dois anos (1935-1937) empreendeu quatro investigações, entre as quais uma sobre a alimentação popular (camponesa) tradicional ${ }^{2}$

O certo é que, em torno da data da difusão do livro de Maurizio, surgem inúmeras publicações, de caráter histórico, a demonstrar, mais que um potencial latente, interesses e recursos já em processo de objetivação. Nenhuma delas, diga-se de passagem, tem a pretensão de panorama global mas, ao contrário, domina o recorte nacional e, até mesmo, local: Cooper (1929) escreve sobre os hábitos alimentares ingleses na história e na literatura; Drumond \& Wilbraham (1939, 2a.ed.1957) tratam de cinco séculos de dieta inglesa; Cereda (1934), Espinosa (1939), Escudero (1934), Madones \& Cox 1942), Bejarano (1941). Guevara (1946) tomam como objeto a alimentação, respectivamente, na Espanha, no México, em Buenos Aires, no Chile, na Colômbia, na Venezuela. O pão (Ashley 1928) e o açúcar (Dorveaux 1917) contam entre os alimentos que atraem atenção.

Consolidação na França: o papel dos Annales

É com as propostas da 'escola dos Annales' que, na década de 60 , ganha fisionomia definitiva e explicitamente programática nosso campo de pesquisa. A primeira vaga de trabalhos está marcada pelo conceito então vigente de vida material (Barlösius 1992) e privilegiava o nível do econômico e do infraeconômico. O nível do econômico foi conceituado por Fernand Braudel, o sucessor de Fevbre na direção dos Annales, como aquele da troca, do mercado. Abaixo dele estaria um outro nivel, infra-econômico, que seria o da vida material e biológica. O conceito de cultura material abrangeria os aspectos mais imediatos da sobrevivência humana: a comida, a habitação, o vestuário. A longa duração, concebida como a escala na qual se davam os fenômenos superiores aos eventos e às conjunturas, tornou-se a dimensão no interior da qual novos objetos tomariam consistência historiográfica. A vida cotidiana, a cultura material, as mentalidades, o corpo, a família e a morte são alguns dos temas que emergem à tona das profundezas aparentemente congeladas dos tempos para se revelarem na dialética da sua transformação e da sua permanência como noções plásticas, sujeitas a mudanças, mesmo que elas apareçam como imperceptíveis para os próprios protagonistas.

Em 1961, a revista Annales E.S.C. abriu as páginas da sua edição de maio-junho com a proposta, num texto assinado por Fernand Braudel, de um retour aux enquêtes. Embora retorno, ele fazia questão de declarar que não se 
tratava das mesmas investigações empíricas que anteriormente haviam sido empreendidas por Marc Bloch e Lucien Febvre, sobre 'nobrezas' e 'técnicas'. A investigação então em pauta, nos anunciava ele, se debruçaria sobre dois temas: 'A história, ciência social atual', e 'A história da vida material e dos comportamentos biológicos'. Na verdade, é apenas o segundo tema que foi desenvolvido naquele número e, ao longo do ano de 1961, nos dois próximos números da revista.

Nesta apresentação inicial da questão, após reafirmar seus esforços em prol de uma história considerada como uma "ciência do atual" e, até mesmo, como uma 'ciência das ciências do homem', ele define o que será um dos centros de preocupação da revista e fecundará muitos estudos vindouros: a história da vida material, 'infra e extra-econômica'. Mais à frente, iniciando o Boletim n. 1 de investigação sobre 'vida material e comportamentos biológicos', é o próprio Braudel quem continuava buscando definir tal domínio, para o qual diversos pontos de vista se oferecem: os da própria História, mas também os da Geografia, da Antropologia, da Sociologia, da Economia, da Demografia, do Folclore, da Pré-história, da Linguística, da Medicina, da Estatística. Diante de tal complexidade ele propõe que cada disciplina coloque o problema nos seus próprios termos.

Ele próprio, no entanto, entende por vida material "cinq secteurs assez proches: l'alimentation; le logement et le vêtement; les niveaux de vie; les techniques; les données biologiques". "La vie matérielle va ainsi, - escreve ele (Braudel 196la:547) — des choses au corps".

Diferentemente da vida econômica ou social, a vida material șe situa num outro patamar, onde quase não há consciência da parte dos atores. É como uma 'infra-história', portanto, ou uma 'infra-infraestrutura', que se apresentava essa história dos 'alimentos, vestimentas e habitações'. Enquanto 'a vida econômica, as instituições, a sociedade, as crenças, as idéias, a política' relacionam-se às 'atenções e vigilâncias', a vida material relaciona-se aos 'hábitos, heranças e escolhas longinquas'.

O método para o estudo da vida material devia ser 'regressivo'. Segundo Braudel, era preciso partir do conhecimento preciso das cifras que a documentação contemporânea oferecia para se poder medir e comparar.

A enquête prossegue com um artigo de Robert Philippe que circunscreve ainda mais o domínio da vida material que a revista se propõe abordar. O artigo intitula-se: Commençons par I'histoire de l'alimentation, apresentada como um vasto domínio com caminhos já traçados. Duas advertências são dadas: apoiar-se sobre os dados da atualidade e não incorrer num 'determinismo alimentar', de querer explicar a história inteira dos homens a partir dos alimentos.

Dois regimes são sugeridos como modelos antípodas: os monótonos e os variados. Esta distinção alimentar é a que separa socialmente as dietas em todas as épocas. O caminho que é proposto, em seguida, é o estudo nos regimes alimentares de como se combinam os elementos nutritivos e se são estabelecidos ou não "equilíbrios biológicos" em cada grupo ou sociedade. No nível da carência só haveria desequilíbrio, ou seja, fome, compreendida como desnutrição. 
3. A saber: 0 abastecimento de seis frotas espanholas entre 1542 e 1642; a corte da Suécia e seus servidores em 1573: uma expediçào conjunta portuguesa $e$ espanhola para a África do Norte em 1578:0 Hospital dos incuráveis em Gênova em 16081609: uma famili nobre na mesma cidade entre 1614 e 1615; Colégio Borromeo de Pávia, entre 1609 e 1618; três despensas civis na Inglaterra em distintas epocas e; enfim, um combois que deveria transportar 2 mil soldados e 608 cavaleiros de Nápoles para a Espanta
Aplicando a primeira advertência, o primeiro estudo da enquête alimentar será sobre a atualidade: En France aujourd'hui: données quantitatives sur les consommations alimentaires, de J.J. Hémardinquer. Dos outros dois artigos Une opération pilote: l'étude du ravitaillement de Paris au temps de Lavoisier, de Robert Philippe e Régimes alimentaires d'autrefois: proportions et calcule en calories, de Frank Spooner - o primeiro trata de um estudo, a partir de um cálculo realizado por Lavoisier sobre o total de viveres consumidos em Paris e os seus preços globais, que conclui por uma deterioração na alimentação parisiense na primeira metade do século XIX. No segundo artigo, expressando um objetivo comum desse primeiro número da revista dedicado à alimentação, trata-se de se esboçar "une méthode uniforme de calcul qui permette les comparaisons entre régimes alimentaires, dans le temps et dans l'espace" (Spooner 1961: 568), o que será feito, no artigo em questão, através da comparação de sete diferentes registros de despensa ${ }^{3}$

O número seguinte dos Annales E.S.C., correspondente a julho-agosto de 1961, traz um Boletim nº 2 da 'História da Vida Material', que inclui um novo artigo teórico de Fernand Braudel: Alimentation et catégories de I'histoire, em que ele discute os eventos e as conjunturas curtas e longas na história da alimentação - que "se décompose régulièrement comme une histoire quelconque en tranches chronologiques de plus ou moins grande épaisseur". Compraz-se em apontar "la vraie longue durée" como a camada mais propícia que "nous libère presque de la pesanteur précise du temps" (Braudel 1961b: 723).

A metáfora da pesca, que ele usa para a História, indica onde Braudel vê os grandes peixes. Através da ampliação das malhas da rede se poderá aumentar também a dimensão da pescaria e se falar, por exemplo, da influência ainda atual da "revolução neolíica". Conseqüentemente ele elogia Adam Maurizio e seu livro clássico, cuja lição permaneceria "válida, útil e indispensável" para os historiadores, completando-se o estudo das plantas coletadas na Pré-História com uma investigação do uso moderno, nas grandes fomes, dessas mesma plantas, como sobrevivências de práticas milenares.

Publica-se também nesse número a reedição de um arligo de Lucien Febvre sobre a distribuição regional das diferentes gorduras usadas na cozinha na França, junto com o comentário e um artigo atualizando a questão de J.J. Hémardinquer; e mais algumas contribuições sobre a alimentação de regiões e épocas bem circunscritas: L'alimentation d'une ville espagnole au XVle siècle. Quelques données sur les approvisionnements et la consommation de Valladolid, de B. Benassar, e Les consommations des villes françaises (viandes et boissons) au milieu du XIXe siècle, de Robert Mandrou.

O terceiro e último número dos Annales E.S.C. a seguir a investigação proposta é o de setembro-outubro de 1961, que traz no Boletim n. 3 da 'Vida material e comportamentos biológicos', um artigo de Jacques Le Goff propondo Une enquête sur le sel dans I'histoire, onde destaca as pesquisas realizadas por Michel Mollat, que dirigiu seminários sobre o sal na Sorbonne, coordenou questionários de pesquisa internacional e, em dezembro de 1961, organizou em Paris um Colóquio Internacional sobre le sel dans le trafic maritime international du Moyen Age à nos jours. Braudel escreve o artigo Achats et ventes de sel à Venise (1587-15931, sublinhando ter sido o sal "la raison du premier essor" de Veneza. Robert Mandrou discute os movimentos de longa duração na história da 
alimentação a partir de dois artigos sobre o consumo de carne na Alemanha, desde a Idade Média até o século XIX, em Théorie ou hypothèse de travail? JeanPaul Aron enfoca a formação das concepções sobre a biologia alimentar, especialmente a análise da fisiologia da digestão, a noção de regime e o conceito de ração alimentar, em Biologie et alimentation au XVIII siècle et au début du XIXe siècle e Roland Barthes em Pour une psycho-sociologie de l'alimentation contemporaine, analisa aspectos da significação das diferenças culturais em relação à alimentação (pergunta-se, por exemplo por que os americanos consumiam quase duas vezes mais açúcar do que os francesesl, introduzindo elementos de uma semiologia da alimentação, na qual os a limentos são vistos como signos de um sistema de comunicação.

A enquête termina, meio abruptamente e sem um balanço, não cumprindo as promessas de abrir novos dossiês, como o do café ou o das plantas viajantes, o milho e a batata, embora a revista continue a publicar artigos esparsos sobre a alimentação na história. Em 1970, será publicado como um Cahier des Annales o livro organizado por Jean-Jacques Hémardinquer (1970), Pour une histoire de l'alimentation, que retoma a história da alimentação como um objeto multidisciplinar e presente em praticamente todos os aspectos da história social e econômica. Mas é somente em 1975, a partir de um debate realizado no Segundo Congresso Nacional dos Historiadores Economistas Franceses, realizado em 1973, que a revista Annales E.S.C. voltará a dedicar mais da metade de um número ao tema da alimentação, desta vez sob a denominação de "Dossiê da História do Consumo", publicando 17 artigos sobre o tema, um dos quais, Pour l'histoire de l'alimentation: quelques remarques de méthode, de Maurice Aymard, coloca criticamente importantes questões metodológicas. Segundo ele, após o apelo lançado pelos Annales, em 1961, três grandes vias se abriram para a história da alimentação: a de uma psico-sociologia da alimentação, ou seja, "dos valores, regras e símbolos" da alimentação; a macroeconômica, que buscaria enquadrar estatisticamente a alimentaçăo, por meio de estudos de consumo, população, preços e comércio exterior; e, finalmente, a do estudo do valor nutritivo e das carências, quantitativas e qualitativas, da alimentação dos tempos passados, considerada como a linha de pesquisas "mais evidente, mas não a mais fácil".

Estas considerações de Aymard, que foram retomadas por comentaristas da historiografia francesa (Barlösius, Flandrin \& Montanari, Hémardinquer, Revel, Burguière), expressam tendências de ocorrência mais ampla.

Assim, pode-se falar, nesta fase de implantação de um campo novo, de uma tônica macro-econômica, preocupada com questões agrárias, com insuficiências tecnológicas, as crises, as fomes, os ingredientes demográficos e climáticos, as curvas de preços e o comércio internacional. Os alemães Schmoller e Abel são impotantes referências externas.. A agricultura sobressaía como foco centralizador, mas tomada, muitas vezes, como acesso para horizontes ainda mais amplos. Nessa direção é que Barlösius (1992:95-6) toma o nascimento do capitalismo como tema da obra de E.Le Roy Ladurie (1966), não diretamente vinculado aos Annales, sobre os camponeses do Languedoc e endossa o parecer de lgger: "Here, perhaps for the first time a serious attempt has been made to write a history of material culture" (ib.: 95). Pena que esta visão da cultura material tenha 
sido tão intensamente tópica e conceitualmente limitada (dos 18 boletins, entre 1961 e 1989, 15 foram reservados para a história dos alimentos). Mesmo com relação aos artefatos, as abordagens nos parecem, agora, de uma certa pobreza, amarradas às implicações imediatas de caráter econômico.

Subproduto deste esforço será o Atlas des cultures vivrières, de Jacques Bertin, Jean-Jacques Hémardinquer, Michel Keul e W.G.L. Randles (1971), que, como definiu Pierre Chaunu (1976: 522), ecoando o entusiasmo de Maurizio, abrange "dez mil anos, a terra inteira $e$ as 18 plantas fundamentais que asseguram $90 \%$ do alimento vegetal humano".

A seguir, cobrindo os anos 60 e 70 , explora-se o consumo, mais que a produção, o que traz ao primeiro plano a nutrição. A procura e exploração de dados estatísticos é intensiva e as fontes provirão da área fiscal, de hospitais e mosteiros, de registros sobre rações de marinheiros, soldados, operários e prisioneiros. Hoje se cobra com facilidade a utilização a-crítica dos dados, sua inadequação freqüente, assim como os vieses da documentação, que não foram suficientemente percebidos (p.ex., não se comem matériasprimas, mas alimentos preparados).

A reação a este cientificismo se consubstancia numa terceira perspectiva, a psico-social, que desloca o foco para o comer e aquele que come. Se um historiador, Jean-Paul Aron (e, outro, mais tarde, Jean-Lovis Flandrin), são referências capitais para esta orientação, é preciso mencionar a repercussão do artigo acima mencionado de Barthes (1961), que coincidia grosso modo com propostas que a Antropologia - e principalmente a Antopologia estruturalista começava a veicular nos anos 60 e 70 , mas que deixaram marcas definitivas nos anos 80 . Sem dúvida, sugestões como a dos gustemas ou a elaboração de um código alimentar de molde logocêntrico não foram absorvidas, como já se observou acima, mas a preocupação com o sentido vai dar consistência aos estudos da sensibilidade alimentar, do gosto, da gastronomia e alinhar os estudos de alimentação nas correntes das histórias das mentalidades.

Ramificações. Irradiação. Institucionalização.

A Inglaterra e a Alemanha, também já se mencionou, de há muito cultivavam interesse por assuntos associados à alimentação, acompanhados de perto pela Holanda e Bégica. Nomes como Wilhelm Abel (1974, 1978), Günter Wiegelmann (1967). Gustav Schmoller (1981) ou Christiann Vandenbroeke (1975) não podem ser esquecidos. Ainda que em escala mais atenuada, a ltália igualmente deve ser incluída neste rol. Nestes países, com pressões muitas vezes diretas recebidas dos historiadores dos Annales, mas também de forma independente, consolidam-se os mesmos padrões acadêmicos de investigação histórica do tema.J á se pode agora falar no 'especialista'.

Derek J.Oddy e John Burnett (1992), ao fazerem um balanço historiográfico da produção inglesa, salientam o papel que a Universidade de Londres, por intermédio do Historians and Nutritionists Seminar do Queen Elizabeth College (mais tarde do King's College), desde 1963, exerceu, dentro e fora da Inglaterra. Ressaltam, igualmente, alguns focos privilegiados na história da alimentação britânica: o período mais estudado é o que sucede a industrialização 
e o ângulo preferencial é a análise do abastecimento, das commodities, do consumo, do status nutricional, da distribuição, dos orçamentos e dos gastos alimentares e, num segundo plano, da cozinha, dos pratos e dos horários de refeição. $\bigcirc$ abastecimento está sempre associado à urbanização Outro tema recorrente na historiografia inglesa são as bebidas, alcoólicas e não alcoólicas, que envolvem questões tão diversas, como a difusão colonial do chá, os aspectos sociais do alcoolismo e da temperança etc. No limiar da década de 90, no prefácio da $3^{\underline{a}}$ edição de uma obra famosa, Plenty and want. A Social History of food in England from 1815 to the present days, originalmente publicada em 1966, John Burnett reconhecia que no espaço de vinte anos a História da Alimentação tornara-se uma área de pesquisa academicamente reconhecida e que nenhum estudo sério da mudança econômica e social dos últimos dois séculos na Inglaterra ousaria omitir "reference to the changing ways in which food has been grown, manufactured, distributed, and consumed" (Burnett 1989: VIII).

A difusão dos estudos de História da Alimentação no restante da Europa e nos Estados Unidos e outras plagas foi em grande parte marcada por este quadro de institucionalização.

Um dos indicadores da maturação de um domínio específico de conhecimento científico é a presença de publicações especializadas - não só livros e artigos, mas principalmente periódicos acadêmicos — a organização de entidades e grupos de especialistas, a promoção de seminários, colóquios, congressos e a formalização de cursos e plataformas de ensino. É importante, aqui, dar algumas pistas sobre associações, encontros e periódicos.

Espaço relevante de atuação destas instituições, assim como de universidades e outros organismos de pesquisa, e que testemunham o grau de enraizamento de uma História da Alimentação, são os encontros, de variada natureza (congressos, seminários, colóquios), e que se têm multiplicado. Para dar uma idéia, sem qualquer pretensão de listagem exaustiva, mencionem-se os principais temas, acrescentando que quase todos tiveram suas atas publicadas Inão se incluíram aqui aqueles encontros de caráter geral ou especializadamente biológico, econômico, sócio-antropologico, embora neles se encontre sempre a presença de questões históricas):

Le sel dans le trafic maritime international du Moyen Âge à nos jours (Paris, 1961).

Changing food habits (Londres, 1964 )

Les problèmes de l'alimentation.93è. Congrès des Sociétés Savantes (Tours, 1968)

Pratiques et discours alimentaires à la Renaissance (Tours, 1979)

Manger et boire au Moyen Âge (Nice, 1982)

Cultura e storia dell'alimentazione limperia, 70031

L'alimentazione nell'antichità (Parma, 1985)

Homo Edens (Verona, 1987)

Histore et animal (Toulouse 1987)

Cuisines, régimes alimentaires, espaces régionau (Nancy, 1987)

A manger des yeux: l'esthétique de la nourriture (Lausanne, 1987)

First Simposium on European Food History (Münster, 1989).

La Sociabilité à table. Commensalité et convivialité à travers les âges (Roven, 1990)

Voeding en Geneeskunde. Alimentation et médecine (Bruxelas, 1990)

'A tavula è trazzera: cultura dell'alimentazione nei paesi del Mediterraneo (Trapani, 1990 )

L'animal dans l'Antiquité romaine (Nantes, 1991)

La production du vin ef de l'huile en Méditerranée (Toulon, 1991). 
Não há nenhuma revista especializada, stricto sensu, na História da Alimentação, como existem para outros domínios (sobretudo a nutrição). No entanto, a revista Food \& Foodways, criada em 1985 e contando entre seus diretores e membros do corpo editorial com muitos historiadores (Steven L.Kaplan, Jean-Lous Flandrin, Maurice Aymard, Claude Grignon etc.), serve de ponto de convergência para os cientistas sociais, principalmente estabelecendo uma profícua colaboração de historiadores e antropólogos dedicados ao conhecimento da 'history and culture of human nourishment.' Em todos os tempos e quadrantes - o que tem estendido as investigações para bem longe do domínio europeu, incluindo o Oriente, a África, o mundo árabe, as Américas.

Caracterização Morfológica da Bibliografia

O caráter caudaloso, heterogêneo e difuso da bibliografia de História da Alimentação já foi por muitas vezes assinalado, até aqui. Se quisermos de alguma forma caracterizála sinteticamente, levando em conta sobretudo a produção recente, talvez a solução mais prática, seja buscar um critério taxonômico que privilegie os aspectos morfológicos.

De início, cumpre salientar que o volume e diversidade das publicações não motivou, entre os especialistas, tentativas de registrá-las em repertórios bibliográlicos gerais, monográficos ou seletivos. São, assim, raríssimas as compilaçōes, como a Biblioteca gastronomica, de André Simon (1953), ou o guia Food and drink in British History, de William Henry Chaloner (1960). Nenhum balanço existe, que se possa comparar aos que são comuns no campo da Antropologia e Sociologia (como Freedman 1981 e 1983, Messer 1984 ou Wilson 19791, embora, com freqüência, tais levantamentos também incluam obras especificamente históricas, como é o caso de The sociology of food (Mennell, Murcott \& van Otterloo 1992). Aliás, algumas obras de caráter geral ou monográfico contam com bibliografias tão extensas que podem ser utilizadas como repertórios genéricos (p.ex. Garine 1990).

Nesse quadro, não se poderia esperar a existência de numerosos trabalhos de cunho historiográfico. Por isso, mais ainda sobressai a utilidade da cobertura européia assegurada pela coletânea que Hans J. Teuteberg organizou (1992) com material apresentado no simpósio European Food History: a research review, sediado na Universidade de Münster, em 1989. Em 16 capítulos, são criticamente sumarizadas pesquisas relativas à alimentação em períodos específicos de 14 países ou regiões da Europa (Inglaterra, Irlanda, Holanda, Bélgica, França, Alemanha, antiga Alemanha Oriental, Áustria, Suiça, Hungria, Polônia, Rússia, Boêmia e Suécial.

A mesma escassez se registra no campo documental. Publicações como The History of Food: a preliminary bibliography of printed sources, de David Sutton (1982) ou os Anais do Encontro de Potenza-Matera, de 1988 (Gli archivi per la storia dell'alimentazione, 1995) são exceções. Finalmente, é preciso assinalar a penúria de obras sobre questões teóricas e metodológicas. Apenas se podem apontar alguns instrumentos de trabalho, nem sempre de rigor impecável, como cronologias (Trager 1995) ou dicionários (Craplet (1979). 
São também pouco numerosas as obras gerais, que pretendem abarcar o horizonte da História da Alimentação como um todo, mas as publicações têm-se multiplicado nestes últimos anos. Raros são os trabalhos devidos a um único autor, como os livros de Gottschalk (1948), Reay Tannahill (1973) ou Carson I.A. Ritchie (1996, ed.or. 1981), todos de grande aceitação popular, ou o encorpado volume da 'história natural e moral' da alimentação, de Maguellonne Toussaint-Samat (1987), muito rico de informações, mas por vezes superficial e, quase sempre, europocêntrico.

Já Jean-touis Flandrin e Massimo Montanari (orgs. 1996) preferiram reunir cerca de cinquenta pesquisadores, numa antologia enciclopédica de mais de 900 páginas, a fim de abordar cronologicamente os hábitos alimentares da humanidade, desde a Pré-história até os tempos correntes, passando pelas grandes civilizações do Próximo Oriente, os gregos, romanos, bárbaros, a ldade Média, as culturas hebraica, islâmica, grega ortodoxa, a época moderna e contemporânea, procurando englobar aspectos ecoômicos, demográficos e simbólicos da produção e consumo, as diferenças entre cidade e campo, arte culinária, gastronomia e dietética, refeições e maneiras à mesa, os regionalismos e sincretismos, a 'macdonaldização' dos costumes, etc., etc.. Claro está que algumas destas contribuições oscilam na qualidade, mas o resultado geral é bastante satisfatório e esta obra pode ser considerada, presentemente, a melhor referência geral para o campo em questão, como um todo.

As coletâneas heterogêneas, de que a de Hémardinquer led. 1970) foi um caso, precoce, têm tido boa fortuna.

É preciso igualmente mencionar a existência de verbetes em obras enciclopédicas ou de capítulos em obras gerais, que constituem tentativas de delinear o campo. Nenhum deles se pode considerar plenamente satisfatório: Renée Valeri (1977), J.F.Revel (1978), Igor de Garine (1990), André Burguière (1986, muito citado, mas excessivamente francocêntrico), Daniel Roche (1997), etc.

O que domina, porém, a bibliografia, são as obras de caráter regional e, muito mais ainda, de recorte nacional ou referindo-se a períodos ou 'civilizações', quase sempre da Europa.

Assim, Montanari (1993) procurou balizar, a partir dos bárbaros e dos romanos, a formação, nos séculos $V$ e VI AD, de uma 'linguagem comum' européia, no domínio da alimentação (Ele também cobriu quadros extensivos da Idade Média, em 1979 e 1988). Fenton \& Kisbón (eds. 1986) também elegeram os hábitos alimentares na Europa, da Idade Média ao presente, assim como Forster \& Foster (1975), a dieta européia.

As civilizações da Antigüidade não deixaram de acumular inúmeras histórias da alimentação. O Egito, por exemplo, já merecera em 1854 um tratamento especial desse problema, por parte de J.G. Wilkinson, numa obra sobre vida e costumes. Daí em diante, a lista foi-se ampliando, embora com predomínio de títulos com caráter essencialmente descritivo - de que não escapam até mesmo sínteses recentes, como a de Bresciani (1996). As civilizações clássicas não ficam atrás. Não só são correntes histórias gerais (como Andrew Dalby 1996 ou André 1980, Blanc \& Nercessian 19921, como também as histórias de alimentos de grande significação cultural, como os cereais, o vinho ou o azeite /Gastet \& Sigarr 1979, Amouretti 1986, Pessanha \& Bastian, eds. 
1991, Tchernia 1986). Além disso, alguns temas tiveram força catalisadora: assim, os padrões de sociabilidade, como aqueles expressos nos symposia e nos banquetes cívicos (Pauline Schmitt Pantel 1992, François Lissarrague 1987), a cozinha profana e a litúrgica (Berthiaume 1982), o tema literário Uones 1993). Mencionem-se, também, obras de conjunto, como Brothwell \& Brothwell (1985; inclui tratamento metodológico relativo à Arqueologia da alimentação e examina, além do mundo mediterrânico, Ásia, África sub-saariana e Américas); Wilkins, Harvey \& Dobson (1996), organizado em torno de problemas-chave, como cereais e cultivares, carne e peixe, contexto social e religioso, medicina, presença na literatura): Longo \& Scarpi (1989) que, além das questöes tradicionais, trata dos filósofos gregos, de lingüística e alimentação, mercado, vegetarianismo, patologias nutricionais, agregando aos povos clássicos os vedas, persas e culturas africanas, sem muita preocupação com organicidade.

Quanto às cozinhas nacionais e locais (até cidades), é especialmente pródiga nestes estudos a Inglaterra, onde diversas obras têm-se interessado pelo tema, dentre as quais Dodd (1856); Bear (1 899); Cooper (1929); Drumond e Wilbraham (1939); Blackmon (1962); Fraser 1981; Barker, Oddy e Yudkin (1966); Burnett (1966); Pullar (1970): Wilson (1973); Johnston (1977); Driver (1983): Stead (1985) e Renfrew (1985a e 1985b). Há até mesmo uma série patrocinada pelo órgão de patrimônio cultural inglês (English Heritage) e denominada Food and cooking in Britain, com mais de sete volumes publicados, e que se estende desde a Pré-história até o século XX. Os Estados Unidos não ficam muito atrás: Root \& De Rochemart (1976), Levenstein (1988 e 1995), Grover (1987), Aidells \& Kelly (1992), Brans (1993), Coe (1993), Mclntosh (1995), etc. Na França, encontramos desde Briffault (1846) e Bourdeau (1841) até Dupin (1978) ou Pitte * 1993). E em diversos outros países, especialmente na América Latina, podemos citar ao menos uma obra que, em geral na primeira metade do século XX, procurou estudar a alimentação nacional: na Espanha, Cereceda (1934); no México, Espinosa (1939); na Colômbia, Bejarano (1941); no Chile, Madones e Cox (1942); e na Venezuela, Guevara (1946), no Peru, Mayolo (1981). Para completar o perfil: Stewart, Trustwell \& Wahlquist (1988), para a Austrália; Chang (1978) ou Anderson 1988) para a China. Ás vezes os estudos são comparativos, como o de Mennell (1987), que analisa em paralelo a França, a Inglaterra e a Alemanha.

A tais obras deveriam ser agregados os livros de receitas, muitas vezes selecionadas e apresentadas com critérios históricos rigorosos (p.ex. Dalby \& Grainger 1996).

Desta vasła bibliografia nem todos os estudos estão envolvidos em problemas de mudança e tranformação ou na historicização de suas informaçōes; nota-se, vez por outra, tendência perceptível de tratamento sincrônico e autônomo. Não obstante, ocorrem obras de amplo espectro e grande consistência histórica, de que boms exemplos são os dois trabalhos de Harvey Levenstein (1988 e 1995), verdadeiro estudo de história das mentalidades à americana (e mais que isso), em que o autor traça um quadro dentro do qual, a partir de 1880, forma-se nos Estados Unidos a convicção da comida apropriada, em detrimento do gosto; mas não é somente o plano das representações que o autor explora, mas os grupos de interesses comerciais e profissionais, as 
1991, Tchernia 1986). Além disso, alguns temas tiveram força catalisadora: assim, os padrões de sociabilidade, como aqueles expressos nos symposia e nos banquetes cívicos (Pauline Schmitt Pantel 1992, François Lissarrague 1987), a cozinha profana e a litúrgica (Berthiaume 1982), o tema literário Uones 1993). Mencionem-se, também, obras de conjunto, como Brothwell \& Brothwell (1985; inclui tratamento metodológico relativo à Arqueologia da alimentação e examina, além do mundo mediterrânico, Ásia, África sub-saariana e Américas): Wilkins, Harvey \& Dobson (1996), organizado em torno de problemas-chave, como cereais e cultivares, carne e peixe, contexto social e religioso, medicina, presença na literatura): Longo \& Scarpi (1989) que, além das questões tradicionais, trata dos filósofos gregos, de lingüística e alimentação, mercado, vegetarianismo, patologias nutricionais, agregando aos povos clássicos os vedas, persas e culturas africanas, sem muita preocupação com organicidade.

Quanto às cozinhas nacionais e locais (até cidades), é especialmente pródiga nestes estudos a Inglaterra, onde diversas obras têm-se interessado pelo tema, dentre as quais Dodd (1 856); Bear (1899); Cooper (1929); Drumond e Wilbraham (1939); Blackmon (1962); Fraser 1981; Barker, Oddy e Yudkin (1966); Burnett (1966); Pullar (1970); Wilson (1973); Johnston (1977); Driver (1983); Stead (1985) e Renfrew (1985a e 1985b). Há até mesmo uma série patrocinada pelo órgão de patrimônio cultural inglês (English Heritagel e denominada Food and cooking in Britain, com mais de sete volumes publicados, e que se estende desde a Pré-história até o século XX. Os Estados Unidos não ficam muito arrás: Root \& De Rochemarł (1976), Levenstein (1.988 e 1995), Grover (1987). Aidells \& Kelly (1992), Brans (1993), Coe (1993), Mclntosh (1995), etc. Na França, encontramos desde Briffault (1846) e Bourdeau (1841) até Dupin (1978) ou Pitte * 1993). E em diversos outros países, especialmente na América Latina, podemos citar ao menos uma obra que, em geral na primeira metade do século XX, procurou estudar a alimentação nacional: na Espanha, Cereceda (1934); no México, Espinosa (1939); na Colômbia, Bejarano (1941); no Chile, Madones e Cox (1942); e na Venezuela, Guevara (1946), no Peru, Mayolo (1981). Para completar o perfil: Stewart, Trustwell \& Wahlquist (1988), para a Austrália; Chang (1978) ou Anderson 1988) para a China. Ás vezes os estudos são comparativos, como o de Mennell (1987), que analisa em paralelo a França, a Inglaterra e a Alemanha.

A tais obras deveriam ser agregados os livros de receitas, muitas vezes selecionadas e apresentadas com critérios históricos rigorosos (p.ex. Dalby \& Grainger 1996).

Desta vasta bibliografia nem todos os estudos estão envolvidos em problemas de mudança e tranformação ou na historicização de suas informações; nota-se, vez por outra, tendência perceptível de tratamento sincrônico e autônomo. Não obstante, ocorrem obras de amplo espectro e grande consistência histórica, de que boms exemplos são os dois trabalhos de Harvey Levenstein (1988 e 1995), verdadeiro estudo de história das mentalidades à americana (e mais que isso), em que o autor traça um quadro dentro do qual, a partir de 1880, forma-se nos Estados Unidos a conviç̧ão da comida apropriada, em detrimento do gosto; mas não é somente o plano das representações que o autor explora, mas os grupos de interesses comerciais e profissionais, as 
contingências da Grande Depressão e da ll Guerra Mundial, o trabalho feminino, a disputa de prestígio entre os excessos conspícuos e as abstinências conspícuas, a difusão do fast food, os paradoxos da abundância.

Outra vertente que representa parte considerável da bibliografia histórica são as monografias sobre determinados alimentos. Podemos exemplificar com as seguintes histórias:

- do pão (Ashton 1904; Ashley 1928; Jacob 1944; McCance \& Widdowson 1956; Shepard \& Newton 1957; Basini 1970; Kropoktin 1972; Zilhr \& Buhrer 1985; Desportes 1987; Macherel \& Zeebroek 1994; Kaplan 1996 e 1997):

- do milho (Birket-Smith 1943; Stoianovitch 1951 e 1966; Temple 1963; Warman 1988);

- da batata (Salaman 1949; Morineau 1970);

- da soja (Saillenpest 1944; Clergeaud 1964);

- do queiio (Cheke 1959; Androvet 1981; Volpato 1983);

- do sal Mollat 1968; Bergier 1984; Hocquet 1985; Denton 19821;

- do açúcar (Dorveaux 1917; Lippman 1941-42; Deerr 1949-50;

Strong 1954; Ely 1963; Hugill 1978; Pancoast 1980; Mintz 1986 e 1996, Cannabrava 1981 l;

- do mel (Crane 1975/76); Kelly 1992l; - da cerveja IKing 1947; Monckton 1966; Houaiss 1986; Aidells \& - do vinho (Dion 1959; Scarpi 1991; McGovern, Fleming \& Katz 1994; Murray \& Tecusan 1995; Garrier 1996, Poo 1995, Le vin 19971;

- da cachaca (Camara Cascudo 1986, enre tantos outros);

Butel 1989): - do chá UUkers 1935; Waugh 1951; Twining 1956; Forrest 1967;

- do café Moreira 1873; Jacob 1953; Camargo \& Telles Jr. 1953; Magalhães 1980; Mauro 1991; Ball, ed. 1991, Brignoli \& Samper 1994; Roseberry \& Gudmundson \& Samper Knuischbach, eds., Williams 1994l; - da mandioca (Muchnick \& Vinck 1984)

- da chicha (Mowat 1989):

- do mate (Linhares 1969);

- do chocolate (Bourgaux 1935; Hardwich 1992; Coe \& Coe 1996,

Camporesi 1996).

- da Cocacola (Pendergast 1993);

- da margarina (Stuyvenberg 1969):

- dos biscoitos (Corley 1972; Adams 1974);

- do hambúrguer (Perl 1974)

- dos animais como alimentos (Zeuner 1963; Vialles 1994).

Alguns destes estudos sobressaem do padrão genérico, por seus horizontes amplos. Mintz (1986 e 1996) ou Salaman (1949), como já se acentuou anteriormente, utilizam, respectivamente, o açúcar e a batata, para vastos panoramas históricos. Outros estudos têm como fio condutor problemas específicos, como o arroz enquanto veículo de identidade cultural no Japão (Ohnuki-Tieney 1993) ou a importância do chá na 'domesticação' do estado turco (Hann 1990), ou o café como vetor de poder e formador de classes na 
América Latina (William Gudmundson \& Knutschbach, (eds. 1995), Brignoli \& Samper (eds., 1994), Williams (1994)..

Finalmente, mencionemos a dispersão de monografias em torno de um sem-número de problemas específicos - econômicos, sociais e culturais - que nos dispensamos de exemplificar, pois já foram abundantemente referidos anteriormente, a propósito das questões de conteúdo.

\section{Tópicos}

Fome

Um aspecto seminal da história da alimentação é o da história da fome, cuja definição oscila entre a apresentada por Sara Millman e Robert W. Kates (1990:3), como sendo uma "inadequacy in individual dietary intake relative to the kind and quantity of food required for growth, for activity, and for maintenance of good health" e, no polo oposto, a de Amartya K.Sen (1981), para quem, a não ser nas economias exclusivamente de subisistência, é a troca que deve servir de referência; assim, formulou o citério de 'failure exchange entitlement'(FEE) para substituir o de 'food availability decline' (FAD): fome é, antes de mais nada, marginalização social, falhas nos créditos de troca e, portanto, está no âmbito das decisões humanas e não dos acidentes climáticos ou sistemas formais.

Outras vertentes entendem as causas estuturais da fome na quebra de um sistema alimentar (food system breakdown), como em Richards (1939); ou a partir de uma teoria da modelização e da administração do imprevisto (thinking on modeling and managing hazards), como em Kates et alii (1985).

Como as teorias sobre a fome rebatem-se nas teorias sobre 0 crescimento populacional e sua relação com o crescimento na produção, três perspectivas teóricas adicionais costumam ser freqüentemente apontadas (cf. Newman, ed. 1990): a de Thomas Malthus, a de Karl Marx e a de Ester Boserup.

A teoria malthusiana, como é sabido, considerava que as populações cresceriam em progressão geométrica (exponencialmente), enquanto que os meios de subsistência apenas em progressão aritmética (linearmente). Marx, discordando com veemência de Malthus, apresenta uma teoria da população especifica para o modo de produção capitalista, onde localizará as raizes da fome e outras formas de miséria humana como decorrência das relações de opressão e exploração do sistema de produção. Ester Boserup (1965), apresentou uma teoria que, ao contrário das previsões malthusianas, identificou no crescimento populacional um mecanismo provocador de inovações tecnológicas e, no longo prazo, de melhorias nas condições de vida.

A Revolução Industrial desmentiu o malthusianismo. Nem as populações cresceram geometricamente nem a capacidade produtiva aumentou numa progressão simplesmente aritmética. A mecanização agrícola e os transportes modernos produziram um salto nos volumes de produção no mundo.

Seja como for, muito do que temos da História da Alimentação poderia ser apresentado como a história da luta contra a fome. Mas, como 
afirmam de novo Sara Millman e Robert Kates 11990: 91, "the history of hunger is interwoven with the history of plenty". E significativa a presença de títulos importantes que associam os dois extremos, como La fame e l'abbondanza. Storia dell'alimentazione (1993), de Massimo Montanari, ou Plenty and want. A social history of food in England from 1815 to the present day (1966), de J.Burnett.

Com efeito, o primeiro excedente é sempre alimentar. A economia humana é, antes de ludo, a dos meios de subsistência. A divisão desigual do produto social é, primariamente, uma divisão dos niveis de consumo alimentar. Mas não são apenas os primados da escassez ou da abundância, ou das formas de controle e estratificação do consumo alimentar que determinam as formas da alimentação humana. A história da alimentação não pode, obviamente, reduzir-se somente à história da fome ou à estatística estimativa dos niveis de consumo e nutrição de diferentes épocas. Essa característica infraestrutural da vida das sociedades, seu nível de consumo de calorias e proteinas e as formas de estratificação social desse consumo, podem ser estudadas economicamente como decorrente do regime de produção e distribuição, ou socialmente, como parte das formações sociais e suas instituições políticas, mas elas se inscrevem na consciência das populações como um fato de dimensões ideologicamente múltiplas e complexas, com profundas significações simbólicas, religiosas e profanas.

Nas suas inúmeras vertentes, os estudos sobre a fome têm procurado responder a um conjunto limitado de questões-chave. Qual tem sido o desenvolvimento histórico da fome, de alimentações carentes ou de consumos satisfatórios nas diversas épocas e regiōes da história da humanidade? Pode-se afirmar que, na época contemporânea, a humanidade no seu conjunto alimentase mais e melhor do que em épocas passadas? Tal suposta melhoria teria sido linearmente progressiva desde o final da época medieval até os dias de hoje?

Se em momentos visiveis, como guerras, pestes, catástrofes climáticas, etc., verificam-se crises alimentares e podem-se medir os níveis agudos de escassez, como mensurar na longa duração o curso da luta pela alimentação, como verificar os índices de consumo alimentar, os períodos ou ciclos de crises, os quadros nosológicos associados a nutrições deficitárias e, enfim, a influência mais geral do tipo de alimentação na constituição biológica das distintas populações?

Tais questões só podem ser respondidas através do exame comparado dos níveis históricos de escassez ou abundância na produção agrícola e das formas de produção e distribuição que constituem o equilibrio ou o desequilíbrio alimentar numa dada sociedade. Por equilíbrio pressupõe-se o consumo em níveis satisfatórios, quantitativo e qualitativo, de proténas, calorias e vitaminas ${ }^{4}$.

Tal história começou a colher seus dados e a buscar sistematizá-los no século XIX. Um dos primeiros estudos foi, como nos informa Jacques Chonchol (1989: 8), o de Cornelius Walford que, em 1878, apresentou à Sociedade Estatística de Londres uma análise de mais de 350 surtos de fome historicamente conhecidos.

O tema da fome, das crises de produção, as oscilações de preços e salários, o espaço amplo reservado à correlação com problemas biológicos e demográficos (fertilidade, mortalidade, epidemias, etc.etc.) foi crucial, como se
4. Existe uma vasta bibliografia médica sobre a nutriçào humana, que define a quantidade de calorias, de proteinas e de vitaminas que constituem uma raçào alimentar adequada e que pode ser facilmente obtida em obras de referência médica geral, assim como em relatósrios e documentos oficiais da FAO e da OMS. 
5. Tais estimativas de valores nutricionais de dietas passadas precisan ser tratadas com cautela. O uso abusivo dos cálculos, tào importante na época da primeira enquete da revista Annales, foi criticado por outros historiadores, $\mathrm{CO}$ mo relata Teuteberg (1992:12): "After the physiology of nutrition had been institutionalized in the second half of the 19 th century, scholars tried for the first time to convert the quantities of food consumed, as determined statistically, into calories and the three most important nutritions units protein, fat and carbohydrates. Although this method was little used at first, it has become common since the middle of the 20 th century Enest Labrousse, Robert Philippe, Frank Spooner, John McKenzie, Derek Oddy, wilhelm Abel. Andrzej Wyczanski and the present author have done such nutritional value calculations. As Eva Barlösius, a trained nutritional physiologist state in this volume, it is astonishing how naively and uncritically some historians have used these physiological calculations in a historical context". viu, na implantação de uma História da Alimentação. Relembre-se o que foi dito com relação ao grupo dos Annales e a importância dada ao abastecimento, pobreza e carências, principalmente na Europa, de 1400 a 1800. Paralelamente, na Alemanha, Wilhelm Abel, que teve boa circulação na França, procurava sumarizar a pobreza e as crises de fome concentrando-as na Europa pré-industrial (1974). Na Inglaterra, John Burnett delineava uma história social, após o influxo da industrialização (1966).

Pat Caplan (1994: 12) observa que é nas grandes disparidades relativas à alimentação que melhor se simbolizam as diferenças de classe. Não é de estranhar, portanto, que o tema das rebeliões e desordem social se tenha transformado numa plataforma estratégica para entender estrưura e relaçōes sociais. Vários trabahos podem servir de exemplo, principalmente na Inglaterra: Food riots in England, 1792-1818, de J.Stevenson (1974); Dearth and the social order in early modern England, de J.Walter e K. Wrightson (1976); Were 'hunger' rioters really hungry? Some demographic evidence, de D.E.Williams (1976); English hunger and industrial disorders, de W.J.Shelton (1973). Löwe (1986) analisa as revoltas, políticas a limentares, regulamentação de mercados na Inglaterra, França e Alemanha setecentistas.

Como resultado do interesse continuado dos especialisłas, dispõe-se hoje de um acervo relevante de obras de qualidade, pertinentes ao tema. Citemse apenas alguns marcos globais ou obras características. Robert I. Rotberg e Theodor K. Rabb (eds. 1985) são responsáveis por uma coletânea que constitui dos primeiros esforços de orientar interdisciplinarmente os estudos sobre a fome. Lucille F.Newman (ed.ger. 1990) reuniu numa antologia intitulada Hunger in History. Food shortage, poverty and deprivation, 16 trabahos apresentados entre 1986/87 na Brown University, no Hunger History Seminar e que analisam os problemas da fome desde os inícios da sociedade humana e a Antigüidade, até a sociedade contemporânea, preocupados com entendêtos para sifuátos numa via de solução.

A preocupação com a quantificação não encontra respaldo, infelizmente, na documentação disponível. A fome, aliás, é um fenômeno que tende a ficar à sombra. É conhecida a dificuldade de obter cálculos precisos do teor da nutrição dos diversos segmentos sociais das diferentes sociedades. Para isso, foi indispensável um esforço teórico para se poder esboçar a comparação de dados de distintas procedências no tempo e no espaço, efetuandó-se estimativas de composição calórica na associações de alimentos diferentes para o que Frank Spooner (1961) e Maurice Aymard (1975) apresentaram importantes contribuições 5 .

Sómente a partir da época moderna as fontes tornam-se estatísticas precisas de produção, circulação e consumo dos alimentos. É sobre a época moderna e contemporânea, portanto, a maior parte dos estudos produzidos sobre a história da fome. $O$ uso de dados demográficos se amplifica, pois o crescimento demogrático é um dos elementos que pode indicar um aumento nos padrões de consumo alimentar em épocas passadas, já que a superação dos índices de mortalidade pelos de natalidade tenderiam a manifestar uma melhoria nas condições de vida, particularmente da nutrição, que teriam permitido às populações uma melhor resistência às doenças e um prolongamento da 
expectativa de vida. Outras características antropométricas ligadas à nutrição, como peso, altura, vulnerabilidade a certas doenças, são também objeto de estudo para a história da fome.

A ocorrência de determinadas doenças por carências alimentares específicas, como o escorbuto, o bócio, a anemia ou o béri-béri, também pode ser um indicativo do tipo de alimentação de épocas ou regiões específicas, assim como também podem evidenciar as enfermidades derivadas de superabundância, como é o caso da obesidade, do colesterol elevado ou da diabetes contemporânea.

É um paradoxo contemporâneo que ocorra um crescimento da fome no planeta na época atual, quando a produção agrícola é a maior de toda a história da humanidade — atingiu-se no fim da década de 80 algo perto de dois bithões de toneladas de cereais - e, devido a diversos recursos tecnológicos (fertilizantes, agrotóxicos e engenharia genética) que possibilitaram uma verdadeira revolução agrícola, tem crescido ao longo do século XX em índices superiores ao crescimento populacional, refutando na prática as previsões malthusianas que tanto impacto produziram no século XIX.

No século XX, acreditou-se que se poderia acabar com a fome no mundo com o aperfeiçoamento dos recursos tecnológicos da Revolução Industrial, que vão desde a invenção dos refrigeradores ou dos fertilizantes químicos, há cerca de um século, até a atual manipulação genética com a conseqüente criação de novas e mais resistentes espécies vegetais e animais. E, de fato, podese verificar no século XIX um salto significativo na melhoria da nutrição média das populações de diversos paises, particularmente aqueles que desenvolveram a mecanização da produção e distribuição agrícola.

Após as duas guerras mundiais, o problema da fome emergiu, entretanto, como a grande realidade mundial: o número dos desnutridos vai de 500 milhões a 1 bilhão e 130 milhões, dependendo das diferentes estimativas ${ }^{6}$. No segundo pós-guerra conheceu-se um boom econômico na Europa, que afastou do velho continente as fomes massivas após os momentos de fome aguda da Segunda Guerra Mundial. Embora não se possa dispor de cálculos seguros para o conjunto do planeta, pode-se afirmar que houve na segunda metade do século XX, uma melhora relativa da alimentação diante da situação anterior da crise dos anos 30. Tal situação sofreu uma piora no final do século XX. Como escreve Jean-Louis Flandrin no balanço dos séculos XIX e XX, "le régime alimentaire ne s'estil pas amélioré de manière continue pendant les deux siècles de l'époque contemporaine: en Europe, un mieux-être n'est incontestable qu'à partir de la seconde moitié du XIXe siècle; et dans les pays pauvres d'Afrique, il a pris fin dans le dernier quart du XXe siècle." (Flandrin 1996b: 721).

$O$ agravamento do problema alimentar foi oficial e institucionalmente reconhecido com a criação da Organização de Alimentação e Agricultura das Nações Unidas (FAO - Food and Agriculture Organization), que teve origem numa conferência realizada em Hot Springs, Estados Unidos, em 1943. Desde então, tal organização dedicou-se a realizar investigações e levantamentos sobre a situação alimentar planetária. Em 1974, sob o impacto de uma crise na produção mundial de cereais e dos surtos de fome na África, na Ásia e na América Latina, realizou-se em Roma, sede da FAO, uma Conferência Alimentar
6. "En nossos dias, estima-se que - as avaliações variam segundo a fonte - um pouco mais de 400 milhões até cerca de 1 bilhão de pessoas sofrem de desnutrição, de forma constante. Para a FAO, tratava-se de $450 \mathrm{mi}-$ lhoes de pessoas em 1974. Para o International Food Policy Research Institute (IFPRI, Washington D.C.), O dobro, ou seja, $900 \mathrm{mi}-$ thòes de pessoas. Para a UINICEF, em 1980, esse número é de 780 milhòes. E para o Banco Mundial, essa população atinge 1 bilhào e 130 milhòes de desnutridos" (Jacques Chonchol 1989:9). 
Internacional, com a participação de 130 países. As resoluções desse encontro, entretanto, se serviram para tornar o tema da fome uma preocupação constante da mídia mundial e para subsidiar uma série de estudos estatísticos e econométricos, não trouxeram efetivamente nenhuma conseqüência prática. A situação da fome, denunciada pelo médico e sociólogo brasileiro Josué de Castro, que foi o presidente do conselho da FAO entre 1952/56, num famoso livro publicado em 1946, Geografia da Fome, qualificado pelo autor como um "ensaio ecológico", continua na pauta dos grandes problemas contemporâneos.

Os números oficiais da FAO, até 1985, mostravam que houvera uma diminuição na proporção dos famintos na população mundial, mas também indicavam que, em números absolutos o número de famintos nunca fôra tão grande: "Over the last three and a half decades, the proportion of hungry people in the world had diminished by almost half - from 23 percent to 10 percent using the FAO data set and estimation method. Nonetheless there are probably as many hungry people today in the world as ever before." (Kates \& Millman 1990: 395). Tal evidência é ainda mais gritante diante do cálculo da produção contemporânea de alimentos, que alcançou uma disponibilidade de alimentos recorde na história humana. Como constata ainda Kates e Milman (1990: 396): "Today we can speak of the global food supply and calculate its sufficiency - enough to feed 120 percent of the world's population on a near-vegetarian diet distributed by need, but only enough to feed half of the world's people on a developed-country diet. Neste mesmo mesmo contexto, Millman et alii (1990: 309) definem as conseqüências do que se caracteriza como "developed-country diet", no crescentemente interdependente "global food system", ao se referirem às preocupações "about the possible global environmental impact of the destruction of tropical forests in Latin America to increase pastureland for raising beef for US consumption"..

A miséria e a fome, longe de serem invariantes das sociedades humanas, têm uma história. A modernidade econômica caracterizou-se pela transformação do estatuto social da pobreza e da fome, ampliando o número dos miseráveis e lançando-os para fora de suas origens. A acumulação capitalista primitiva baseou-se na desterritorialização de amplas camadas sociais antes vinculadas à agricultura, transformando-as em marginais. A respeito deste processo de pauperização na Europa na época moderna a obra de Bronislau Geremek (1995) é uma referência obrigatória, mostrando como a pobreza e a fome desempenharam papéis diferenciados na ldade Média e na época moderna. Na sociedade medieval, cumpriam um papel funcional ao servir para justificar a instituição da caridade, valiosa não apenas do ponto de vista simbólico, na construção da ideologia cristã, mas também necessária economicamente como fonte de renda para a lgreja, que, através das esmolas, arrecadava guantias não despreziveis numa sociedade de limitada circulação monetária. Além disso, a fome como jejum era apresentada pelo cristianismo como uma manifestação de humildade, como um valor, que levava a que ela fosse buscada por um tipo particular de faminto voluntário que eram os peregrinos, os monges e os eremitas, além dos dias de jejum previstos no calendário religioso para todos os fiéis.

A pauperização de estratos cada vez mais vastos na época moderna não é comparável às situações de desigualdade social medieval, mais ou menos 
estáveis, perturbadas apenas por crises ponfuais, como a do século XIV. O período moderno foi, portanto, um período de estratificação social acelerada, com grandes camadas de excluídos reduzidos à desnutrição crônica, ao mesmo tempo em que os produtos do comércio de longo curso ampliavam sua esfera de consumo, popularizando gêneros como o açúcar, as especiarias, as bebidas coloniais, além das novas espécies americanas difundidas pelo mundo.

Religião

A importância seminal da alimentação, para manutenção da vida, abre espaço para que ela se imbrique intimamente com o domínio religioso. A própria expressão do religioso se faz comumente por intermédio dos fenômenos alimentares. Garine (1994: 266) aponta a importância, nos Evangethos, de vocabulário e metáforas originários de alimentos e seus contextos: pão, vinho, pesca, colheita, vindima etc. Da mesma forma, o calendário litúrgico é que organiza o ciclo alimentar, com suas prescrições, positivas e negativas, em especial os jejuns. Nem seria o caso de levantar na mitologia das diversas culturas, o papel matriz desempenhado pela alimentação. A própria condição humana se expressa, na Bíblia, como tendo sido motivada por um aito alimentar - a ingestão indevida do fruto da árvore do bem e do mal (Soler 1975 e 1996).

Se quisermos nos ater aos modelos a imentares atuando no patamar religioso, vale lembrar exemplo registrado por Montanari 11996: 3191, a propósito da conversão dos povos eslavos. A crônica russa da época conta que, em 986, quando o príncipe de Kiev, Vladimir, decidiu converter seu povo, chamou a palácio representantes das quatro grandes religiões /catolicismo, cristianismo ortodoxo, judaismo e islamismol; um dos elementos de sua opção pela ortodoxia foi alimentar, pois os eslavos não poderiam aceitar a proibição do álcool pelos muçulmanos, nem a do porco pelos judeus le também pelos muçulmanos), e tampouco podiam aceitar a exigência católica de sucessivos jejuns. Restou, portanto, o cristianismo ortodoxo bizantino, bem menos rígido nas exigências disciplinares em relação à comida.

Falfam obras gerais sobre o tema. Quase todas partem do recorte de uma sociedade, como The Lord's table, de Gillian Feeley-Harnik (1994), em que a autora explora a significação do alimento no Judaismo primitivo e no Cristianismo, examinando o imaginário e os sistemas classificatórios e reealçando a reversão de símbolos, valores e objetivos do ritual da Pessach em confronto com a última ceia, a crucifixão e a ressureição de Cristo. Aliás, o Judaismo, da Antigüidade aos tempos correntes, suscitou inúmeras investigações: Aviva Paraiso (1988) estudou o comer e o beber judaicos, salientando suas dimensões religiosas; Susan Starr Sered (1988) procurou entender o preparo do alimento como um ato sagrado, etc.

A maioria dos trabalhos sobre conteúdos simbólicos no alimento e na alimentação terminam por valorizar a dimensão religiosa. Sirvam de exemplo o estudo de Loveday e Chiba (1985) sobre os códigos simbólicos na sociedade japonesa ou do simbolismo do pão no Ocidente cristão, por Galavaris (1970). .

Alguns estudos se concentraram em alimentos específicos. Destes, o uncho talvez tenha sido o mais concorrido, em especial por sua capacidade de 
provocar estados de superação das condições habituais de percepção. Para exemplo é bom referir-se ao estudo de Mu-Chou Poo (1995), que toma o vinho e as ofertas de vinho como via de acesso a aspectos fundamentais da religião egípcia. Associada ao vinho, é uma técnica de processamento que vai servir de eixo ao trabalho de Dominique Fournier e Salvatore d'Onofrio 119911, que pretendem, sem meias palavras, que a civilização começa com o domínio da fermentação: dom divino, em vários miłos de origem em várias culturas de matriz indo-européia, é um vetor direto para o sagrado; daí os efeitos de desestruturação cultural que podem ocorrer nos confrontos e substituições, como quando, no Novo Mundo, as bebidas destiladas européias tomaram o lugar dos licores fermentados tradicionais.

Parte considerável da bibliografia temática pode ser agregada em torno de alguns poucos eixos principais: o sacrificio, o tabu, o jejum, a antropofagia.

O sacrifício é um tema fundamental, quer no campo religioso, quer no campo alimentar (Grottanelli 1988). Como foi reiteradamente analisado pelos especialistas, o sacrifício é um ritual de comunicação cuja estrutura básica implica a consagração (sacer facere) de uma vítima, retirada, portanto, de seu contexto profano e, por isso mesmo, integrada ao contexto dialeticamente oposto, o do sagrado, e sua posterior ingestão pelos fiéis. É essa mesma estrutura que se encontra presente, por exemplo, no sacramento da Eucaristia. Portanto, é por um ritual de alimentação que se abre a via da transcendência.

As pesquisas, de inspiração estuturalista, sobre a 'cozinha do sacrifício' na Grécia antiga, desenvolvidas pelo grupo parisiense de estudo comparativo das religiões e sociedades antigas contribuíram decisivamente para fixar pontos importantes desta problemática e fomentar inúmeros desdobramentos. Jean-Pierre Vernant e Marcel Détienne (1979) são menção obrigatória, assim como, para entendimento de significações religiosas da comensalidade, associadas à política, os nomes de François Lissarrague e Pauline Schmitt Pantel (1988).

O tabu alimentar é outro foco de interesse dos estudiosos que buscaram entender a alimentação da perspectiva religiosa - embora, é claro, o fenômeno tenha várias outras dimensöes (cf. o tabu como forma de dominação de gênero em O'laughlin 1974). O repertório de estudos de caso é grande, e poucos os estudos gerais, como o de Frank Simoons (1994) que traçou um panorama das evitações alimentares, da Pré-história aos tempos correntes. $\bigcirc$ que aqui é de interesse mais profundo, porém, são as tentativas de buscar os fundamentos dessas práticas alimentares negativas. Basicamente, são três as linhas mais consistentes. A primeira é de teor materialista e funcionalista. Marvin Harris (1978, 1989) leva ao extremo tal abordagem, numa vertente ecológica e biológica, a ponto de pressupor que uma rígida racionalidade regeria todos os comportamentos alimentares. Nessa perspectiva, os critérios de alimento preferencial ou interdito las proibiçōes islâmica e judaica para o consumo do porco ou a hinduista para o da vacal estariam intimamente associados a valores nutritivos e os próprios sacrifícios humanos dos astecas não dispensariam considerações sobre carências protéicas. Mas, como nota Garine (1994:248), salvo na India, poucos tabus permanentes comportam conseqüências nutricionais. 
Uma segunda alternativa leva em conta problemas cognitivos e classificatórios. Duas referências devem ser apontadas. Em 1966 Mary Douglas publicou um livio que teve ampla circulação e que estudava os conceitos de poluição e tabu na tradição bíblica, a partir dos conceitos de pureza e perigo. A raiz do perigo, sustenta a autora, está nos interstícios das categorias classificatórias: quando os fenômenos e os seres não podem ser alocados a classes cognitivas identificáveis sem ambigüidade lela examina principalmente os animais interditos), gera-se uma insegurança que recomenda a não-tocabilidade - pressuposto da pureza. Mais recentemente, M.Douglas (1996) retomou a questão, reconhecendo algumas complexidades que antes haviam sido marginalizadas e restringindo um alcance universal que pudesse ter sido visto em seu trabalho anterior). O outro nome é o de Marshall Sahlins (1976). Em linha próxima, mas num contexto bem diverso, procura explicar por que muitos sistemas alimentares incorporam a carne de cães e cavalos como alimento, ao contrário da rejeição radical na sociedade americana. É também no plano cognitivo e classificatório que vê ele o critério de distinção: "edibility is inversely related to humanity"(p. 175); por isso, quanto mais os sistemas classificatórios reconhecerem a proximidade de um animal com o homem, num nível estreito de convivência e individualização (como é o caso do cão nos E.U.A.), mais a ingestão de sua carne se assemelharia ao canibalismo.

Uma terceira vertente nos parece que, sem negar a anterior, ampliathe o alcance. Trata-se da consideração do tabu como marca de identidade. As interdições alimentares, com efeito, funcionam de forma muito eficaz para distinguir e isolar, o que é da natureza dos processos de identidade, entendida como mecanismo antes de exclusão do outro, que de referência a si próprio. Os títulos de Jean Soler, acima mencionados, vão nessa direção, ao interpretar as regras alimentares hebraicas como um recurso de distinção e isolamento cultural, destinado a manter o povo judeu separado dos demais pela exigência de que os animais a serem comidos fossem apenas aqueles que "respeitassem o lugar que thes foi fixado no plano da criação".

Próximo dos tabus alimentares está o jejum, cuja dimensão política já foi aqui ressaltada, mas cuja dimensão religiosa é também fundamental. (Baver 1989). Um trabalho que pode servir de referência é o de Veronica Grimm (1995), significativamente intitulado From feasting to fasting: the evolution of a sin, em que a autora discute o Cristianismo primitivo e o Judaismo no mundo greco-romano para estudar atitudes cristãs diante da alimentação, considerando as significações da comida, do comer e da abstenção de comer. Em particular, considera as conotações de pecado associadas à carne e às mortificações que the devem ser infligidas para obter a purificação. Aponta para os desdobramentos que esse modo particular de jejum tem ainda hoje no ascetismo alimentar. Aliás, a associação dos health movements com as crenças e práticas religiosas não deixou de ser tratada. Jill Dubisch (1989) os analisa como uma forma de sistemas religiosos, com seu corpo geral de crenças, sua simbologia própria, prescrições morais, ideais de pureza do corpo, mecanismos de segregação, etc. A segregação alimentar, aliás, dá pista para Colin Spencer (1995) estudar a 'festa dos heréticos', ao tratar do vegetarianismo. A última grande corrente religiosa ocidental a propugnar pelo vegetarianismo foi uma 
7. "As a trope. cannibalism has a somatic anchor by definition: it uses metamorphic extension of physical consumption of what is substancial and tactile in the human body to explain or encode with complex emotional value other, more symbolic, forms of consumption, for example, ideas of incest as cannibalism of "eating blood" "Brady 1996: 166). heresia, a cátara, que a Inquisição eliminou após uma acirrada campanha iniciada no início do século XIII (Le Roy Ladurie 1978). A recusa de toda alimentação carnívora expressa-se filosoficamente na tradição indiana, que chega ao Ocidente na doutrina piłagórica, igualando todo consumo de carne a um ato canibal e recusando a ingestão de cadáveres. Se tal ideologia, vinculada às crenças reencarnacionistas da mentempsicose oriental não conseguiu impor-se no Ocidente cristão, renascem, entre os anti-carnivoros contemporâneos, crenças às vezes próximas (Fiddes 1991; Twigg 1983).

A antropofagia é um tema próximo do tabu e como este também tem uma marca religiosa, embora seu alcance seja maior. Mesmo dotado de conteúdo candente, não atraiu muitos especialistas e a bibliografia ainda é muito insuficiente: faltam estudos gerais mais amplos e consistentes, embora se tenham bons acervos de dados (como Tuzin \& Browns 1983). Não é tema novo; iá no século $V$ a.C. Heródoto atribuía aos citas tal costume abominável. Mas é no séc.XVI que sua significação passa a ter um peso maior. Arens 119791 procurou analisar os relatos feitos pelos europeus, no contacto com os nativos do Novo Mundo e colocou em dúvida seus testemunhos. O livro é panfletário e nem sempre se podem acompanhar suas conclusões, mas teve o mérito de chamar a atenção para o que representou o canibalismo na mentalidade dos conquistadores e para a legitimação da conquista. Frank Lestringant (1994) e Ronald Raminelli (1997) podem ser citados como autores que se preocuparam com esse filão, procurando entender o imaginário do canibalismo.

O canibalismo foi explicado no séc.XIX pelo positivismo neomalthusiano como a conseqüência necessária do conflito entre uma população ilimitadamente crescente e uma disponibilidade limitada de recursos. Michael Harner (1977) e Marvin Harris (1977) são versões contemporâneas, atualizadas com preocupações ecológicas e nutricionais, dessa postura altamente redutora. Com efeito, antes de mais nada é preciso distinguir o canibalismo ritual do sacrifício sem consumo de vítimas humanas (como entre os astecas), o consumo emergencial de carne humana, as práticas médicas (ingestão de placenta, ou do corpo humano embalsamado e pulverizado), as vendetas etc.etc. (Brady 1996). Doutra parte, o canabalismo é polissêmico, desdobrando-se em inúmeras significações religiosas, políticas, afetivas, psíquicas, simbólicas ${ }^{7}$

Os fatores religiosos, enfim, também foram determinantes na fixação de padrões de alimentação que se transformaram em padrões de identidade cultural. Na antigüidade grega e romana, além do sacrifício canônico em que a carne, de consumo escasso, era importante, havia um modelo de alimentação 'civilizada' assentado na trindade do pão, vinho e óleo de oliva. Três produtos da indústria humana que se opunham ao modelo bárbaro germânico do consumo de produtos 'naturais', especialmente a carne e o leite. O Cristianismo irá incorporar essa tradição clássica revestindo-a dos atributos de representação da própria divindade ao adotar, na sua liturgia, o pão como o corpo de Cristo, o vinho como o seu sangue e o óleo como a unção sagrada. Note-se que o Novo Testamento rompe com as restrições vétero-testamentárias e com o particularismo judaico, o que the deu base para universalizar-se aceitando todas as formas de alimentação (com a exceção da proibição do sangue que, vinda do Levítico, permaneceu nos Atos dos Apóstolos). Mas foram sacralizados alguns alimentos 
particulares, como a trindade mediterrânica do pão, vinho e óleo. Tal partido europeu não impediu a autorização pela lgreja, em lugares distantes, como na América, da fabricação de hóstias de farinha de mandioca e de óleo crismático de cabreúva onde havia ausência de trigo, uvas e azeite (Feeley-Harnik 1994).

Os descobrimentos e a mundialização da alimentação.

A maior revolução na alimentação humana ocorreu no período moderno com a ruptura no isolamento continental, quando o intercâmbio de produtos de diferentes continentes, que ocorreu no bojo da expansão colonial européia, alterou radicalmente a dieta de praticamente todos os povos do mundo. As especiarias asiáticas se difundiram para a Europa e chegaram aos outros continentes. As plantas alimentícias das Américas: o milho, a batata, o tomate, o amendoim, os pimentões, propagaram-se pelo planeta. Gêneros tropicais como a cana de açucar, o chá, o café e o chocolate, combinaram-se para fornecerem um novo padrão de consumo de calorias e de bebidas excitantes, que, ao lado do tabaco, tornaram-se hábitos internacionais. Produtos típicos da Europa mediterrânica como o trigo e a uva acompanharam a colonização de diversos países e o álcool destilado penetrov em todos os continentes.

Os impactos sobre os padrões alimentares foram sentidos de forma diferenciada mas com uma intensidade análoga na Europa e na América. Um livro que se dedica especialmente ao estudo das 'migrações'de alimentos e técnicas culinárias são as atas do Congresso de Oxford Food in motion (1983); ver também Sentieri \& Zazzu 1992.

O tráfico comercial interoceânico que inaugurou o período moderno produziu a acumulação primitiva do capital, alterando profundamente a vida social em todo o mundo. A cultura árabe iá vinha transmitindo lentamente, desde Baixa Idade Média, diversos produtos asiáticos para a alimentação européia, desde as especiarias (pimenta, cravo, canela, noz moscada) até 0 arroz e as frutas cítricas. Como relata Sidney Mintz (1985: 25), antropólogo especialista no Caribe, em sua obra sobre a influência cultural do açúcar, foram difundidos, acompanhando a expansão do Islão, muitos vegetais importantes, como o arroz, o sorgo, o trigo, o algodão, a beringela, as frutas cítricas, bananas, mangas e a cana-de-açúcar, mas toi no momento em que essa alimentação deixou de ser um luxuoso privilégio e começou a expandir-se para diversas camadas sociais que surgiu o primeiro mercado mundial.

O comércio dos novos gêneros foi o motor do aparecimento de novas formações sócio-econômicas, como foi o caso do sistema de plantations na América e, ao mesmo tempo, da expansão num grau nunca antes conhecido do tráfico de seres humanos. Os capitais criados nesse tráfico triplo - produtos asiáticos para a Europa, escravos africanos para a América, produtos americanos para a Europa e Africa - alavancaram as transformaçōes no sistema de produção artesanal na Europa, fornecendo a demanda, o produto (algodãol e o capital para o surgimento da indústria têxtil que deflagrou a Revolução Indusirial (Novais 1979; Mintz 1985).

A pimenta moveu as naus dos descobridores e o açúcar produziu a escravidão africana, deslocando massas humanas entre continentes. Como 
afirma o já citado Sidney Mintz (1985: 71), "sugar - or rather, the great commodity market demanding it - has been one of the massive demographic forces in world history".

Diversas monografias específicas de cada um destes alimentos (Salaman 1949 para a batata, Birket-Smith 1943 para o milho, etc.) perseguiram o percurso da migração vegetal provocada pelo descobrimento da América e de suas conseqüências na alteração da dieta européia. Um autor que, mais recentemente, discute a relação do milho com a economia capitalista é Arturo Warman (1988). Outras obras mais gerais estudaram a importância destas plantas no período dos descobrimentos portugueses (Ferrão 1992), ou no bojo de análises mais gerais sobre o Império português e sobre a constituição do sistema colonial (Disney 1981). Um produto específico da cultura colonial que adquiriu grande importância econômica foram os destilados de álcool de cana, como a aguardente brasileira e o rum do Caribe, que serviram de moeda de escambo para a compra de escravos na África (Câmara Cascudo 1986).

Mas o grande gênero alimentício cuja ampliação do consumo mais influiu na alteração dos hábitos alimentares foi o açúcar, não só adoçando as bebidas coloniais que nunca o haviam sido nos sẹus países de origem los chineses consideravam os europeus bárbaros por adoçarem o chá, e os povos árabes condimentavam o café com cravos, canela ou cardamomo, mas nunca o adoçavam), como estendendo sua utilização para quase todos os tipos de alimentos, inlusive as carnes e outros pratos salgados. Seu comércio foi o principal da época colonial: após 1660 superou todas as outras importações coloniais da Inglaterra, somadas (Mintz 1985: 44).

Um exemplo intrigante de uma influência decisiva da alimentação na história política e econômica é a avidez pelas especiarias, a cuja motivação foram atribuídas diferentes origens. As especiarias são alimentos/drogas, substâncias de consumo gustativo, mas também medicinal e afrodisíaco. As atribuições de origens míticas para essas substâncias, que viriam do próprio Jardim do Éden, carregadas pelos quatro rios que nele nascem, e que corporificariam as virtudes solares das regiões quentes e desconhecidas do Oriente foram analisadas por Jean-Pierre Albert (1990). Podem-se encontrar também em estudo sobre o cronista das drogas da India, Garcia da Orta, e os herbários do século XVI, informações a respeito dos diferentes valores atribuídos às especiarias (Henrique Carneiro 1994).

A época moderna deve alguns dos seus elementos fundadores essenciais à ânsia pelas especiarias, a qual levou ao ciclo das navegações, aos grandes descobrimentos, ao sistema mundial, ao comércio transoceânico e à formação dos modernos impérios europeus, o que fez o historiador A. R. Disney (1981) chamar Portugal de Império da Pimenta

Essa busca de especiarias, levando à descoberta da América, provocou indiretamente uma revolução nos hábitos alimentares mundiais, colocando em contato espécies que nunca antes tinham sido transplantadas. Algumas das centenas de variedades de batatas que a cultura Aimará do altiplano boliviano conhece se deixam aclimatar no Velho Mundo para difundir uma parcela desse saber: o tubérculo que Charles l'Ecluse descreveu pela primeira vez e que Parmentier conseguiu popularizar na Europa. Os contatos e as 
influências se fazem em diversos sentidos: a batala, o milho, o tomate, o amendoim, o pimentão, o feijão e o cacau das Américas difundem-se pelo mundo, junto com o chá da China, o café da Etiópia, a canela do Ceilão, o cravo das Molucas, a pimenta do Malabar, e a noz moscada de Banda (Ferrão 1992; Ferronha 19921, enquanto produtos da dieta européia, como o trigo, o vinho e o álcool destilado, também expandem-se de sua área original para uma difusão mundial.

Cada um dos produtos de origem americana teve uma história específica na sua expansão para fora do continente de origem. Alguns, como os pimentões, por exemplo, vieram a influenciar culinárias tão distantes como a africana, a do sudeste asiático, e a húngara, onde se tornou o condimento mais característico do país: a páprica do gulash (Flandrin 1996: 559). A batata, o tomate, o milho, o feijão e, entre os animais, o caso singular do peru, foram sendo adotados lentamente, e só no século XIX se incorporaram definitivamente à alimentação européia e de grande parte do mundo.

Revolução semelhante somente ocorrera antes quando, em meados do ano 1000, os árabes começaram a fazer lenta difusão de uma série de produtos que a Europa até então não conhecia, como o álcool destilado, o açúcar, a laranja, e as próprias especiarias asiáticas, até então seu monopólio comercial. Tais produtos de luxo naquela época mantiveram-se, entretanto, restritos à nobreza.

A história da alimentação moderna é a de uma expansão no consumo de diversos produtos de luxo, a pimenta e as especiarias no século XVI, e o açúcar e as bebidas coloniais (chocolate, café e chá) a ele associadas, que se tornaram os gêneros mais importantes do comércio mundial. Apenas o chá, por exemplo, constituiu $81 \%$ do valor dos carregamentos da East India Company, da Inglaterra (Flandrin 1996b: 561).

Sidney Mintz (1986: 99) designou estas substâncias 'alimentosdrogas', como o chá, que levaram a Inglaterra a um tal grau de vício que, para obtê-lo, transferiram para a China em pagamento a maior parte da prata extraída das minas da América.

Wolfgang Schivelbusch (1991) é outro autor que escreveu uma história disso que em alemão se chama Genussmittel, que pode ser traduzido como "estimulantes", destacando os aspectos morais implicados na adoção do chocolate, considerado como aristocrático e afrodisíaco, e do chá, café e tabaco, reputados como burgueses e sóbrios.

Ao mesmo tempo em que se expandia o comércio de longo curso e se iniciava a introdução das plantations de açúcar nas colônias, para o qual se intensificou em um nível nunca antes visto o tráfico de escravos, numa diáspora africana para a América, a alimentação camponesa na Europa declinava consideravelmente em qualidade e quantidade.

Diversos autores (Courie 1964; Neveux 1973; Benassar \& Goy 1975; Flandrin 1983) escreveram sobre a alimentação européia na época moderna. O período moderno foi o momento em que a alimentação cerealífera se impôs à maioria da população européia, limitando a maior diversificação existente no período medieval, assim como diminuindo o consumo de carne até a sua desaparição em amplas camadas sociais (Flandrin 1996: 550). 0 cercamento dos campos, a expulsão dos camponeses da terra, de cuja 
8. Há poucos estudos dedicados especificamente à questão estética do alimento. As atas do Colóquio de Lausanne (Stern, ed. 1987) apropriadamente intitulado A manger des veux, é uma exceção. propriedade são cada vez mais excluídos, a alta generalizada de preços, entre outro fatores, provocam, entre os séculos XVI e XVIII, algumas das maiores crises de abastecimento e as grandes fomes se generalizam.

Nestas épocas de grandes fomes do período moderno se generalizaram também as dietas dos períodos de crise, baseadas no consumo de raizes e vegetais impróprios para o consumo, como o joio e, particularmente, cereais contaminados pelo esporão do centeio. Sua ingestão provocava efeitos de epidemias coletivas, onde se destacavam os sintomas mentais, como é o caso das manias convulsivas conhecidas como "dança de São Vito". O italiano Piero Camporesi (1980) escreveu um livro clássico sobre este assunto, II pane selvaggio, que trata do "imaginário da fome da Renascença ao século XVIII". A historiadora canadense Mary Kilbourne Matossian (1 989) também abordou estes fenômenos de uma alimentação deletéria e causadora de distúrbios psíquicos coletivos no livro Poisons of the Past: Molds, epidemics and History. No Brasil, Josué de Castro (1987:220-227) listou dezenas de plantas tóxicas usadas em dietas de épocas de seca e fome no nordeste, os chamados alimentos "brabos".

Se a busca das especiarias impulsionou as grandes descobertas marítimas e a adoção do açúcar levou à escravidão africana, os desequilibrios provocados pelas crises alimentares do século XVIII deflagraram as revoltas que culminaram na Revolução Francesa em 1789. A alimentação ocupa, como um ator invisível, o cenário dos grandes processos constitutivos da modernidade, assim como forja, no âmbito menos visível dos hábitos e costumes, essa revolução silenciosa que constitui o que Norbert Elias (1990) chamou de 'processo civilizatório', no qual as maneiras à mesa ocupam tão destacado papel.

Gosto e gastronomia

O interesse histórico pela gastronomia surge desde o início da institucionalização da História da Alimentação, na década de 60, mas se desenvolve plenamente duas décadas depois. O ponto de partida é, de um lado, o reconhecimento da importância psico-social dos significados alimentares, como assinalada por Barthes (1961) e acentuada a seguir pela Antropologia, e, de outro, a instituição do gosto como objeto legítimo de pesquisa histórica. Assim, J.F.Revel, J.P.Aron e J.L. Flandrin vão superar o universo predominante das necessidades e carências nutritivas, das quantificações e das malérias-primas alimentares, para ocupar-se das escolhas, das qualificações e dos pratos preparados. Os três perceberam o papel do gosto e da moda como estratégias para entender a dinâmica social da sociedade moderna, paticularmente (mas não exclusivamente) no que diz respeito à distinção social (Gronow 1997). Além disso, tratava-se de historicizar o universo do corpo e dos sentidos e valorizar os atributos estéticos do alimento, ressaltando a vista e o paladar ${ }^{8}$.

Flandrin desde 1978 coordenava pesquisas para escrever uma história do gosto. Em 1983, num estudo sobre o uso das gorduras nas cozinhas da Europa ocidental, do séc.XIV ao XVII, estabelece esta diferença básica: "dans le comportement alimentaire des peuples comme celui des individus, il faut distinguer la part du go † et la part de la nécessité" (1983: 369). No artigo do mesmo ano (1983b), La diversité des goûts et des pratiques alimentaires en 
Europe du XVle. au XVIIle. siècle, resume suas principais posições (v.também 1986). Revel (1979) vai explorar 'a história liferária da sensibilidade gastronômica'. Aron, também envolvido com a 'sensibilidade alimentar' na Paris do séc.XIX, coloca a História da Alimentação em sintonia com a História das Mentalidades. Comentando trabalhos como estes, Stephen Mennell 11992: 279), que também poderia incluir-se nesta corrente, salienta o deslocamento da atenção para o que ele denomina "the demand side — that is, the study of social influences shaping people's tastes in food".

Outro nome que se distingue é o do casal Grignon. Claude Grignon (1981, 1988) vai estudar, por via da alimentação, a estratificação social e delinear uma sociologia do gosto; em companhia de Christiane Grignon (1980, 1986), retomará o tema da estraifificação social e introduzirá o do gosto popular.

Do gosto se pode passar à gastronomia propriamente dita. Jean François Revel (1996: 18) vê em meados do século XVIl três marcos de superação da uniformidade na culinária tradicional, que se perpetuava em toda a Europa: a a publicação, em 1651, do Cuisinier français, de F.de la Varenne; logo após, 1656, do Cuisinier, de Pierre de Lune; e, em 1662, do Le cuisiner méthodique ou l'école des ragoûts, de autor anônimo. Estas raizes vão desabrochar no século XIX numa alentada bibliografia, em que cumpre salientar os nomes de Grimod de la Reynière, que publicou de 1803 a 1812 o Almanach des gourmands - e por isso é considerado o pai fundador da literatura gastronômica - e o nome mais célebre, o de Jean Anthelme Brillat-Savarin, autor da Physiologie du goût, de 1825. A alimentação, que sempre tivera um espaço particular nas utopias desde a ldade Média, como as do país de Cocanha, vai também agora incorporar a gastronomia, como em Charles Fourier (1972), que previa o advento da gasirosofia, quado a questão culinária se tomaria, ao lado do sexo, a mais importante preocupação e atividade dos cidadãos. ${ }^{9}$ Este material, mais o que se refere a disputas gastronomicofilosóficas a partir do século XVII l"science et philosophie s'emparent alors de la marmite", observa o Barão Grimm, apud Roche 1997: 266l, além de cadernos de receitas ou testemunhos sobre sua transmissão oral, livros de viagem etc. vão permitir que se desenvolva uma bibliografia histórica, em geral de caráter nacionalmente particularizado: J.R.Pitte (1993) faz a história e a geografia da gastronomia francesa; Piero Camporesi (1996) trata da arte de viver na época das Luzes, com espaço privilegiado para nosso tema; Emilio Faccioli (1992) traça um panorama da gastronomia italiana; Lucie Bolens (7990) estuda a cozinha andalusa dos séculos XI a Xlll etc.etc. Alguns poucos textos têm caráter mais genérico, como o Homo culinarius de P.Falk (1991), que se orienta por uma antropologia histórica do gosto, ou, ainda que calcados no caso francês, Flandrin (1992), ou então Rowley (1994). Alguns trabalhos se centraram em aspectos documentais, como la cuisinière bourgeoise de A.Girard (1977), que explora os livros culinários dos séculos XVII e XVIII; V. Maclean (1981) lista o mesmo material para a Inglaterra, entre 1701 e 1800.

De um caráter um pouco particular é a obra de Jack Goody (1982), Cooking, cuisine and class, onde o autor distinguea haute cuisine da cozinha camponesa e se pergunta por que algumas sociedades, como as africanas, não dispõem da primeira categoria. A resposta, associada à organização hierárquica dessas sociedades e à presença de uma tradição literária na produçção de
9. Cf. Edmund Leach (1964: 53) que explora o que ele chama de uma "universal tendenc) to make ritual and verbal association between eating and sexual intercourse". 
repertórios, é mais ou menos óbvia. Stephen Mennell parte de Goody para, em All manners of food (1985), supera-o e desenvolve um estudo comparativo entre a França e a Inglaterra: "to explain why complex differentiated societies produce complex differentiated cuisines is a less difficult task than to explain why complex differentiated societies have produced culinary cultures with perceptible different culinary cultures" (1992: 280). Para tanto, estudou as diferenças no processo de urbanização; o abastecimento diferencial e a dependência, ou não, do campo; as características da nobreza em cada país (especialmente o caráter marcante da 'country gentry' inglesa), etc.

O estudo da gastronomia, por sua vez, introduziu figuras e espaços novos, em nosso cenário: o gourmet, o glutão, o cozinheiro, o 'bebedor', o restaurante. Um dos marcos é a obra de J.P.Aron, Le mangeur au XIXè.siècle 11973; ver também 1974), em que ele leva em conta a emergência da burguesia e a disponibilidade, depois da Revolução Francesa, dos 'officiers de bouche', antes vinculados às famílias nobres - o que também vai ensejar a abertura de restaurantes. B.Watson (1962) já se havia interessado pelos cozinheiros, glutões e gourmets. Quanto às representações do ébrio, é o tema da obra de Didier Nourrisson (1990), Le buveur du XIXè.siècle, anteriormẹnte citada.

Historiografia Brasileira: Recortes

A hisłoriografia brasileira da alimentação é muito pobre. É um tema que, efetivamente, ainda não foi descoberto pelos historiadores, embora sua presença possa ser detectada, sempre como apêndice, em várias circunstâncias. Como se verá adiante, apenas no seio da História econômica e em filöes abertos pela Antropologia e pela História do cotidiano ou da vida privada é que começa a surgir uma produção mais continuada e sistemática.

Há alguns quadros gerais descritivos, que mais funcionam como crônicas ou ensaios, a desenvolver sem base empírica mais sólida problemas de escala muito vasta (p.ex., Brandão 1948, Costa 1942). Apenas uma obra de síntese, representando uma experiência acumulada ao longo de anos de pesquisas, está disponivel: A História da alimentação no Brasil, do antropólogo e foldorista Luís da Câmara Cascudo (1983, la.ed. 1967-8). Como ele relata no prefácio, era seu projeto escrever uma obra em colaboração com um geógrafo também envolvido com o tema, Josué de Castro: a empreitada comum, segundo ele, frustrou-se talvez porque o grande cientista social pernambucano tratasse da fome e seu quase parceiro potiguar estivesse mais interessado em comida.

Os dois volumes da História de Câmara Cascudo abrangem vastíssimo panorama. O primeiro cuida do cardápio indígena, da dieta africana e portuguesa, da alimentação dos viajantes e escravos. Utilizando fontes históricas e etnográficas, esboça uma tentativa sociológica de caracterizar a a limentação do Brasil colonial (que hoje nos parece um pouco superficial, mas cujo valor não pode de maneira alguma ser reduzido). Se descarta os alimentos aculturados (arroz, cana-de-açúcar, café), insiste nos nativos. O segundo volume trata da cozinha brasileira, de sua 'fundação' (insistindo no séc.XVII), na provisão e consumo dos alimentos, nos rituais da refeição, na alimentação viática |farnel 
de trabalho, farnel de viagem), nas superstições e no folclore da alimentação, nos mitos e realidades da cozinha africana. Interessa-se pelas bebidas, sal, açúcar, pimenta, feijão, farinha, hortaliças, verduras. Não exclui problemas de interdependências e assimilações - em suma, transformações - ao considerar a fisionomia alimentar de grupos étnicos.

É também graças a Cascudo (1977) que devemos uma cômoda compilação de textos, de toda ordem e teor, referentes à alimentação no Brasil: trechos de cronistas e viajantes (Luccock, Koster, Saint-Hilaire, Marcgrave, von Martius, Ivo d'Evreux, etc.), excertos literários (Coelho Neto, Vinícius de Morais, Santa Rita Durãol, além de pequenos estudos de geógrafos, sociólogos, historiadores contemporâneos. Cascudo publicou ainda monografias sobre a cozinha africana no Brasil (1964), a aguardente (1968) e o açúcar (1971).

Doutra parte, é preciso apontar as dificuldades de ordem documental. Até mesmo para estudos da fome em nosso século contam-se com enormes dificuldades de registros. Se tem sido freqüente a exploração dos textos dos viajantes e naturalistas, pouco uso se fez da literatura em geral e absolutamente nada com registros visuais. Utensílios e equipamentos, livros de receita e etiqueta ainda não mereceram tratamento sistemático, embora exceções recentes apontem que este desconhecimento pode ser superado (Lima 1996). Da mesma forma, poucos têm sido os estudos dos espaços associados à preparação e consumo dos alimentos, embora se possam mencionar obras sobre a arquitetura e as funções da cozinha (Lemos 1976). Já os engenhos de açúcar mereceram mais atenção, ainda que o interesse seja, sobretudo, a tecnologia (Gama, 1983; Azevedo 1990|. A preocupação historiográfica também tem sido rala e uma tentativa como a de Saldanha (1971) de traçar a evolução, desde a época colonial, dos estudos sobre o açúcar é muito sumária.

Última observação geral: se tem sido pobre o interesse de historiadores estrangeiros sobre a problemática da alimentação no Brasil (salvo, em parte, com relação ao café e ao açúcar), é praticamente nula a produção brasileira pertinente a questões externas a nossa sociedade.

Conviria agora, aqui também, antes de definir os traços mais específicos dos estudos históricos, esboçar um panorama dos estudos antropológico-sociológicos, que estão, muitas vezes, próximos daqueles - e nos quais a presença da alimentação sempre foi mais sensivel.

\section{Estudos antropológico-sociológicos}

Deixamos de lado, aqui, a bibliografia arqueológica, não só porque se refere a um foco de atenção diverso da sociedade brasileira, como também porque ela é extremamente dispersa e parcelar. Isto não é negar seu valor, sobretudo na contribuição para o conhecimento de alguns cultivares lem particular a mandioca e o milhol, ou em práticas como a caça e a pesca, ou, ainda, em técnicas que se transmitirão aos indígenas historicamente conhecidos - mas para fundamentar um tratamento de síntese historiográfica é insatisfatório. Felizmente, com a atenção dada nestes últimos anos a questões como o surgimento e difusão da agricultura, vem-se acumulando material para outros patamares de interesse, 
como, por exemplo, a correlação com formas materiais e sociais de organização do território e dos assentamentos.

Quanto à bibliografia etnográfica e etno-histórica, é muito ampla e já apresenta certa continuidade. Ainda faltam, é certo, estudos gerais: um pequeno texto de Eduardo Galvão (1979, la.ed. 1962) ainda hoje muito citado, ou então a tentativa mais antiga de Herbert Baldus (1950) são ocorrências excepcionais. Mesmo uma antologia publicada no vol. I, Etnobiologia, da Suma etnológica brasileira organizada por Berta Ribeiro (1986), obra utilíssima, revela um campo ainda pouco amadurecido. A antologia inclui quase tudo de importância e de caráter ou interesse geral que se publicou, cobrindo vasto espectro de questões etnobotânicas e etnozoológicas luso e classificação de plantas, animais e solos, estimulantes e venenos, agricultura, caça, pesca, funções rituais e medicinais dos alimentos, etc.). É significativo o peso de alguns grandes 'clássicos', como Sauer, Lévi-Strauss, Carneiro, Métraux, ao lado de relativamente poucos estudos mais recentes. Entre estes vale lembrar o de José Proenza Brochado (1977) sobre a Floresta Tropical.

O volume de uma vasta produção de teor folclórico pode ser avaliado na bibliografia de uma obra sobre alimentação e folclore publicada por Souto Maior 17988), obra em que se reuniu um número considerável de provérbios, ditos, crenças e referências populares. Completando suas sinalações, pode-se confirmar que, entre estudos de base antropológica e simples registros pitorescos, alinham-se poucos trabalhos gerais ou que abordem temas técnicos: a alimentação sertaneja (Sampaio 1944), a conservação de alimentos (Faria 1965), alimentação e linguajar popular (Moura 1969). A maioria gira em torno de alimentos específicos: açúcar (Salles 1967, Souto Maior 1977), Souto Maior 1977, Ribeiro 1977), cachaça (Cascudo 1968, Julião 1921, Souto Maior 1970 e 1973, Barbatho 1974), café (Magalhães 1980, la. ed. 1936, Marconi 1976), pão (Souto Maior 1971), caju (Souto Maior 1981) e assim por diante. Apesar da vitalidade do tema, que estes trabalhos representam, deve-se reconhecer que, salvo poucas exceções, sua contribuição à História se reduz ao fornecimento de informação empírica. Pelo contrário, a insistência recorrente em caracterizar o 'típico' congela os processos e exclui a possibilidade de transformação histórica. Além disso, centrados em seus próprios interesses, tais estudos perdem de vista o contexto mais amplo da sociedade.

Entre a Etnografia e o Folclore, um tema tem despertado muita atenção, nestes últimos tempos. É a cozinha associada aos rituais afro-brasileiros. $\bigcirc$ trabalho mais completo e de rigor acadêmico é o de Giobellina-Dumana (1988), que procura examinar a 'cozinha de santo' como alimentação alternativa, enfocando questões como identidade, classificações, papéis terapêuticos, relações com o sobrenatural. Da mesma forma, Raul Lody (1998) investe no caráter de celebração e nos padrões morais (cf. relação adequada entre a comida, o fiel e o temperamento do santo, as interdições, etc.). Outros trabahos, como Farell (1997) e Varella (1990), este último incluindo a umbanda, têm menos força interpretativa.

É preciso mencionar o desenvolvimento de monografias acadêmicas, sobre temas variados, de orientação antropológica mas, sobretudo, sociológica (às vezes, até mesmo, psicológical, e que, tomando como referência a 
alimentação, buscam estudar questões de gênero (Woortman 1996), hábitos e ideologias em camadas de baixa renda (Woortman 1978, Velho 1977), mudança cultural (Bonin \& Rolim 1991); representações alimentares, incluindo tabus (Maués \& Maués 1978, Garcia 1995).

Questões como a adequação, ou não, de nossos hábitos alimentares (nutrição, subnutrição, saúde, fome), também receberam por vezes um tratamento. que as torna úteis para a História - apesar de muitas vezes como fontes de informação, mais do que como análises propriamente ditas. Citem-se os Problemas da alimentação no Brasil, de Agostinho Monteiro (1944), ou População, alimentação, saúde e segurança nacional, de Jorge Saldanha Bandeira de Melo (1966) e, sobretudo, a obrá do médico Antonio da Silva Mello (1943, 1946), que teve ampla divulgação, principalmente por causa de sua crítica à industrialização excessiva dos alimentos e à perspectiva vitalista da ciência médica, com conselhos de bom senso para a alimentação das crianças, internatos, hospitais etc., visando à 'felicidade natural'. Silva Mello constitui excelente fonte - juntamente com vários outros médicos de sua geração - para conhecimento de preconceitos e crenças (científicas ou populares) vigentes à sua época, assim como das condiçōes de emergência da indústria alimentar no Brasil e da difusão de novos produtos (soja, leite em pó desnatado etc.).

Já de outra natureza é a produção de Josué de Castro, calcada, com rigor, na perspectiva geográfica e sócio-econômica. A Geografia da fome (1946) e a Geopolítica da fome (1951), juntamente com outras obras sobre o tema (1933, 1935, 1937, 1938, 1949, 1966, 1984), alcançaram merecida repercussão internacional. Mais limitada é sua tentativa, com Fisiologia dos tabus: com um apêndice contendo vários tabus alimentares brasileiros (1938), de desenvolver uma interpretação de tipo reflexeologista-pavloviana, muito questionável.

Finalmente, cumpre tratar da contribuição valiosa, ao mesmo tempo de caráter antropológico, sociológico e histórico, representada por Gilberto Freyre. Quando publicou Açúcar, em 1939 (1997, 3a.ed.) - incluindo receitas de bolo e doce (algumas coleładas em Goa), registro de formas e papel recortado para forrar prateleiras, assim como testemunhos de estrangeiros sobre nossos doces e assim por diante - Gilberto Freyre temia ser julgado frívolo. Seu temor era infundado, apesar do caráter evocativo e impressionístico de seu texto. Mas não se pode dizer que seu pioneirismo tenha gerado vasta descendência. Ele próprio já abordara o tema, com um tom mais contido em Nordeste (1937), cujo subtítulo é Aspectos da influência da cana sobre a vida e a paisagem do Nordeste do Brasil. Para o autor, sem o açúcar não se compreenderia o homem do Nordeste. Ao descrever a 'sacarocracia' brasileira, que produziu uma alimentação edulcorada, em variada gama de doces feitos da fusão do açúcar com as mais diversas frutas, G. Freyre buscou entender dimensões da identidade 'nacional', assim como mecanismos de miscigenação dos paladares português, hispânico, árabe, judaico, indígena e africano.

Estudos históricos

Já se disse, acima, que a historiogafia sobre o Brasil não deixou de levar em conta a alimentação, mas quase sempre como apêndice: Sérgio Buarque de 
Holanda, em Caminhos e fronteiras (1994), acrescentou um capítulo sobre 'a civilização do milho'; Evaldo Cabral de Mello, em Olinda restaurada — que, aliás, tem como subtítulo Guerra e açúcar - (1975) não deixou de lado a 'munição de boca'; em Tempo de flamengos, José Gonsalves de Mello (1987) discorre sobre a contribuição holandesa à alimentação em Pernambuco. E assim por diante.

Os apêndices têm-se multiplicado e, alargado quando está em causa a história do cotidiano ou da vida privada. É o que ocorre com os capítulos 'Hábitos alimentares' e 'Tradições alimentares e culinárias' de Maria Beatriz Nizza da Silva, respectivamente em Cultura e sociedade no Rio de Janeiro, 1808-1821 (1978 / e Vida privada e quotidiano no Rio de Janeiro na época de D. Maria e D.João VI (1993), ou em três capílulos de Cotidiano e solidariedade. Vida diária da gente de cor nas Minas Gerais, séc.XVIII, de Julita Scarano (1994; ver também, seu artigo sobre o mesmo assunto, em outra época, 1990-11.

É de estranhar que a importante série História da vida privada no Brasil, em quatro volumes (organização geral de Fernando Novais), não tenha considerado a problemática da alimentação digna de um tratamento específico. No entanto, Leila Mezan Algranti (1997), ao elaborar seu capítulo sobre famílias e vida doméstica no Brasil colônia, no lo.volume; não deixou de reservar algumas páginas ao tema, tocando em questões como dieła e abastecimento, utensílios, posturas corporais, padrões de sociabilidade e intimidade, remédios, mezinhas e alimentação de doentes, etc.

Muitos estudos tomam a alimentação como pano de fundo para outros problemas, como questões de gênero (Figueiredo \& Magaldi 1985), o cotidiano operário (Bertucci 1995), padrões e espaços de sociabilidade (Chaloub 1986).

Há também um certo número de histórias da alimentação, de caráter regional, numa linha iniciada nos anos 50 por Donald Pierson (repr. 1994), mais tarde seguido por Lisanti Filho (1962), ambos tratando de São Paulo e por Eduardo Frieiro (1966) com seu ensaio sobre a comida do mineiro. Ainda sobre Minas, Mônica Abdala (1997), mais que retomar os quadros evolutivos que estavam disponiveis, preocupou-se com a questão da identidade, a partir das peculidaridades históricas da formação da capitania lque nasceu urbana e só mais tarde se ruralizou; que dependeu de alternativas no abastecimento e do espírito de sociabilidade e hospitalidade, para fazer face ao isolamento geográfico; que foi objeto, por variadas razões, do cultivo de um mito, o da 'mineiridade'). Maria Stella Libânio Christo, uma das mentoras do projeto de valorização da cozinha mineira, recolheu e comentou receitas que cobrem trezentos anos de informação culinária (1986). Ortencio Barini (1981), além de receitas, fornece dados históricos sobre a cozinha goiana. Outras muitas obras semelhantes disponíveis não se enquadram no perfil deste mapeamento.

A única área em que os problemas da alimentação ganharam um status consolidado e mais definido é no interior da História Econômica. Assim, são já de tradição antiga os estudos de abastecimento, como aquele pioneiro de Mafalda Zemella (1951), sobre a capitania das Minas Gerais no séc. XVIII, ou as histórias da agricultura, como a de Luís Amaral (1940), que, nas suas próprias palavras, procurava combinar aspectos políticos, sociais e econômicos. Mais recentemente, estes estudos ganharam alento e renovação com o grupo de História da Agricultura, nucleado por Maria Yeda Linhares, centrado no estudo da 
sociedade rural e estruturas agrárias no Brasil. Mencionem-se os seguintes títulos: História do abastecimento, uma problemática em questão, 1530-1917 (Linhares, 1979). História da agricultura brasileira: combates e controvérsias (Linhares \& Silva 19811, Pecuária, alimentos e sistemas agrários no Brasil, séculos XVII e XVIII (Linhares 1996), etc. Outros muitos trabalhos são próximos desta linha, como o de Carlos Roberto Antunes dos Santos (1995) sobre o abastecimento no Paraná, ou, mais à parte, sobre a economia do açúcar, explorando as imbricações de terra, trabalho e poder, o de Vera Ferlini (1988).

Mencionem-se, por fim, os numerosos estudos de alimentos específicos, principalmente o açúcar e o café (cujas referências constam em vários momentos deste texto). Talvez valesse a pena assinalar especificamente as publicações produzidas pelo Museu do Açúcar do Recife, criado em 1960 e posteriormente integrado à Fundação Joaquim Nabuco de Pesquisas Sociais: a Revista do Açúcar e várias monografias ou coletâneas, reunindo material dispar, quer de alíssimo interesse, quer de cunho puramente circunstancial.

Fica evidente, deste apanhado sumário, que a História da Alimentação ainda é, entre nós, um teritório a descobrir - principalmente na sua dimensão cultural. Não se trata de propor mais uma 'Nova História', mas apenas de não ignorar uma problemática ubíqua e de suma relevância.

\section{BIBLIOGRAFIA}

ABDALA, Mônica Chaves, Receita de mineiridade. A cozinha e a construção da imagem do mineiro. Uberlândia, Universidade Federal de Uberlândia, 1997.

ABEL, Wilhelm, Massenarmut und Hungerkrisen im vorindustriellen Europa. Versuch einer Synopsis. Göttingen, 1974, 2.Auf1..

ABEL, Wilhelm, Agrarkrisen und Agrarkonjunktur. Hamburg, Paul Parey, 1978, 3.Aufl.

ADAMS, C. J., The sexual politics of meat. A feminist-vegetarian critical theory. New York, Continuum, 1990.

ADAMS, D., The long dark tea-time of the soul. London, Pan, 1988

ADAMS, James S., A fell fine baker The story of United Biscuits. London, 1974.

AIDELLS, Bruce \& KELLY, Denis, Real beer and good eats. The rebirth of America's beer and food traditions. Knopf/QFB, 1992.

ALBERT, Jean-Pierre, Odeurs de sainteté. La mythologie chrétienne des aromates. Paris, Éds. EHESS, 1996.

ALGRANTI, Leila Mezan, Famílias e vida domética. In: SOUZA, Laura de Mello e, org., História da vida privada no Brasil. Vol. I: Cotidiano e vida privada na América Portuguesa. São Paulo, Compahia das Letras, 1997: p. 83-154. 
AMARAL, Luís, História geral da agricultura brasileira. No tríplice aspecto político-socialeconômico. São Paulo, Cia. Editora Nacional, 2a.ed.,1940, 2 vols. (Brasiliana, 160). (1a.ed., 1940-1).

AMOURETTI, M. C., Le pain et l'buile dans la Grèce ancienne, Paris, 1986.

ANDERSON, Eugene N., Plants, man and life. Boston, Little \& Brown, 1952.

ANDERSON, Eugene N., The food in China. New Haven, Yale University Press, 1988

ANDRÉ, J., L'alimentation et la cuisine à Rome. Paris, Les Belles Lettres, 1980.

ANDROUET, P. , Un fromage pour chaque jour Paris, Ed. de Verfèvre, 1981.

APPADURAI, Arjun, Gastro-politics in hindu South Asia, American Etbnologist, v.8, n.3: p.494$511,1981$.

APPADURAI, Arjun, How to make a national cuisine: cookbooks in contemporary India, Comparative Studies in Society and History, 30: p. 2-24, 1988.

APPLEBY,A., Famine in Tudor and Stuart England,. Stanford, Stanford University Press, 1978.

APFELBAUM, M.; PERLEMUTER, L.; NIClOS, P.; FORAT, C. \& BERGON, M., Dictionnaire pratique de la nutrition, Paris, Masson, 1981.

ARENS, W., The man-eating myth. Anthropology and anthropophagy. Oxford, Oxford University Press, 1979.

ARNABOLDI, J. Les Français et la table. Paris, 1986.

ARNOLD, David, Famine. Social crisis and historical change. Oxford, Basil Blackwell, 1988.

ARNOTT, Margaret L., ed., Gastronomy. The anthropology of food habits.The Hague, Mouton, 1976.

ARON, J.-P., Biologie et alimentation au XVHIe siècle et au début du XIXe siècle", Annales ESC, v. 16: p.971-977, 1961 .

ARON, J.-P., Essai sur la sensibilité alimentaire à Paris au XIXe siècle. Paris, A. Colin, 1967 (Cahier des Annales).

ARON, J.-P., Le mangeur du XIXe siècle. Paris, R. Laffont, 1973.

ARON, J.-P., A cozinha: um cardápio do século XIX. In: LE GOFF, Jacques \& NORA, Pierre, eds., História. Novos objetos. Rio, Fancisco Alves, 1974: p.160-185.

ARON, Jean-Paul, Sur les consommations avariées à Paris dans la deuxième moitié du XIXe siècle, Annales ESC, v.30, n.2-3: p.553-562, mars-juin 1975. 
ASHLEY, Sir William, The bread of our forefatbers. Oxford, 1928.

ASHTON, John, The bistory of bread. London, 1904.

AURELL, Martin; DUMOULIN, Olivier \& TÉLAMON, Françoise, eds., La sociabilité à table. Commensalité et convivialité à travers les ages. Actes du Colloque de Rouen 1990. Rouen, Université de Rouen, 1992.

AYKROYD, W.R., Sweet malefactor Sugar, slavery and human society. London, Heinemann, 1967.

AYMARD, Maurice, Pour l'histoire de l'alimentation: quelques remarques de méthode, Annales ESC, n. 30: p. 431-444, 1975.

AYMARD, M. \& BRESC, H., Nourritures et consommation en Sicile entre le XIVe et le XVIIIe siècle, Annales ESC, v.30, n.2-3: p. 592-599, mars-juin 1975.

AYMARD, Maurice; GRIGNON, Claude \& SABBON, Françoise, eds., Le temps de manger: Alimentation, emploi du temps et rythmes sociaux. Paris, Eds. De la Maison des Sciences de l'homme / Institut National de la Recherche Agronomique, 1993.

AZEVEDO, Esterzilda de, Arquitetura do açúcar. São Paulo, Nobel, 1990.

BACCI, Livi, Popolazione e alimentazione. Saggio sulla storia demografica europea. Bologna, Il Mulino, 2. ed., 1989.

BALDUS, Herbert, Alimentação dos índios do Brasil, Sociologia. São Paulo, v.12, n.1: p.44-58, 1950.

BALL, Daniela, ed., Kaffee im Spiegel europäiscber Trinksitten. Zürich, Johann Jacobs Museum, 1991.

BARKER, T. C.; ODDY, D.J.\& YUDKIN, John, eds., Our changing fare. Two hundred years of British food habits. London, 1966.

BARLÖSIUS, Eva, The history of diet as a part of the vie matérielle in France. In:Teuteberg, H.-J., ed., European food bistory: A research review. Leicester, Leicester University Press, 1992: p.90-108.

BARTHES, Roland, Pour une psycho-sociologie de l'alimentation contemporaine, Annales ESC, n. 16: p. $977-986, .1961$

BASINI, G.L., L'uomo e il pane. Milano, Giuffrè, 1970.

BATAILlE-BENGUIGUI, M.C., Cuisines, reflets des sociétés. Paris, Sepia, 1996.

BAUER, Beatrice, Il digiuno.In: Longo \& Scarpi, eds., Miti e realtà nella civiltà contemporanea. Milano: Diapress Documenti, 1989: p. 231-234 (Homo edens).

BAULANT, M., Niveaux de vie paysans autour de Meaux en 1700 et 1750 , Annales ESC, v.30, n.23: p.505-18, mars-juin 1975. 
BEAUREGARD, M. Guerry de, Vers une internationalisation des comportements alimentaires?, Annales de Geograpbie, n.493, mai-juin 1980.

BEJARANO, Jorge Alfonso, Alimentación y nutrición en Colombia. Bogotá, 1941.

BELASCO, Warren, Appetite for change: how the counterculture took on the food industry, 19661988. Ithaca, Cornell University Press, 2nd.ed., 1993.

BELL, David \& Gill VALENTINE, Consuming geograpbies. We are where we eat. London, Routledge, 1997.

BENASSAR, B. B. \& GOY, J., Contribution à l'histoire de la consommation alimentaire du XIVe au XIXe siècle, Annales ESC, v.30: p. 402-430, 1975.

BENNET, M. K., The world's food. New York, Harper \& Row, 1954.

BENTLEY, Amy, Islands of serenety. Gender, race, and ordered meals during American World War II, Food E Foodways, v.6, n.2: p.131-156, 1996.

BERGIER, J.-F, , Une histoire du sel. Lausanne, Office du Livre, 1984.

BERTHIAUME, G., Le rôle du mageiros: étude sur la boucherie, la cuisine et le sacrifice dans la Grece ancienne. Leiden, Brill, 1982.

BERTIN, Jacques; HÉMARDINQUER, Jean-Jacques; KEUL, Michael \& RANDLES, W.G.L., Atlas des cultures vivrières. Paris/Haia, Mouton, 1971.

BERTUCCI, Liane, Casa e comida. Aspectos do cotidiano operário em São Paulo no início do século XIX. Cadernos de História Social/UNICAMP, n.2, 1995

BIRABEN, J.N., Alimentation et démographie historique, Démograpbie bistorique, p.23-40, 1976.

BIRKET-SMITH, K., The origin of maize cultivation. Kobenhavn, Munksgaard, 1943.

BLANC, Nicole \& NERCESSIAN,Anne, La cuisine romaine antique. Grenoble, Glénat/Faton, 1992.

BLOND, G. et G., Histoire pittoresque de notre alimentation. Paris, Fayard, 1960.

BOGUCKI, Peter,The spread of early farming in Europe,American Scientist, v.4. n.3:p.242-53, 1996.

BOIRE (numéro spécial), Terrains. Carnets du patrimoine ethnologique, n. 13, 1989.

BOIS, D., Les plantes alimentaires chez tous les peuples et à travers les âges. Paris, Lechevalier, 1927-1928, 2 vols.

BOLENS, Lucie, La cuisine andalouse. Un art de vivre, XIè.-XIIIè.siècle. Paris, Albin Michel, 1990

BONASSIE, Pierre, Consommation d'aliments immondes et cannibalisme de survie dans l'Occident du Haut Moyen Âge, Annales ESC, n.5: p.1035-1056, 1989. 
BONIN, Ana Maria A.\& ROLIM, Maria do Carmo, Hábitos alimentares: tradição e inovação, Boletim de Antropologia, UFPR/Dept. de Antropologia, v.4, n.1: p.75-90, junho 1991.

BONNET, J.-C., Le réseau culinaire dans l'Encyclopédie, Annales ESC, n.31:p.891-914, 1976.

BOSERUP, Ester, The conditions of agricultural growth. Chicago, Aldine, 1965.

BOURDEAU, L., Histoire de l'alimentation. Paris, 1894.

BOURGAUX,A, Quatre siècles d'bistoire du cacao et du chocolat. Bruxelles, Office international du cacao et du chocolat, 1935.

BRAA, Dean M., The great potato famine and the transfformation of Irish peasant society, Science ESociety, v.61, n.2: p.193-215, Summer 1997.

BRADY, Ivan, Cannibalism. In: LEVINSON, David \& EMBER, Melvin, eds., Encyclopedia of Cultural Anthropology. New York, Holt, v.1, 1996: p. 163-7.

BRANDÃO, Darwin, A cozinba brasileira. Salvador, Livraria Universitária, 1948.

BRANS, Jo, Feast bere awbile. Adventures in american eating. Ticknor \& Fiels, 1993.

BRAUDEL, Fernand, Civilização material e capitalismo. Lisboa, Cosmos, 1970.

BRAUDEL, Fernand, Alimentation et catégories de l'histoire, Annales E.S.C., v.16. n.4: p.623-8, juillet-août 1961 .

BRAUDEL, Fernand, Vie matérielle et comportements biologiques, Annales E.S.C., v.16, n.3: p.5459, Mai-Juin 1961.

BRENNAN, T. Public drinking and popular culture in 18tb-century: Princeton, Princeton University Press, 1991.

BRESCIANI, Edda, Nourritures et boissons de l'Egypte ancienne. In: FLANDRIN \& MONTANARI, eds., Histoire de l'alimentation. Paris, Fayard, 1996: p.61-72.

BRIfFAUlT. E, Paris à table. Paris, J. Hetzel, 1846.

BRIGNOLI, Héctor Pérez \& SAMPER, Mario, eds. Tierra, café y sociedad. San José, FLACSO, 1994.

BRILlat-SAVARIN, J.A., Physiologie du Goût, Paris, Savoi-Hermann, 1975 (ed.or.1825).

BROCHADO, José Proenza, Alimentação na floresta tropical. Porto Alegre, IFCH-UFRGS, 1977.

BROTHWELL, Don \& BROTHWELL, Patricia, Food in antiquity. A survey of diet of early peoples. Baltimore, The Johns Hopkins University Press, 1998.

BROWN, L.K. \& K.MUSSELL, eds., Ethnic and regional foodways in the United States. Knoxville, University of Tennessee Press, 1984. 
BRUEGEL, M., 'Un sacrifice de plus à demander au soldat': l'armée et l'introduction de la boite de conserve dans l'alimentation française, 1872-1920, Revue Historique, n.596: p.59-84, oct./déc. 1995.

BRUN, Thierry A., Des famines climatiques aux famines économiques, Tiers Monde, n.63, t.XVI, juillet-septembre 1985.

BRYANT, Carol; COURTNEY,Anita; MARKESBERY, Barbara A. \& DEWAIT, Kathleen M., The cultural feast. An introduction to food and society. New York, West Publishing, 1985.

BURGUIÈRE, André, Alimentation. In: Burguière, A., org., Dictionnaire des sciences historiques. Paris, PUF, 1986: p. 7-11.

BURNETT, J., Plenty and want. A social history of food in England from 1815 to the present day. London, 3rd.ed., 1989 (1a.ed. 1966).

BUTEL, P., Histoire du thé. Paris, 1989.

BYNUM, Caroline W., Holy feast and boly fast. The religious significance of food to medieval women. Berkeley, University of California Press, 1987.

CALVO, I., Migration et alimentation, Information sur les Sciences Sociales, v.21, n.3: p. 383-446, 1982.

CAMARGO, Rogério de \& TELLES JR., Adalberto de Queiroz, O café no Brasil. Sua aclimatação e industrialização. Rio, Serviço de Informação Agrícola, 1953, 2 vols.

CAMPORESI, Piero, Le pain sauvage. L'imaginaire de la faim de la Renaissance au XVIIIe siècle. Paris, Le Chemin Vert, 1981.

CAMPORESI, Piero, Hedonismo e exotismo. A arte de viver na época das Luzes. São Paulo, Edunesp, 1996.

CANNABRAVA,Alice, O açúcar nas Antilhas (1697-1755). São Paulo, IPE/USP,1981 (1a.ed. 1946)

CAPIAN, Pat. Feasts, fasts, famine. Food for thought. Oxford, Berg, 1994.

CARNEIRO, Henrique, Filtros mezinhas e triacas. As drogas no mundo moderno. São Paulo, Xamã,1994

CARNEY, George O., ed., Fast food, stock cars, and rock'n-roll. Their place in American popular culture. Lanham, Rowman \& Littlefield, 1995.

CASCUDO, Luís da Câmara, $A$ cosinba africana no Brasil. Luanda, Museu de Angola, 1964.

CASCUDO, Luís da.Câmara, ed., Antologia da alimentação no Brasil. Rio de Janeiro, LTC, 1977.

CASCUDO, Luís da Câmara, História da alimentação no Brasil. Pesquisa e notas. Belo Horizonte, Itatiaia / São Paulo, EDUSP, 2a.ed.,1983, 2 vols. (1a.ed., 1967-8). CASCUDO, Luís da Câmara, 
Prelúdio da cacbaça. Etnologia, história e sociologia da aguardente no Brasil. Rio de Janeiro, Instituto do Açúcar e do Álcool, 1986.

CASTRO, Josué de, Os problemas da alimentação no Brasil. São Paulo, Ed. Nacional, 1933.

CASTRO, Josué de, Alimentação e raça. Rio de Janeiro, Civilização Brasileira, 1935.

CASTRO, Josué de, A alimentação brasileira à luz da Geografia Humana. Rio de Janeiro, Livraria do Globo, 1937

CASTRO, Josué de, Fisiologia dos tabus. Com um apêndice contendo vários tabus alimentares brasileiros. São Paulo, Melhoramentos, 1938.

CASTRO, Josué de,A fome mundial e o neo-malthusianismo, América Indígena, n. 4, vol. 9, out. 1949.

CASTRO, Josué de, Geopolítica da fome. Ensaios sobre os problemas de alimentação e de população do mundo. Rio de Janeiro, C.E.B., 1951.

CASTRO, Josué de, Geografia da fome. O dilema brasileiro:pão ou aço. Rio de Janeiro, Casa do Estudante, 1953 (1a. ed., 1946).

CASTRO, Josué de, O livro negro da fome. São Paulo, Brasiliense, 2a.ed. 1966.

CASTRO, Josué de, Fome, um tema proibido: últimos escritos de Josué de Castro (org.Anna Maria de Castro). Petrópolis, Vozes, 2a.ed. 1984..

CAUVIN, J., Naissance des divinités, naissance de l'agriculture. La révolution des symboles au néolithique. Paris, CNRS, 1994.

CEPEDE, M. \& LENGELLE, M., Léconomie de l'alimentation. Paris, PUF, 1954.

CERECEDA, Dantin, La alimentación española. Madrid, 1934.

CHALONER, William Henry, Food and drink in British history. A bibliographical guide, Amateur Historian, London, n.4: p.15-19, 1960.

CHALOUB, Sidney, Trabalbo, lar e botequim. São Paulo, Brasiliense, 1986.

CHANG, Kwang-chih, ed., Food in Cbinese culture. Anthropological and historical perspectives. New Haven, Yale University Press, 1977.

CHARBONNIER, P., La consomation des seigneurs auvergnats du XVe au XVIIIe siècle, Annales ESC, v.30, n.2-3: p. 465-77, mars-juin 1975.

CHARLES, Nicky \& KERR, Maion, Food for feminist thought, Sociological Review; v.34, n.3: p.53772 , aug. 1986.

CHARLES, Nicky \& KERR, Marion, Women, food and families. Manchester, Manchester University Press, 1988. 
CHARSLEY, Simon R., Wedding cakes and cultural bistory. London, Routledge, 1992.

CHAUDIEU, G., De la gigue d'ours au hamburger Paris, La Corpo, 1971.

CHAUNU, Pierre, A História como ciência social. A duração, o espaço e o homem na época moderna, Rio de Janeiro, Zahar, 1976.

CHEKE, Valerie, The story of cheese making in Britain. London, 1959.

CHONCHOL, Jacques, O desafio alimentar A fome no mundo. São Paulo, Marco Zero, 1989.

CHRISPEEIS, M.J.; e SADAVA, D., Plants, food and people. San Francisco, W.H. Freeman, 1977.

CHRISTO, Maria Stella Libânio de, Fogão de lenba. 300 anos da cozinha mineira. Petrópolis, Vozes, 7 a.ed., 1986.

5000 ans de gastronomie (numéro spécial), L'Histoire, Paris, n. 86, 1986.

CLUTTON-BROCK, Juliet, ed., The walking larder Patterns of domestication, pastoralism, and predation. London, Unwin Hyman, 1989.

COE, Sophie D., America's first cuisine. Austin, Univesity of Texas Press, 1994.

COE, Sophic D.\& COE, Michael D., The true bistory of chocolate. London, Thames and Hudson, 1996.

COHEN, M. N., The food crisis in prebistory. New Haven, Yale University Press, 1977.

COHEN, M.N., La crisis alimentaria de la prébistoria: la superpoblacion y los origenes de la agricultura. Madrid, Alianza, 1984.

COOK, Ian \& Phillip CRANG, The world on a plate. Culinary culture, displacement and geographical knowledges, Journal of Material Culture, v.1, n.1: p.131-153, 1996.

COOPER, Charles, The English table in bistory and literature. London, 1929.

CONNEL, K. H., The potato in Ireland, Past and present, v.23: p. 57-71, 1962.

CORLEY, T. E. B., Quaker enterprise in biscuits. Huntley and Palmers of Reading, 1822-1972. London, 1972.

COSTA, Dante, O sensualismo alimentar em Portugal e no Brasil. Rio de Janeiro, CFC, 1952.

COUNIHAN, Carole, Food habits and social relations in modernizing Sardinia, Antbropological Quarterly n.57: p.47-59, 1957.

COUNIHAN, Carole \& VAN ESTERIK, Penny, eds., Food and culture. A reader. London, Routledge, 1997. 
COURIE, P., L'alimentation au XVIIe siècle: les marchés de pourvoirie, Annales ESC, v.19: p. 467$479,1964$.

CLERGEAUD, C. \& L., Mystères et secrets du soja. Paris, La Vie claire, C.E.VI.C., Paris, 1964.

CRANE, E., Honey: London, Heinemann, 1975 e 1976.

CRAPLET, C. \& J., Dictionnaire des aliments et de la nutrition. Paris, 1979.

CURTIN, Deane W. \& HELDKE, Lisa M., eds. Cooking, eating, thinking. Transformative philosophies of foood. Bloomington, Indiana University Press, 1992.

DALBY,Andrew, Siren feasts. A history of food and gastronomy in Greece. London, Routledge, 1995.

DALBY, Andrew \& GRAINGER, Sally, The classical cookbook. London, British Museum Press, 1996.

DANDO,W.A., The Geography of famine. London, Arnold, 1980.

DAUPHIN, C. \& PÉZERAT, P., Les consommations populaires dans la seconde moitié du XIXe siècle à travers les monographies de l'École de Le Play, Annales ESC, v.30, n.2-3: p.537-552, mars-juin 1975.

DAVID, Louis \& GASPARD-DAVID, Élise, Le café à la conquête de l'Europe, Revue du Palais de la Découverte, v.232, n.229: p.13-20, juin 1995.

DEERR, Noel , The History of sugar London, Chapman \& Hall, 1949-50, 2 vols..

DE BENEDETTIS, Renata, Ministero dell'interno e intendenze: la statistica murattiana in materia di alimentazione. In: Gli archivi per la storia dell'alimentazione. Atti del Convegno PotenzaMatera, 5-8 settembre 1988. Roma, Ministero per i Beni Culturali e Ambientali / Ufficio Centrale per i Beni Archivistici, 1995: p. 470-508.

DE LAET, Sigfried Jan, ed., History of Humanity. Vol.I: Prehistory and the beginnings of civilization. London, Routledge, 1994.

DE NIRO, M.; ISAAC, G. \&WALKER,A., Diet and human evolution. Oxnard, Gordon Conference, 1984.

DEL PRIORE, Mary, ed., História das mulberes no Brasil. São Paulo, Edunesp/Contexto, 1997.

DENTON, Derek, The bunger for salt. An anthropological, physiological and medical analysis. München, Springer-Verlag, 1982.

DÉSERT, G., Viande et poisson dans l'alimentation des Français au milieu du XIXe siècle, Annales ESC, v.30, n.2-3: p. 519-36, mars-juin 1975.

DESPORTES, F, Le pain au Moyen Age. Paris, 1987.

DETIENNE, Marcel \& VERNANT, J.-P., La cuisine du sacrifice en pays grec. Paris, Gallimard, 1979. 
DION, R., Histoire de la vigne et du vin en France, des origines au XIXe siècle,.Paris, R. Dion, 1959.

DISNEY,A.R, A decadência do Império da pimenta. Lisboa, Editorial 70, 1981.

DODD, George, The food of London. London, Longman, Brown, Green, and Longmans, 1856.

DORVEAUX, P., Le sucre au Moyen Age. Paris, Honoré Champion, 1917.

DOUGLAS, Mary, Purity and Danger: London, Routledge \& Kegan Paul, 1966.

DOUGLAS, Mary, Deciphering a meal, Daedalus, n.101: p.61-91, 1972.

DOUGLAS, Mary, Taking the biscuit. The structure of British meals, The New Society, v. 30: p.7447, 1974 .

DOUGLAS, Mary, Food studied as a system of communication. Food as an art form. The food art exhibition. Food is not feed. In: In the active voice. London, Routledge \& Kegan Paul, 1982: p. $82-102$

DOUGLAS, Mary, Standard social uses of food In: Food in the social order Studies of food and festivities in three american communities. New York, Russel Sage Foundation, 1984.

DOUGLAS, Mary, Thought styles. Critical essays on good taste. London, Sage, 1996.

DOUGLAS, Mary, ed., Constructive drinking. Perspectives on drink from Anthropology. Cambridge, Cambridge University Press, 1991.

DRIVER, Christopher, The British at table. London, 1983.

DRUMOND, J. C. \& WILBRAHAM A., The Englishman's food. A history of five centuries of English diet. London, 2a.ed., 1957.

DUBISCH, Jill, You are what you eat: religious aspects of the health and food movement. In: LEHMAN, A. \& MYERS, J., Magic, witchcraft and religion. 1989.

DUPIN, H., L'alimentation des Français. Paris, E.S.F, 1978.

ECKSTEIN, Fritz, GRIMM, Jacob und Wilhelm \& WHÄLER, Martin, Die deutsche Volksnahrung. In: Pessler, Wilhelm, ed., Handbuch der deutscben Volkskunde. Potsdam, v.3, 1938: p. 140-155.

EIRAS ROEL, A.\& ENRIQUEZ MORALES, M. J., La consommation alimentaire d'Ancien Régime: les collèges de Saint-Jacques-de-Compostelle, Annales ESC, v.30, n.2-3: p. 454́-64, mars-juin 1975.

ELIAS, Norbert, O processo civilizador. Rio de Janeiro, Zahar, 1990.

ELLEN, Roy, Modes of subsistence: hunting and gathering to agriculture and pastoralism. In: INGOLD, Tim, ed., Companion Encyclopedia of Anthropology. Humanity, culture and social life. London, Routledge, 1994: 197-226. 
ELLIS, Ellen D., An introduction to the bistory of sugar as a commodity. Philadelphia, J.C. Winsten, 1905.

ELLIS, Myriam, O café. Literatura e História. São Paulo, Melhoramentos/EDUSP, 1977.

ELY, Roland T., Cuando reinava su majestad el azúcar. Estudio histórico-sociológico de una tragedia latinoamericana: el monocultivo en Cuba, origen y evolución del proceso. Buenos Aires, 1963.

ESCUDERO, Pedro, Alimentación. Buenos Aires, Flores \& Maño, 1934.

ESPINOSA, Alfredo Ramos, La alimentación en México. México, 1939.

FACCIOLI, Emilio, Larte della cucina in Italia. Torino, Einaudi, 1992.

FALK, P.,Homo culinarius. Towards a historical anthropology of taste, Social Science Information, v.3, n.4: p. $757-90,1991$.

FARB, P. \& ARMELAGOS, G, Antbropologie des coutumes alimentaires. Paris, Dénoël, 1980.

FARELL, M.H. \& SILVA, N.P.da, Comida de santo. Rio de Janeiro, Pallas, 1997.

FARIA, Oswaldo Lamartine de, Conservação de alimentos nos sertões do Seridó. Recife, Instituto Joaquim Nabuco de Pesquisas Sociais, 1965.

FEBVRE, L., Vignes, vins et vignerons, Annales ESC, v. 2: p.281-287, 1947.

FEELEYHARNIK, Gillian, The Lord's table. The meaning of food in early Judaism and Christianity. Washington, Smithsonian Institution Press, 1994.

FENTON,A. \& KISBON, E., Food in change. Eating habits from the Midlle Ages to the present day. Edinburgh, Jonh Donald Publishers, 1986.

FERLINI, Vera Lúcia do Amaral, Terra, trabalbo e poder. São Paulo, Brasiliense, 1988.

FERRÃO, José E. Mendes, A aventura das plantas e os descobrimentos portugueses. Lisboa, Instituto de Investigação Científica Tropical/Comissão Nacional para as comemorações dos Descobrimentos Portugueses, 1992.

FERRONHA, António Luís A. Ferronha, coord. A viagem das plantas. Lisboa, Grupo de Trabalho do Ministério da Educação para as Comemorações dos Descobrimentos Portugueses, 1992.

FIDDES, Nick, Meat. A natural symbol. London, Routledge, 1991.

FIELD, R., Irons in the fire. A history of cooking equipment.London, Crowood Press, 1984.

FIELDHOUSE, Paul, Food and nutrition: customs and culture, London, Croom Helm, 1986. 
FIGUEIREDO, Luciano R. de Almeida \& MAGALDI, Ana Maria B. de Mello, Quitandas e quitutes. Um estudo sobre rebeldia e transgressões femininas numa sociedade colonial, Cadernos de Pesquisa / Fundação Carlos Chagas, v.54: p. 177-86, ago.1985.

FINE, Gary Alan, Kitcbens. The culture of restaurant work, Berkeley. University of California Press, 1996.

FINE, Ben; HEASMAN, Michael \& WRIGIT, Judith, eds., Consumption in the age of affluence. The world of food. London, Routledge, 1995.

FINKELSTEIN, Joanne, Dining out. A sociology of modern manners. Oxford, Polity Press, 1989.

FISCHLER, Claude, Gastro-nomie et gastro-anomie. Sagesse du corps et crise bioculturelle de l'alimentation moderne, Communications, n.31, p.189-210, 1979.

FISCHLER, Claude, Food habits, social change and the nature/culture dilemma, Social Science Information, v. 19, n.6: p.937-53, 1980.

FISCHLER, Claude, Alimentation, cuisine et identité. L'identification des aliments et l'identité du mangeur, Recherches et travaux de l'Institut d'Ethnologie, v.6: p. 171-92, 1985.

FISCHLER, Claude, Attitudes towards sugar and sweetness in historical and social perspective. In: DOBBING, J., ed., Sweetness. Berlin, Springer Verlag, 1987: p.83-98.

FISCHLER, Claude, Food, self and identity, Social Science Information, v.27: p.275-292, 1988.

FISCHLER, Claude, L’bomnivore. Le goût, la cuisine et le corps. Paris, Éditions Odile Jacob, 1990.

FITCHEN, J.M. Hunger, malnutrition and poverty in the contemporary United States. Some observations on their social and cultural context, Food E Foodways, v.2: p. 309-33, 1988.

FITZGERALD,T.K., ed., Nutrition and Antbropology in action. Amsterdam, Van Gorcum, 1977.

FLANDRIN, Jean-Louis, Le goût et la nécessité: sur l'usage des graisses dans les cuisines d'Europe occidentale (XIVe-XVIle siècles), Annales ESC, n. 38: p. 369-401, 1983.

FLANDRIN, Jean-Louis, La diversité des goûts et des pratiques alimentaires en Europe du XVIe au XVIIle siècle, Revue d'Histoire Moderne et Contemporaine, t.XXX: p.63-83, janvier-mars $1983 \mathrm{~b}$.

FLANDRIN, Jean-Louis, La distinction par le goût. In: ARIÈS, Philippe \& DUBY, Georges, eds., Histoire de la vie privée. Paris, 1986, vol.3: p.267-309.

FLANDRIN, Jean-Louis, Chronique de platine. Pour une gastronomie historique. Paris, O.Jacob, 1992.

FLANDRIN, Jean-Louis, Mealtimes in France before the nineteenth century", Food E Foodways, v.6, n. 3-4: p. 261-282,1996.

FLANDRIN, Jean-Louis, Les temps modernes. In: FLANDRIN, J.-L. \& MONTANARI, M., eds., Histoire de l'alimentation. Paris, Fayard, 1996b: p. 549-75. 
FLANDRIN, Jean-Louis, Les XIXe. et XXe. siècles. In: FLANDRIN, J.-L.

\& MONTANARI, M., eds., Histoire de l'alimentation. Paris, Fayard, 1996c.: p. 717-723.

FLANDRIN, Jean-Louis \& MONTANARI, Massimo, eds. Histoire de l'alimentation, Paris, Fayard, 1996.

FLANDRIN, Jean-Louis; HYMAN, P. \& HYMAN, M., Le cuisinier français. Paris, 1983.

FOOD IN MOTION. The migration of foodstuffs and cookery techniques. Proceedings of the Oxford Symposium. London, Prospect Books, vol.1, 1983.

FORREST, D. M., Tea for the British. A social and economic history of a famous trade London, Chatto \& Windus, 1967.

FORSTER, E. \& FOSTER, R., eds., European diet from pre-industrial to modern times. New York, Harper \& Row, 1975.

FORSTER, Robert \& RANUM, Orest, eds., Food and drink in bistory. Selection of articles of Annales ESC. Baltimore, Johns Hopkins University Press, 1979.

FOSTER, Nelson \& CORDELL, Linda S., eds., Chilies to cbocolate. Food the Americas gave the world. Tucson, University of Arizona Press, 1992.

FOURIER, Charles, El Nuevo Mundo amoroso, organizado por Simone Debout-Oleszkiewicz, México, Siglo XXI, 1972.

FOURNIER, Dominique \& D'ONOFRIO, Salvatore, eds., Le ferment divin. Paris, Eds. de la Maison des Sciences de l'Homme, 1991

FRANKLIN, T. B., A bistory of agriculture, London, G. Bell, 1948.

FREEDMAN, R.L., Human food uses. A cross cultural comprehensive bibliography. Westport, Greenwood Press, 1981.

FREEDMAN, R.L., Himan food uses. A cross cultural comprehensive bibliography: Supplement. Westport, Greenwood Press, 1983.

FREYRE, Gilberto, Açúcar São Paulo, Companhia das Letras, 3a.ed., 1997 (1a.ed. 1939).

FREYRE, Gilberto, Nordeste. Aspectos da influência da cana sobre a vida e a paisagem do Nordeste do Brasil. Rio de Janeiro, José Olympio, 1937.

FRIEIRO, Eduardo, Feijão, angu e couve. Ensaio sobre a comida dos mineiros, Belo Horizonte, Centro de Estudos Mineiros, 1966.

FRIJHOFF, W.\& JULIA, D., L'alimentation des pensionnaires à la fin de l'Ancien Régime (Auch, Beaumont-en-Auge, Molsheim et Toulouse), Annales ESC, Paris, v.30, ns. 2-3, pp. 491-504, marsjuin 1975. 491-504. 
GANDHI, M., Diet and diet reform. Ahmedabad, Navijan, 1949.

GALAVARIS, George, Bread and liturgy. The symbolism of early Christian and Byzantine bread stamps. Madison, 1970.

GALVÃO, Eduardo, Elementos básicos da horticultura de subsistência indígena. In: Encontros de sociedades. Rio de Janeiro, Paz e Terra, 1979: p. 229-256.

GAMA, Ruy, Engenbo e tecnologia. São Paulo, Livraria Duas Cidades, 1983.

GARCIA, Rosa, Representações sociais da comida no meio urbano. Dissertação de Mestrado em Psicologia. São Paulo, Instituto de Psicologia / USP, 1995.

GARINE, Igor de, Les modes alimentaires. Histoire de l'alimentation et des manières de table. In: POIRIER, Jean, dir., Histoire des moeurs. I: Les coordonnées de l'homme et la culture matérielle. Paris, Gallimard, 1990: p.1447-1630. (Encyclopédie de la Pléiade).

GARINE, Igor de, The diet and nutrition of human populations. In: Tim Ingold, ed., Companion Encyclopedia of Antbropology. Humanity, culture and social life. London, Routledge, 1994: p. 226-264.

GARNSEY, P.D.A., Famine and food supply in the Graeco-Roman world. Cambridge, Cambridge University Press, 1988.

GARRIER, G., Histoire sociale et culturelle du vin. Paris, 1996.

GÉOGRAPHIE DE L'ALIMENTATION, Annales de Géographie (numéro spécial), n.493, 1980.

GEREMEK, Bronislao, Os filbos de Caim. Vagabundos e miseráveis na literatura européia 14001700. São Paulo, Companhia das Letras, 1995.

GIBLIN, James Cross, From hand to mouth. Or, how we invented knives, forks, spoons and chopsticks \& table manners to go with them. New York, Crowell, 1987.

GIOBELLINA-BRUMANA, F, La comida de santo en el candomblé, América Indígena, v.48, n.3: p.605-17, 1988.

GIRARD, A., La cuisinière bourgeoise. Livres culinaires, cuisine et société au 17e. et 18e. siècles, Revue d'bistoire moderne et contemporaine. Paris: p. 437-523, 1977.

GLI ARCHIVI per la storia dell'alimentazione. Atti del Convegno Potenza-Matera, 5-8 settembre 1988. Roma, Ministero per I Beni Culturali e Ambientali / Ufficio Centrale per I Beni Archivistici, 1995.

GOFTON, Leslie, Food fears and time famines: some social aspects of choosing and using food, Britisb nutrition Foundation Bulletin, n.15: p. 79-95, 1990.

GOLDEN, Lilly, ed., A Literary feast. An anthology, Athlantic Monthly, 1993. 
GOODY, Jack, Cooking, cuisine and class. A study in comparative Sociology, Cambridge, Cambridge University Press, 1982.

GOTTSCHALK,A., Histoire de l'alimentation et de la gastronomie depuis la prébistoire jusqu'à nos jours. Paris, Ed. Hippocrate, 1948, 2 vs.

GOWERS, E., The loaded table. Representations of food in Roman literature. Oxford, Clarendon Press, 1993.

GRIGNON, Claude, Alimentation et stratification sociale, Cabiers de nutrition et de diététique, v. 16, n. 4: p.207-17, 1981

GRIGNON, Claude, Les enquêtes sur la consommation et la sociologie des goûts, Revue économique, v.1: p.15-32, 1988.

GRIGNON, Claude \& GRIGNON, Christiane, Styles d'alimentation et goûts populaires, Revue française de sociologie, v.21, n.4: p.531-69, 1980.

GRIGNON, Claude \& GRIGNON, Christiane, Alimentation et stratification sociale, Cabiers de nutrition et de diététique, v.16, n.4: p.207-17, 1986.

GRIMM, Veronika, From feasting to fasting. The evolution of sin. London, Routledge, 1996.

GRONOW, Jukka, The Sociology of taste. London, Routledge, 1997.

GROTANELLI, Cristiano, Uccidere, donare, mangiare: problematiche attuali del sacrificio antico. In: GROTTANELLI, G. \& PARISE, N.F., eds., Sacrificio e società nel mondo antico. Bari, Laterza, 1988: p. 3-41.

GROVER, Kathryn, ed., Dining in America, 1850-190. Amherst, University of Massachusetts Press, 1987.

GUEVARA, Arturo, El poliedro de la nutrición: aspectos económico y social del problema de la alimentación en Venezuela. Caracas, Grafolit, 1946.

HALPERN PEREIRA, M., Niveaux de consommation, niveaux de vie au Portugal (1874-1922), Annales ESC, v.30, n.2-3: p.610-31, mars-juin 1975.

HANN, C. M., Tea and the domestication of the Turkish state. Cambridge, Eothen Press, 1990.

HARDWICH, Nikita, Histoire du chocolat. Paris, Desjonquères, 1992.

HARRIS, David R., ed. The origins and spread of agriculture and pastoralism in Eurasia. Washington, Smithsonian Institution Press, 1996.

HARRIS, David R.\& HILLMAN, G.C., eds., Foraging and farming. The evolution of plant exploitation. London, Routledge, 1989. 
HARRIS, Marvin, Cannibals and kings. London, Fontana, 1978.

HARRIS, Marvin, Bueno para comer. Enigmas de la alimentación y cultura. Madrid, Alianza, 1989.

HARRIS, Marvin \& ROSS, Eric B., eds., Food and evolution. Toward a theory of human food habits. Philadelphia, Temple University Press, 1987.

HARRISON, Brian, Drink and sobriety in England 1815-1872: a critical bibliography, International Review of Social History, n.12: p.204-76, 1967

HARRISON, Brian, Drink and the Victorians. Pittsburgh, University of Pittsburgh Press, 1971. .

HAUDRICOURT, A.-G. \& HÉDIN, L., L'bomme et les plantes cultivées. Paris, Gallimard, 1943.

HELDKE, Lisa M.,, Food politics, political food. In: CURTIN, D. \& HELDKE, L., eds., Cooking, eating, thinking.Transformative philosophies of food. Bloomington, Indiana University Press, 1992. EL \&

HÉMARDINQUER, J.J., et alii., Pour une bistoire de l'alimentation. Paris, A. Colin, 1970 (Cahier des Annales, 28).

HÉMARDINQUER, J.J., Faut-il démythifier le porc familial de l'Ancien Régime ?, Annales ESC, Paris, n. 25: pp.1745-1766, 1970.

HÉMARDINQUER, J.J., À propos de l'alimentation des marins, Annales ESC v. 18: p. 1141-1150, 1963.

-HÉMARDINQUER, J.J., Essai de cartes de graisses de cuisine en France. Annales ESC v.16: p.747$771,1961$.

HERPIN, N. Le repas comme institution: compte-rendu d'une enquête exploratoire, Revue Française de Sociologie, v. 29: p.503-21, juillet-sept. 1988.

HEYNE, Moriz, Das deutsche Nabrungswesen von den ältesten Zeiten bis zum Ende des 16.Jabrbunderts. Leipzig, 1901.

HINZ, Evelyn, ed., Diet and discourse. Eating, drinking and literature, Mosaic (Special Issue), Winnipeg, University of Manitoba, 1991.

HOBUSCH, Histoire de la chasse. Paris, Pygmalion, 1984.

HOCQUET, Jean-Claude, Le sel et le pouvoir Paris, Albin Michel, 1985.

HOLANDA, Sérgio Buarque de, Caminbos e fonteiras. São Paulo, Companhia das Letras, 3a. Ed., 1994.

HOUAISS, Antonio, A cerveja e seus mistérios. Rio de Janeiro, Salamandra, 1986.

HUGILL, Antony, Sugar and all that. A history of taste and style. London, 1978 
IOSSIFIEDES, A. Marina \& GEFOU-MADLANOU, eds. Alcobol, gender and culture. London, Routledge, 1992.

JACOB, H.-E., Six thousand years of bread: its holy and unholy history. Garden City, Doubleday, 1944.

JACOB, H.-E., L'épopée du café. Paris, Eds. du Seuil, 1953.

JEROME, N.W., Diet and acculturation: the case of Black-American in-migrants. In: JEROME, N.W; Kandel, R. \& PELTO, G., eds., Nutritional Antbropology: contemporay approaches to diet and culture. New York, Redgrave, 1980.

JOHNSSON, M., Food and culture among Bolivian Aymara. Symbolic expressions of social relations, Uppsala. Acta Universitatis Upsaliensis, 1986.

JOHNSTON, F.E., Nutritional Antbropology. New York, Allan R.Liss, 1987.

JOHNSTON, James P., A bundred years of eating. Food, drink and the daily diet in Britain since the late nineteenth century. London, 1977.

JULIÃO, Francisco, Cachaça. Recife, Editora Nordeste, 1921.

KAPLAN, Steve Laurence, The times of bread in eighteenth-century, Food E Foodways, v.. 6, n.3-4: p. 283-306, 1996.

KAPLAN, Steve Laurence, Breadways, Food E Foodways, v. 7, n.1: p.1-44, 1997.

KATES, Robert \& MILLMAN, Sara, On ending hunger: the lesson of History.

In: NEWMAN, L.F., gen.ed., Hunger in History. Food shortage, poverty, and deprivation. Oxford, Blackwell, 1990: p. 389-410.

KHARE, R.S.\& RAO, M.S.A., eds., Food, society, and culture. Aspects in South Asia food systems. Durham, Carolina Academic Press, 1986.

KING, Frank A., Beer has a bistory. London, 1947.

KNAGGS, Menry V., The trutb about sugar. London, 1913.

KRAUT,A., Etbnic foodways. The significance of food in the designation of cultural boundaries between immigrant groups in the US, 1840-1921, Journal of American Culture, v.2: p.409$20,1979$.

KROPOTKIN, Piotr, The conquest of bread. London, Allen Lane, 1972 (ed.or. 1892).

KUPER, Jessica, ed., La cocina de los antropólogos. Barcelona,Tusquets, 1984.

LaFOLLETE, Robert, The sugar trust, an amazing conspiracy. Washington, 1925. 
LEACH, E.,Anthropological aspects of language: animal categories and verbal abuse. In: P. Maranda, ed.. Mythology, Harmondsworth, Penguin, 1972, p.56-66.

LEACH, Helen, The terminology of agricultual origins and food production systems - a horticultural perspective, Antiquity, 71: 135-48, 1997.

LEAF, Murray J., Agriculture and farming system. In: LEVINSON, David \& EMBER, Melvin, eds., Encyclopedia of Cultural Antbropology. New York, Holt, 1996, v.1: p.31-38.

LECLANT, J., Le café et les cafés à Paris (1644-1693), Annales ESC v.6: p. 1-14, 1951.

LEIDNER, Robin, Fast food, fast talk. Service work and the routinization of everyday life, University of California Press., 1993.

LEGRAND D'AUSSY, Pierre J.B., Histoire de la vie privée des français. Paris, 1782.

LEMERY, Louis, Traité des aliments, où l'on trouve la différence, et le choix, qu'on en doit faire; les bons, et les mauvais effets, qu'ils peuvent produire; leurs principes; les circonstances où ils conviennent. Paris, Chez Durand, 3è.éd., 1755.

LEMOS, Carlos Alberto Cerqueira, Cozinhas etc. Um estudo sobre as zonas de serviço da casa paulista. São Paulo, Perspectiva, 1976.

LENTZ, Carola, Changing food habits: an introduction, Food \& Foodways, v.5, n.1: p/1-13, 1991.

LEVENSTEIN, Harvey A., Revolution at the table. The transformation of the American diet. Oxford, Oxford University Press, 1988.

LEVENSTEIN, Harvey A.. Paradox of plenty. A Social History of eating in modern America. Oxford, Oxford University Press, 1993.

LE VIN (numéro spécial), Dix-buitième siècle, n.29, 1997.

LÉVI-STRAUSS, Claude, Le cru et le cuit (Mythologiques I). Paris, Plon, 1964.

LÉVI-STRAUSS, Claude, Du miel aux cendres (Mythologiques II). Paris, Plon, 1966.

LÉVI-STRAUSS, Claude, Lorigine des manières de table (Mythologiques IID). Paris, Plon, 1968.

LÉVI-STRAUSS, Claude, L'bomme nu (Mythologiques IV). Paris, Plon, 1968a.

LÉVI-STRAUSS, Claude, Le triangle culinaire, L'Arc. Paris, v.26: p. 19-29, 1968 b.

LE ROY LADURIE, Emmanuel, Montaillou, Harmondsworth, Penguin, 1978. 
LIFSCHITZ, Javier, Significação e práticas alimentares, ECO. Publicação da Pós-graduação em Comunicação e Cultura / ECO-UFRJ, v.1, n.4: p. 129-151, 1993.

LIMA, Tania Andrade, Pratos e mais pratos: louças domésticas, divisões culturais e limites sociais no Rio de Janeiro, século XIX, Anais do Museu Paulista. História e Cultura Material, nova série, v.3, n.3: p.129-191, jan.-dez. 1995.

LINHARES, Maria Yedda, História do abastecimento, uma problemática em questão (15301917). Brasília, Ministério da Agicultura / BINAGRE, 1979.

LINHARES, Maria Yedda, Pecuária, alimentos e sistemas agrários no Brasil (séculos XVII e XVIII), Tempo, v.1, n.2; p. 132-150, 1996.

LINHARES, Maria Yedda \& SILVA, Francisco Carlos Teixeira da, História política do abastecimento. Brasília, Binagri, 2 vols., 1979.

LINHARES, Maria Yeda \& SILVA, Francisco Carlos Teixeira da, História da agricultura brasileira (combates e controvérsias). São Paulo, Brasiliense, 1981.

LINHARES, Temístocles, História econômica do mate. Rio de Janeiro, José Olympio, 1969.

LIPPMAN, Edmund Oskar von, História do açúcar: Rio de Janeiro, Editora do IAA, 1941-42, 2 vols.

LISANTI Fo., Luís, Sur la nourriture des 'paulistes' entre XVIIe et XIXe siècles. Annales, v. 17: p. 55240, 1962 (Bulletin n.10).

LISSARRAGUE, François, Un flot d'images. Une esthétique du banquet grec. Paris, Biro, 1987.

LIFSCHITZ, Javier, Significação e práticas alimentares, ECO. Publicação da Pós-graduação em Comunicação e Cultura / ECO-UFRJ, v.1, n.4: p. 129-151, 1993.

LISSARRAGUE, François \& PANTEL, Pauline Schmitt, Spartizione e comunità nei banchetti greci. In: GROTTANELLI, C. \& PARISE, N.F, eds., Sacrificio e società nel mondo antico. Bari, Laterza, 1988: p.211-230.

LIVI-BACCI, M., Popolazione e alimentazione. Saggio sulla storia demografica europea. Bologna, 1987.

LLAURIOUX, Bruno, Spices in the medieval diet: a new approach, Food \& Foodways, n. 1: p. 43$76,1985$.

LODY, Raul, Santo também come. Rio de Janeiro, Pallas, 2a.ed., 1998.

LOMBARDO, Mario, Pratiche di commensalità e forme di organizzazione sociale nel mondo greco. 'Symposion' e 'Sissitia'. In: LONGO \& SCARPI, eds., Homo edens. Milano, Diapress Documenti, 1989: p. 311-26.

LONGO, Oddone; e SCARPI, Paolo, eds., Homo edens. Regimi, mitti e pratiche dell'alimentazione nella civiltà del Mediterraneo, Milano, Diapress Documenti, 1989. 
LOPES, Renato Souza, A ciência de comer e de beber: Rio de Janciro, Editora A Noite, 1939.

LOVEDAY M. \& CHIBA, S., Partaking with the divine and symbolizing the societal: the semiotics of Japanese food and drink, Semiotics, V.56, ns.1-2: p.115-31, 1985.

LÖWE, Heinz-Dietrich, Teuerungsrevolten, Teuerungspolitik und Marktregulierung im 18.Jahrhundert in England, Frankreich und Deutschland, Saeculum, v.37, n.3-4: p. 291-312, 1986

LUCAS, Michael T., A la russe, à la pell-mell or à la practical? Ideology and compromise at the late 19th -century dinner table, Historical Archaeology, v.28, n.4: p.80-93, 1994.

LUPTON, Deborah, Food, memory and meaning. The symbolic and social nature of food events, Sociological Review, v.42, n.4: p. 665-685, 1994.

LUPTON, Deborah, Food, the body and the self. London, Sage, 1996

MACHEREL, Claude \& ZEEBROEK, Renaud, Une vie de pain. Faire, penser et dire: le pain en Europe. Bruxelles, Crédit Communal, 1994.

MACLEAN, Virginia, A sbort title catalogue of bousebold and cookery books, 1701-1800. London, 1981.

MADONES, G.\& COX, R., La alimentación en Cbile. Santiago, Consejo Nacional de Alimentación, 1942.

MAGALHÃES, Basílio de, O café na história, no folclore e nas belas-artes. São Paulo/Ed. Nacional; Brasília/ INL, 3a.ed.,1980 (1a.ed. 1936).

MAGALHÃES, Eduardo Fernandes de, Higiene alimentar Rio de Janeiro, Imprensa Nacional, 1908.

MALINOWSKI, B., Argonauts of the Western Pacific. London, Routledge \& Kegan Paul, 1922.

MANDERSON, Leonore, ed., Shared wealth and symbol: Food, culture and society in Occania and Southeast Asia. Cambridge, Cambridge University Press, 1986.

MARCONI, Marina de Andrade, Folcore do café. São Paulo, Conselho Esstadual de Cultura, 1976.

MARENCO, C., Manières de table, modèle des moeurs, XVIIe.-XXe siècle. Paris, 1992.

MARS, Gerald \& MARS, Valerie, eds., Food, culture and bistory. London, The London Food Seminar, v. I, 1993.

MATOSSIAN, Mary Kilbourne, Poisons of the past. Molds, epidemics and History. Yale, Yale University Press, 1989.

MAUÉS, Raimundo H. \& MAUÉS, Maria Angélica Motta, O modelo da 'reima'. Representações alimentares em uma comunidade amazônica, Anuário Antropológico, v.77: p.120-47, 1978 
MAUÉS, Maria Angélica Motta \& MAUÉS, Raymundo H., O folclore da alimentação. Tabus alimentares da Amazônia, Manaus, 1980.

MAURIZIO, Adam., Die Geschichte unserer Pflanzennabrung von den Urzeiten bis zur Gegenwart. Berlin, 1927. Tradução francesa: Histoire de l'alimentation végétale depuis la prébistoire jusqu’à nos jours, Paris, Payot, 1932.

MAURO, Frédéric, Histoire du café, Paris, Desjonquières, 1991.

MAYOLO R., Santiago E. Antúnez de, La nutrición en el antiguo Perú. Lima, Banco Central de Reserva del Peru, 1981.

MAZZINI, Innocenzo, Lalimentation et la médecine dans le monde antique. In: FLANDRIN, J.L. \& MONTANARI, M., eds. Histoire de l'alimentation. Paris, Fayard, 1996: p. $253-64$.

MCCANCE, Robert A. \& WIDDOWSON, Elsie, Breads, white and brown. Their place in thought and social history. Philadelphia, 1956.

McCOLLUM, Elmer Verner, History of nutrition. The sequence of ideas in nutritional investigation. Boston, Houghton Mifflin Co., 1957.

McGEE, Harold, On food and cooking. The science and lore of the kitchen. New York, Collier Books, 1988.

MCGOVERN, Patrick; FLEMING, Stuart \& KATZ, Solomon H., eds., The origins and ancient bistory of wine. Reading, Gordon \& Breach, 1994.

McINTOSH, Laine N., American food babits in bistorical perspective. Westport, 1995.

McKEOWN, Thomas, The rise of modern population. London, 1976.

McMilLAN, Della E., ed., Antbropology and food policy. Human dimensions of food policy in Africa and Latin America. Athens, University of Georgia Press, 1991.

MELLO,Antônio da Silva, A alimentação no Brasil. Rio de Janeiro,José Olympio, 1961 (1a.ed. 1946).

MELLO, Evaldo Cabral de, Otinda restaurada. Guerra e açúcar no Nordeste, 1630-1654. Rio de Janeiro / São Paulo, Forense Universitária / EDUSP, 1975.

MELLO, Jorge Saldanha Bandeira de, População, alimentação, saúde e segurança nacional. Rio de janeiro, Ed.VEG, 1996.

MELLO, José Antonio Gonçalves de, Tempo dos flamengos. Influência da ocupação holandesa na vida e na cultura do norte do Brasil. Recife, Ed.Massangana, 3a.ed., 1987.

MELO, Antonio da Silva, Alimentação, instinto e cultura. Perspectivas para uma vida mais feliz. Rio, José Olympio, 1943 (4a.ed., 2 vols., 1956). 
MELO, Antonio da Silva, A alimentação no Brasil. Rio, José Olympio, 1946 (2a.ed.aum.1961).

MENNELL, Stephen, All manners of food. Eating and taste in England and France from the Middle Ages to the present. Oxford, Basil Blackwell, 1985.

MENNELL, Stephen, On the civilizing of appetite, Theory, Culture and Society, v.4, n.3: p. 373-403, 1987.

MENNELL, Stephen, Divergences and convergences in the development of culinary cultures. In: .TEUTEBERG, H.-J., ed., European food bistory. A research review. Leicester, Leicester University Press, 1992: p. 278-88.

MENNELL, Stephen; MURCOTT, Anne \& VAN OTTERLOO, Anneke H., The Sociology of food. Eating, diet and culture.London, Sage, 1992.

MENDEL, G., La chasse structurale. Paris, Payot, 1977

MEPHAM, Bem, ed., Food etbics. London, Routledge, 1996.

MESSÉGUÉ, Maurice, Of man and plants. New York, Bantam Books, 1974.

MESSER, Ellen,Anthropological perspectives on diet, Annual Review of Anthropology, v.13:p.20549,1984 .

MICHEL, Henri; BLANCHARD, Anne \& PELAQUIER, Élie, eds., De l’berbe à la table. La viande dans la France méridionale à l'époque moderne. Actes du Colloque de Montpellier, 1993. Montpellier, Université Paul-Valéry, 1994.

MILLMAN, Sara \& Kates, Robert K., Toward understanding hunger. In: NEWMAN, Lucile F, gen.ed., Hunger in History. Food shortage, poverty and deprivation. Oxford, Basil Blackwell, 1995: p.3-24,

MILLMAN, Sara et alii, Organization, information, and entitlement in the emerging global food system. In: NEWMAN, L.F, gen.ed., Hunger in History. Food shortage, poverty and deprivation. Oxford, Basil Balckwell, 1995: p.307-30

MIGLIARI, M.L. \& AZZOLA,A., Storia della gastronomia. Novara, Edipem, 1978.

MINTZ, Sidney W., Sweetness and power. The place of sugar in modern history, New York, Viking Press, 1986.

MINTZ, Sidney W., The changing role of food in the study of consumption. In:BREWER, R. \& PORTER, R., eds., Consumption and the world of goods. London, routledge, 1993.

MINTZ, Sidney W., Tasting food, testing power Excursions into eating, culture and the past. Boston, Beacon Press, 1996. 
MONCKTON, H.A., A bistory of english ale and beer: London, Bodley Head, 1966.

MONTANARI, Massimo, La fame e l'abbondanza. Storia dell'alimentazione in Europa. Bari, Laterza, 1993.

MONTANARI, Massimo, Alimentazione e cultura nel Medievo. Bari, Laterza, 1988.

MONTANARI, Massimo, L'alimentazione contadina nell'alto Medievo, Napoli, Liguori, 1979.

MONTANARI, Massimo, Modèles alimentaires et identités cultuelles. In: FLANDRIN, J.L. \& MONATANARI, eds. Histoire de l'alimentation. Paris, Fayard, 1996: p. 319-24.

MONTEIRO, Agostinho, Problemas de alimentação no Brasil. Rio de Janeiro, Imprensa Nacional, 1946.

MONTEIRO, Mário Ypiranga, Alimentos preparados à base de mandioca, Revista Brasileira de Folclore, v.5: p.37-82, 1963.

MOREIRA, Nicolau,Joaquim, Breves considerações sobre a bistória e cultura do cafeeiro. Rio de Janeiro, Typographia Imperial, 1873.

MORINEAU, M., La pomme de terre au XVIIIe siècle, Annales ESC, n.25: p. 1767-1784, 1970.

MOSKOWTTZ, H., The sweetness and pleasantness of sugars, American Journal of Psycbology, v.84, n.3: p. 387-405, 1971.

MOULIN, L., Bière, houblon et cervoise. Bruxelles, Académie Royale de Langue et de Littérature Française, t. 59, n.2.

MOULIN, L., L'Europe à table. Introduction à une psychologie des pratiques alimentaires. Paris, Elsevier-Séquoia, 1975.

MOUNT, J.L., The food and bealth of western man. New York, Wiley, 1975.

MOURA, Hugo, Alimentação e linguajar popular, Revista do Instituto Histórico e Geográfico Paraibano. João Pessoa, n. 17, 1969.

MOWAT, Linda, Cassava and chicha. Bread and beer of the Amazonian indians. Aylesbury, Shire Publications, 1989.

MUCHNIK, J. \& VINCK, D., La transformation du manioc. Paris, PUF, $1984 .$.

MURCOTT, Anne, Cooking and the cooked. A note on the domestic preparation of meals. In: MURCOTT,A., ed., The Sociology of food and eating. Aldershot, Gower, 1983; p.178-93.

MURCOTT, Anne, Sociological and social anthropological approaches to food and eating, World Review of Nutrition and Dietetics, n.55: p.1-40, 1989. 
MURCOTT,Anne, Talking of good food.An empirical study of women's conceptualisations, Food $\mathcal{E}$ Foodways, v.5, n.3: p. 305-18, 1993.

MURCOTT,Anne, Food as an expression of national identity. In: GUSTAVSSON, Sv. \& LEWIN, Leif, eds., The future of the national state: essays on cultural pluralism and political integration. London, Routledge, 1997.

MURCOT', Anne, ed., The Sociology of food and eating. Aldershot, Gower, 1983.

MURRAY, Oswyn, ed., Sympotica. Oxford, Clarendon Press, 1990.

MURRAY, Oswyn \& TECUSAN, Manuela, eds., In vino veritas. London, Oxbow Books/British School at Rome, 1995.

NAHOUM-GRAPPE, Véronique, La culture de l'ivresse. Essai de phénoménologie historique. Paris, Quai Voltaire, 1991.

NALLO, E. Di, ed., Cibi simbolo nella realtà d'oggi. Milano, F.Angeli, 1986.

NELSON, M.; Geissler, C. \& Oddy, D., eds., Social-class trends in British diet, 1860-1980. Food, diet and economic change past and present. Leicester, Leicester University Press, 1993.

NEVEUX, H., L'alimentation du XIVe au XVIIIe siècles: essai d'une mise au point, R.H.E.S., n. 51: p.336-379, 1973 .

NEWMAN, Lucile F, ed., Hunger in History. Food shortage, poverty, and deprivation. Oxford , Blackwell, 1990.

NICOLAÏDES, Stylianos, Du rôle du goût dans la vie et l'alimentation de l'homme. In:Manger. Cours public de l'Université, 1995-6. Lausanne, Éditions Payot Lausanne, 1996: p. 37-46.

NIELSEN, Inge \& NIELSEN, Hanne Sigismund, eds. Meals in a social context. Aarhus, Jutland AS, 1998 (Aarhus Studies in Mediterrranean Antiquity, 1).

NOURRISON, Didier, Alcoolisme et antialcoolisme en France sous la Troisième République: 1 'exemple de la Seine-inférieure.Paris, La Documentation Française, 1988, 2 vs.

NOURISSON, Didier, Le buveur du XIXè. siècle. Paris, Albin Michel, 1990.

NOVAIS, Fernando, Portugal e Brasil na crise do antigo sistema colonial (1777-1808). São Paulo, Hucitec, 1979.

O'LAUGHLIN, Bridget, Meditation of contradiction: why Mbum women do not eat chicken. In: ROSALDO, M.Z. \& LAMPHERE, L., eds., Women, culture and society: Stanford, Stanford University Press, 1974.

OHNUKI-TIERNEY, Emiko, Rice as self. Japanese identities through time, Princeton, Princeton University Press, 1993. 
ORBACH, Susie, Fat is a feminist issue. London, Paddington Press, 1978.

ORNELLAS, Lieselotte Hoeschl, A alimentação através dos tempos. Rio de Janeiro, Fename, 1978.

ORTENCIO, Bariani, Cozinba goiana. Estudo e receituário. Goiânia, Oriente, 2a.ed., 1981.

ORTIZ, Fernando, La cocina afrocubana. La Habana, 1941.

ORTIZ, Fernando, Contrapunto cubano del tabaco y del azúcar La Habana, 1940.

PALMER, Arnold, Movable feasts. A reconnaissance of the origins and consequences of fluctuations in meal-times, Oxford. 1952.

PALMER, Catherine, Fom theory to practice. Experiencing the nation in everyday life, Journal of Material Culture, v.3, n.2: p. 175-199, July 1998.

PANCOAST, H. \& JUNK, W., Handbook of sugars. Westport, AVI Publishing, 2.ed., 1980.

PARAISO, Aviva, Jewish food and drink. Hove, Wayland, 1988.

PANTEL, Pauline Schmitt, La cité au banquet. Histoire des repas publics dans les cités grecques. Roma/Paris, École française de Rome/De Boccard, 1992.

PATRONE, A. M. Nada, Il cibo del ricco e il cibo del povero. Contributo alla storia qualitativa dell'alimentazione. L'area pedemontana negli ultimi secoli del Medio Evo,Torino, 1981.

PENDERGAST, Mark, For God, country and Coca-cola. New York, Scribners, 1993.

PEREIRA, J., Treatise on food and diet. London, 1843.

PERL, L., The bamburger book. N.York, Seabury, 1974.

PERLĖS, Catherine, Les stratégies alimentaires dans les temps préhistoriques.

In: FLANDRIN, Jean-Louis \& MONTANARI, Massimo, eds, L'bistoire de l'alimentation. Paris, Fayard, 1996: p. 29-46.

PESEZ, Jean-Marie, Histoire de la culture matérielle. In: LE GOFF, Jacques, dir., La Nouvelle Histoire. Paris, Complexe, 1988.

PESSANHA, Nely M. \& BASTIAN, Vera Regina F, eds., Vinbo e pensamento. Rio, Tempo Brasileiro/SBEC, 1991.

PICTON, Lionel James, Nutrition and the soil. Thoughts on feeding. New York, Devin-Adair, 1949.

PIERSON, Donald, Hábitos alimentares em São Paulo, Revista do Arquivo Municipal de São Paulo. São Paulo, n.98, 1994. 
PILLSBURY, Richard, From boarding bouse to bistro. The American restaurant then and now. London, Unwin Hyman, 1990.

PIPERNO, Dolores R., On the emergence of agriculture in the New World, Current Anthropology v. N.5: p.637-43, dec. 1994 .

PITTE, Jean-Robert, Gastronomia francesa. História e Geografia de uma paixão, Porto Alegre, L\&PM, 1993.

PIUZ, A.M. , Le marché du bétail et la consommation de la viande à Genève au XVIIIe siècle, Annales ESC, v.30, n.2-3: p.575-83, mars-juin 1975.

POKHLEBKIN, William , A bistory of vodka. New York, Verso, 1992.

POO, Mu-chou, Wine and wine offering in the religion of ancient Egypt. London, Kegan Paul, 1995.

POTTIER, Johan, Food. In: BARNARD, Alan \& SPENCER, Jonathan, eds., Encyclopedia of Social and Cultural Anthropology. London, Routledge, 1996: p.238-41.

POULOT, Dominique, Une nouvelle histoire de la culture matérielle?, Revue d'bistoire moderne et contempoaine, v.44, n.2: p. 34457, 1997.

PRAKASH, O., Food and drinks in ancient India. New Delhi, Munshiram Manodar Lal, 1961.

PRENTICE, Parmalle, Hunger and bistory. New York, 1939.

PRICE, T. Douglas \& GEBAUER, Anne Brigitte, eds., Last bunters, first farmers. New perspectives on the prehistoric transition to agriculture, School of American Research Press, 1995.

PRICE, Weston, Nutrition and phisical degeneration. A comparaison of primitive and modern diets and their effects. California,The American Academy of Applied Nutrition, 1948.

PULLAR, P., Consuming passion. A History of English food and appetite. London, Hamish Hamilton, 1970.

PYNSON, P., La France à table, 1960-1986. Paris, Éditions de la Découverte, 1987.

QUIGLEY, D.T., The national malnutrition. Milwaukee, The Lee Foundation for Nutritional Research, 1943.

RAINWATER, Dorothy, Victorian dining silver. In: GROVER, Kathryn, ed., Dining in America, 18501900. Amherst, Massachusetts University Press, 1987.

RAMINELLI, Ronald, Eva Tupinambá. In: DEL PRIORE, Mary, ed., História das mulheres no Brasil. São Paulo, Edunesp/Contexto, 1997: p. 11-44.

REDDING, Richard W., A general explanation of subsistence change. From hunting and gathering to food production. San Diego,Academic Press, 1991. 
REED, William, History of Sugar. London, Longmans Green \& Co., 1866.

REEDS, J.A., The grocery trade. Its history and romance. London, Duckworth, 1910, 2 vols..

RENFREW, J., Food and cooking in prebistoric Britain. History and recipes. London, English Heritage, 1985.

RENFREW, Colin \& BAHN, Paul, Ch.7: What did they eat? Subsistence and diet. In: Archaeology. Theories, methods and practice. London, Thames \& Hudson, 1991: 233-270.

RENNER H. D., The origin of food habits. London, Faber and Faber, 1944.

REVEL, Jean François, Alimentation. In: LE GOFF, Jacques \& REVEL, Jean François, eds., La Nouvelle Histoire, Paris, CEPL/Les Encyclopédies du Savoir Moderne, 1978: pp.24-26.

REVEL, Jean François, Un festin en paroles. Histoire littéraire de la sensibilité gastronomique de 1'Antiquité à nos jours. Paris, Pauvert, 1979. (tradução brasileira: Um banquete de palavras, São Paulo, Companhia das Letras, 1996).

REVEL, Jacques, Les privilèges d'une capitale: l'approvisionnement de Rome à l'époque moderne, Annales ESC v.30, n.2-3: p.563-574, mars-juin 1975.

RIBEIRO, Berta G., coord., Suma Etnológica Brasileira, vol.1, Etnobiologia. Petrópolis, Vozes, 1986.

RIBEIRO, Joaquim, Folclore do açúcar Rio de Janeiro, Campanha de Defesa do Folclore Brasileiro, 1977.

RICHARDS, Audrey I., Hunger and work in a savage tribe. A fuctional study of nutrition among the Southern Bantu. London, Routledge, 1932.

RICHARDS, Audrey I., Land, labour and diet in Northern Rbodesia. An economic study of the Bemba tribe. Oxford, Oxford University Press, 1939

RITCHIE, Carson I.A., Comida y civilización. Madrid, Alianza Editorial, 1981 (E1 Libro de Bolsillo, 1214).

RIVERS, J., An bistorical erspective on nutrition. London School of Hygiene and Tropical Medicine: MSc \& Diploma in Human Nutrition, 1981.

ROBSON, John R.K., ed., Food, ecology and culture. Readings in the Anthropology of dietary practices, vol. 1, 1980.

ROCHE, Daniel, Ch.IX: Le pain, le vin, le goût. In: Histoire des choses banales. Naissance de la consommation, XVIIe.XXe. siècle. Paris, Fayard, 1997: p.239-67.

RODINSON, M., Recherches sur les documents arabes relatifs à la cuisine, Études islamiques, p.116-70, 1949-1950. 
ROOT, Waverly \& DE ROCHEMONT, Richard, Eating in early America. A history. New York, Ecco Press, 1976.

ROSE, Lisa \& MARSHALL, Fiona, Meat eating, hominid sociality and home bases revisited, Current Antbropology, v. 37, n.2: p.308-38, apr.1992.

ROSEBERRY, William; GUDMUNDSON, Lowell \& KNUTSCHBACH, Mario Samper, eds., Coffee, society and power in Latin America. Baltimore, The Johns Hopkins University Press, 1995.

ROSS, E., Patterns of diet and forces of production. An economic and ecological history of the ascendancy of beef in the United States diet. In: ROSS, E., ed., Beyond the myths of culture. Essays in cultural materialism. New York, Academic Press, 1980.

ROTBERG, R.I. \& RABB, T.K., Hunger and History. The impact of changing food production and comsumption patterns on society. Cambridge, Cambridge University Press, 1985.

ROTH, Bodris, Tea-drinking in 18th-century America. Its etiquette and equipage. In: ST.GEORGE, Robert Blair, ed., Material life in America, 1600-1860. Boston, The Northeastern University Press, 1988.

ROWLEY,Anthony, À table! La fête gastronomique. Paris, Gallimard, 1994.

ROYER, C., Les vignerons. Paris, Berger-Levrault, 1983.

ROZIN, Elizabeth \& BARKER, L.M., eds., The structure of cuisine. The psychobiology of human food selection. Westport Conn., Avi Press, 1982.

SABBAN, Françoise, Food notes from the East, Food E Foodways, v..5, n.4,: p.391-394, 1994.

SABBAN, Françoise, De la main à la pâte. Réflexion sur l'origine des pâtes alimentaires et les transformations du blé en Chine ancienne (Illè.av.-Vlè ap.JC), l'Homme, n.113, jan.-mar. 1990.

SAHLINS, Marshall, Food preference and tabu in American domestic animals. In: Culture and practical reason. Chicago, The University of Chicago Press, 1976: p. 169-176.

SAHLINS, Marshall , Cosmologias do Capitalismo: o setor trans-Pacífico do sistema Mundial, Anais da XVI Reunião da ABA (Associação Brasileira de Antropologia). (

SAILLENPEST, J., Le soja, sa culture et sa civilisation. Paris, Montsouris-Rustica, 1944.

SALAMAN, Redcliffe N., The bistory and social influence of the potato. Cambridge, Cambridge University Press, 1949.

SALDANHA, Nelson, A evolução dos estudos sobre o açúcar. In: FREYRE, Gilberto et alii, Sociologia do açúcar. Recife, Museu do Açúcar, 1971: p.61-82.

SAMPAIO,A.J. De, Alimentação sertaneja e do interior da Amazônia. Onomástica da alimentação rural. São Paulo, Cia. Ed. Nacional, 1944. 
SANTOS, Carlos Roberto Antunes dos - História da alimentação no Paraná, Curitiba, Fundação Cultural, 1995 (Farol do Saber).

SCARANO, Julita, Algumas considerações sobre o alimento do homem de cor no século XVII, Revista de História, n.123-4: p. 71-80, ago-jul.1990-1.

SCARANO, Julita, Cotidiano e solidariedade. Vida diária da gente de cor nas Minas Gerais, século XVIII. São Paulo, Brasiliense, 1994.

SCARPI, Paolo, ed., Homo Edens. II. Storie del vino. Milano, Diapress Documenti, 1991.

SCHIVELBUSCH, Wolfgang, Histoire des stimulants. Mayenne, Le Promeneur, 1991.

SCHWARTZ, Hillel, Never satisfied. A cultural history of diets, fantasies and fat. New York, Free Press, 1986.

SCHWARTZ, Stuart B., Segredos internos. Engenhos e escravos na sociedade colonial. São Paulo, Companhia das Letras, 1988.

SCRIMSHAW, Nevin S., The value of contemporary food and nutrition studies for historians, Journal of Interdisciplinary History, v.14, n.2: p.529-34, 1983.

SEEGER, Anthony, A pesca no Rio Amazonas. Manaus, INPA, 1979.

SEN, Amartya K., Poverty and famines. An essay on entitlement and deprivation. Oxford, Oxford University Press, 1981.

SENTIERI, M. \& ZAZZU, G.N., I semi dell'Eldorado. L'alimentazione in Europa dopo la scoperta dell'America. Bari, Laterza, 1992.

SERED, Susan Starr, Food and holiness. Cooking as a sacred act among Middle-eastern Jewish women. Antbropological Quarterly, v.61, n.3: p. 129-39, 1988.

SHAND, P.M, A book of food. London, Jonathan Cape, 1927.

SHAW,T.;ALEXANDER, J.\& OKPOKO,A., eds., Foods, metals and towns in African bistory. African adaptations in subsistence and technology. Cambridge, University of Cambridge/University of Ibadan/Nigeria, 1986.

SHELTON, Allen, A theater for eating, looking and thinking. The restaurant as symbolic space, Sociological Spectrum, v.10: p. 507-26, 1990.

SHELTON, Walter James, English hunger and industrial disorders. A study of social conflict during the first decade of George II's reign. London, 1973.

SHEPPARD, Ronald \& NEWTON, Edward, The story of bread. London, 1957.

SILVA, Francisco Carlos Teixeira da, Produção de alimentos e trabalho escravo no Brasil Colonial, História: Questões e Debates, ano 9, n. 10, julho 1988. 
SILVA, Francisco Carlos Teixeira da, A morfologia da escassez. Política econômica e crises de subsistência no Brasil colonial (Salvador e Rio de Janeiro, 1690-1790). Niterói, Universidade Federal Fluminense, 1990 (Tese de Doutorado, mimeo)

SILVA, G.J. da Rosa e, Alimentação e subdesenvolvimento no Brasil, Revista Brasileira de Geografia. Rio de Janeiro, v.26, n.3: p. 291-457, 1964.

SILVA, Maria Beatriz Nizza da, Vida privada e quotidiano no Brasil na época de D.Maria e D.João VI. Lisboa, Estampa, 1993.

SILVA, Maria Beatriz Nizza da, Cultura e Sociedade no Rio de Janeiro (1808-1821). São Paulo, Cia. Editora Nacional, 1978.

SIMMEL, Georg, Sociología de la comida. In: El individuo y la libertad. Ensayos de crítica de la cultura. Madrid, Peninsula, 1986: p. 236-270.

SIMON, André, Bibliotbeca gastronomica. London, 1953.

SIMOONS, Frederick J., Eat not this flesh. Food avoidances from prehistory to the present. Madison, University of Wisconsin Press, 1994.

SLATER, W.J., ed., Dining in a classical context, Ann Arbor, 1991.

SLOCUM, S. , Woman the gatherer. Male bias in Anthropology. In: EVANS, M., ed., Tbe woman question. London, Fontana, 1982.

SMART, Barry, Digesting the modern diet: gastro-porn, fast food, and panic eating. In:TESTER, K., ed., The flàneur. London, Routledge, 1994.

SMITH, Bruce D., The emergence of agriculture. Scientific American Library, 1995.

SMITH, R.E.F. \& CHRISTIAN, David, Bread and salt. A social and economic history of food and drink in Russia. Cambridge, Cambridge University Press, 1984.

SOLER, Jean, Sémiotique de la nourriture dans la Bible, Annales ESC, v.28: p.943-55, juillet-août 1973.

SOLER, Jean, Les raisons de la Bible: règles alimentaires hébraiques. In: FLANDRIN

\& MONTANARI, eds., Histoire de l'alimentation. Paris, Fayard, 1996: 73-84.

SORRO, M., La géographie de l'alimentation, Annales de géograpbie, n.61: p. 184-199, 1952.

SOUTO MAIOR, Mário, Alimentação e folclore. Rio de Janeiro, Funarte, 1988.

SOUTO MAIOR, M., Em torno de uma possível etnografia do pão, Recife, 1971.

SOUTO MAIOR, M., Cachaça. Rio de Janeiro, Instituto do Açúcar e do Álcool, 1970. 
SOUTO MAIOR, M., Dicionário folclórico da cacbaça. Recife, Mousinho, 1973.

SPENCER, Colin, The heretics' feast. A history of vegetarianism. Hanover, University Press of New England, 1995.

STEAD, J., Food and cooking in 18tb-century Britain. History and recipes. London, English Heritage, 1985.

STERN, Radu, ed., A manger des yeux: l'estbétique de la nourriture. Colloque de Lausanne, Lausanne, Université de Lausanne / Musée des arts décoratifs de Lausanne, 1987.

STEWART, A.; TRUSTWELL, M. \& WAHLQVIST, L., eds., Food babits in Australia. Victoria, Rene Gordon, 1988.

STOIANOVITCH,T., Le maïs, Annales ESC v.6: p. 190-193, 1951.

STOIANOVITCH,T., Le maïs dans les Balkans, Annales ESC v.21: p. 1026-1040, 1966.

STOUFF, Louis, Ravitaillement et alimentation en Provence aux XIVe et XVe siècles. Paris, Mouton, 1970.

STRONG, L.A.G., The story of sugar London, George Weidenfeld \& Nicolson, 1954.

STRUNG, Norman, An Encyclopedia of knives. Philadelphia, J.B.Lippincott, 1976.

STUYVENBERG, J. H. Van, ed., Margarine. An economic, social and scientific history 18691969.Liverpool, 1969.

SUPER, John C., Food, conquest and colonization in 17th-century Spanish America, Albuquerque, University of New Mexico Press, 1988.

SUTTON, David C., The vegetarian anthropologist, Antbropology Today, v.13, n.1: p.5-8, Feb. 1997.

SUTTON, David C., The History of Food: a preliminary bibliograpby of printed sources, Coventry, 1982.

SUYEUX, J., Le grand livre des produits et de la cuisine exotiques. Paris, Le Sycomore, 1980.

TANNAHILL, Reay, Food in bistory. London, Methuen, 1973.

TARRANT,J., A review of the international food trade, Progress in Geograpby, v.9: p.275-54, 1985.

TAUNAY,Affonso d'E.,História do café no Brasil. Rio de Janeiro, Departamento Nacional do Café, 1939

TCHERNIA,A., Le vin de l'Italie romaine. Essai d'histoire économique d'après les amphores. Paris, De Boccard, 1986.

TELFER, Elizabeth, Food for thought. Philosophy and food. London, Routledge, 1996. 
TELEKI, G. \& HARDING, R., Omnivorous primates. Gathering and hunting in human evolution. New York, Columbia University Press, 1981.

TEMPLE, E.J., Célébration du maïs. Forcalquier, Morel, 1963.

TEUTEBERG, Hans-Jürgen,Agenda for a comparative European history of diet.In: H.J.Teuteberg, ed., European food bistory. A research review. Leicester, Leicester University Press, 1992: p. 1-18.

TEUTEBERG, Hans-Jürgen, ed. European food bistory. A research review. Leicester, Leicester University Press, 1992.

TEUTEBERG, H.-J. \& WIEGELMANN, G., Der Wandel der Nabrungsgewobnbeiten unter dem Einfluss der Industrialisierung. Göttingen, 1972.

THIEL, Barbara, Further thoughts on why men share meat, Current Antbropology, Chicago, v.35, n.4: p.440-1, 1994.

TOMLISON, A, ed., Consumption, identity and style: marketing, meanings and the packaging of pleasure. London, Routledge, 1990.

TOUSSAINT-SAMAT, Maguelonne, Histoire naturelle et morale de la nourriture. Paris, Borda, 1987.

TOUTAIN, J.-C., La consommation alimentaire en France de 1789 à 1964. Économies et Societés, Cabiers de l'I.S.E.A., tome A, n.11, Genève, 1971.

TRAGER, James, The food chronology: A food lover's compendium of events and anecdotes, from prehistory to the present. New York, Henry Holt, 1995.

TUZIN, D. \& BROWN, P., The etbnography of cannibalism. Washington, Society for Psychological Anthropology, 1983.

TWIGG, J., Vegetarianism and the meaning of meat. In: MURCOTT, A., ed., The Sociology of food and eating. Essays on the sociological significance of food.Aldershot, Gower, 1983.

TWINING, Stephen H., Twinings. Two hundred and fifty years of tea and coffee 1706-1956. London, 1956.

UKERS, W.H., All about tea, New York, The Tea and Coffe Trade Journal Co., 1935, 2 vols.

UNWIN, T., The wine and the vine. An historical geography of viticulture and the wine trade. London, Routledge, 1991.

VAILLANT, G.E., A natural bistory of alcobolism. Cambridge MA, Harvard University Press, 1983.

VALENSI, L. , Consommation et usages alimentaires en Tunisie aux XVIIIe et XIXe siècles, Annales ESC, v.30, n. 2-3: p.600-9, mars-juin 1975. 
VALENTINE, Gill \& LONGSTAFF, Beth, Doing porridge. Food and social relations in a male prison, Journal of Material Culture, v.3, n.2: p. 131-52, july 1998.

VALERI, René, Alimentazione. In: Enciclopedia Einaudi. Torino, Einaudi, v.1, 1977: p.344-361.

VAN BATH, B.H.Slicher, Historia agraria de Europa Occidental (1500-1850). Barcelona, Ediciones Península, 1978.

VAN DEN BERGHE, Pierre, Ethnic cuisine, culture in nature, Ethnic and Racial Studies, v.7, n.3: $387-97,1984$.

VANDENBROEKE, Christiaan, Agriculture et alimentation dans les Pays-Bas autricbiens. Ghent/Louvain, 1975.

VANDENBROEKE, Christiaan, L'alimentation à Gand pendant la première moitié du XIXe siècle, Annales ESC, v.30, n.2-3: p. 584-591, mars-juin 1975a.

VARELLA, J.S. das Chagas, Cozinba de santo. Culinária de umbanda e candomblé. Rio de Janeiro, Espiritualista, 1991.

VEDEL, J., La consommation alimentaire dans le Haut Languedoc aux XVIIe et XVIIIe siècles, Annales ESC, v.30, n.2-3: p.478-90, mars-juin 1975.

VELHO, Octávio Guilherme, Hábitos alimentares em camadas de baixa renda. (Relatório de Pesquisa). Rio de Janeiro, Museu Nacional / UFRJ, 1977.

VELOSO, Carlos, A alimentação do século XVIII nos relatos dos viajantes estrangeiros.Coimbra, Minerva, 1992.

VELOSO, Cleto Seabra, Alimentação. Rio de Janeiro, 1940.

VERDIER, Y., Pour une ethnologie culinaire, L'Homme, v.9: p. 49-59, 1969

VIALLES, Noëlle, Animal to edible. Cambridge, Cambridge University Press, 1994.

VINCENT, B., Consommation alimentaire en Andalousie orientale (les achats de l'Hôpital Royal de Guadix, 1581-1582), Annales ESC, Paris, v.30, n.2-3. p.445-453, mars-juin 1975.

VISSER, Margaret, Much depends on dinner. The extraordinary history and mythology, allure and obssessions, perils, and taboos of an ordinary meal London. Grove/QPB, 1987.

VOLPATO, G., Il formaggio nei secoli. Milano, Mondadori, 1983.

WALDORF, Cornelius, The famines of the world, 1878.

WALL, Diana Di Zerega, Sacred dinners and secular teas. Constructing domesticity in mid-19thcentury New York. In: Seifert, Donna J., ed., Gender in Historical Archaeology, Historical Archaeology, v.25, n.4: p. 69-81, 1991. 
WATSON, B., Cooks, gluttons and gourmets. New York, Garden City, 1962.

WATSON, James, L., ed., Golden arches East. McDonald's in East Asia. Cambridge, Cambridge University Press, 1998.

WATT, James; FREEMAN, E.J. \& BYNUM, W.F., eds., Starving sailors. The influence of nutrition on Naval and Maritime History. London, 1981.

WAUGH,A., The Lipton story. London, 1951.

WEISMANTEL, Mary, Food, gender and poverty in the Ecuadorian Andes. Philadelphia, University of Pennsylvania Press, 1988.

WIDDOWSON,J., Food and traditional vebal modes in the social control of children. In: FENTON, A. \& OWEN,T., eds., Food in perspective. Edinburgh, John Donald, 1981.

WIEGELMANN, Günter, Alltags-und Festspeisen. Wandel und gegenwärtige Stellung. Marburg, Elwert, 1967.

WIESSNER, Polly \& SCHIEFENHÖVEL, Wulf, Food and the status quest. An intgerdisciplinary perspective. Oxford, Berghan, 1996

WILDT, Michael, Plurality of taste. Food and comsumption in West Germany during the 1950s, History Workshop Journal, v. 39: p.23-41, 1995.

WILKINS, John Harvey \& DOBSON, Michael David, eds., Food in Antiquity. Studies in ancient society and culture. Exeter, University of Exeter Press, 1996.

WILLIAMS, Robert G., States and social evolution. Coffee and the rise of national governments in Central America. Chapel Hill, University of Carolina Press, 1994.

WILSON, Constance Anne, Food and drink in Britain, from the stone age to recent times. London, Constable, 1973.

WILSON, C.S., Food custom and nurture: an annotated bibliography on sociocultural and biocultural aspects of nutrition, Journal of Nutrition Education, v.2, n.4, Suppl.1: p.210-164, 1979.

WOOD, R., The Sociology of the meal. Edinburgh, Edinburgh University Press, 1995.

WOODMAN-SMITH, C., The great hunger: Ireland, 1845-49. In: FORSTER, Elborg

\& FORSTER, Robert, eds., European diet, from preindustrial to modern times. New York, Harper \& Row, 1975.

WOORTMANN, Klaas, Hábitos e ideologias alimentares em grupos sociais de baixa renda (Relatório Final). Brasília, Universidade Nacional de Brasília, 1978 (Série Antropologia, 20). 
WOORTMAN, Klaas, A comida, a família e a construção do gênero feminino, Revista de Ciências Sociais, v.29, n.1: p.103-30, 1986.

WYNNE-TYSON, J., Food for a future. The ecological priority of a human diet. Londres, DavisPointer, 1975.

YOUNG, L. The Geogaphy of bunger. London, Routledge, 1998.

YUDKIN, John, Sweet and dangerous. New York, Bantam Books, 1972.

YVOREL, Jean-Jacques, Les poisons de l'esprit. Drogues et drogués au XIXè.siècle. Paris, Quai Voltaire, 1992 (Coll. Histoires).

ZEMELLA, Mafalda, Abastecimento da Capitania das Minas Gerais no século XVIII. São Paulo, FFLCH/USP (Boletim 118)

ZEUNER, E E, A bistory of domesticated animals. London, Hutchinson, 1963.

ZILHR, W.\& BUHRER, E. M., Le pain à travers les âges. Paris, 1985. 


\title{
RESUMOS / ABSTRACTS:
}

\author{
A História da Alimentação: balizas historiográficas
}

Ulpiano T.Bezerra de Meneses e Henrique Carneiro

Os AA. pretenderam traçar um quadro da História da Alimentaçāo, não como um novo ramo epistemológico da disciplina, mas como um campo em desenvolvimento de práticas e atividades especializadas, incluindo pesquisa, formação, publicações, associações, encontros acadêmicos, etc. Um breve relato das condições em que tál campo se assentou faz-se preceder de um panorama dos estudos de alimentação e temas correlatos, em geral, segundo cinco abordagens la biológica, a econômica, a social, a cultural e a filosófical, assim como da identiticação das contribuiçōes mais relevantes do Antropologia, Arqueologia, Sociologia e Geografia. A fim de comentar a multiforme e volumosa bibliografia histórica, foi ela organizada segundo critérios morfológicos. A seguir, alguns tópicos importantes mereceram tratamento à parte: a lome, o alimento e o domínio religioso, as descobertas européias e a difusão mundial de alimentos, gosto e gastronomia. $\bigcirc$ artigo se encerra com um rápido balanço crítico da historiografia brasilieira sobre o tema.

UNITERMOS:Alimentação. História da Alimentação. Estudos de alimentação: Brasil .

Food History: historiographical landmarks

Ulpiano T.Bezerra de Meneses and Henrique Carneiro

The AA intended to draw a picture of Food History, not as a new epistemological branch of the discipline, but as an ever growing field of specialized practices and activities, including research, education, publications, academic meetings and societies, etc. A short account of the conditions on which such a field was grounded is preceded by a portrayal of the study of food and foodways in general, according to five approaches (biological, economic, social, cultural and philosophical ones) as well as by the recognition of the main contributions brought forth by Anthropology, Archaeology, Sociology and Geography. In order to allow analytical comments, the multifarious and bulky historical bibliography has been organized according to morphological traits. A few important topics are then discussed separately: hunger and famine, food and the religious domain, European discoveries and the worldwide circulation of toods, taste and gastronomy. The article draws to a close with a short critical survey of Brazilian historiography on food.

UNITERMS: Food. Food History. Historiography. Food studies: Brazil.

Chá e simpatia. uma estratégia de gênero no Rio de Janeiro oitocentista

Tania Andrade Lima

Inicialmente, a A. traça um quadro do chá e do riłual do chá na Inglaterra, foco da Revolução Industrial, e chama a atenção para seus significados como um instrumento de liberação feminina. A seguir, mobilizando especialmente material arqueológico suplementado por fontes literárias, ela dirige sua análise para a periferia do capitalismo e esboça a introdução do chá no Brasil. O ritual do chá, claramente sob autoridade feminina, no entanto apresenta uma peculiaridade singular nas classes médias do Rio de Janeiro oitocentista: é servido num espaço masculino por excelência, a sala de jantar. Tal ambiguidade é estudada juntamente com outros rituais mais recentes (que esvaziaram a etiqueta original do chá enquanto rito de passagem), do ponto de vista das estratégias de gênero. 